\title{
HYDROGEN PRODUCTION FOR FUEL CELLS VIA REFORMING COAL-DERIVED METHANOL
}

\section{R08.pdf}

Quarterly Technical Progress Report

Reporting Period Start Date: October 1, 2004

Reporting Period End Date: September 30, 2005

Principal Author: Paul A. Erickson

Report Issue Date: October 2005

DOE Award Number: DE-FC26-03NT41850

Submitting Organization:

The Regents of the University of California, Davis

One Shields Avenue

Davis, California 95616 


\section{DISCLAIMER}

This report was prepared as an account of work sponsored by an agency of the United States Government. Neither the United States Government nor any agency thereof, nor any of their employees, makes any warranty, express or implied, or assumes any legal liability or responsibility for the accuracy, completeness, or usefulness of any information, apparatus, product, or process disclosed, or represents that its use would not infringe privately owned rights. Reference herein to any specific commercial product, process, or service by trade name, trademark, manufacturer, or otherwise does not necessarily constitute or imply its endorsement, recommendation, or favoring by the United States Government or any agency thereof. The views and opinions of authors expressed herein do not necessarily state or reflect those of the United States Government or any agency thereof. 


\begin{abstract}
Hydrogen can be produced from many feedstocks including coal. The objectives of this project are to establish and prove a hydrogen production pathway from coal-derived methanol for fuel cell applications.

This progress report is the eighth report submitted to the DOE reporting on the status and progress made during the course of the project. This report covers the time period of October 1, 2004 - September 30, 2005 and includes an entire review of the progress for year 2 of the project.
\end{abstract}

This year saw progress in eight areas. These areas are:

1. steam reformer transient response,

2. steam reformer catalyst degradation,

3. steam reformer degradation tests using bluff bodies,

4. optimization of bluff bodies for steam reformation,

5. heat transfer enhancement,

6. autothermal reforming of coal derived methanol,

7. autothermal catalyst degradation,

8. and autothermal reformation with bluff bodies.

The project is on schedule and is now shifting towards the design of an integrated PEM fuel cell system capable of using the coal-derived product. This system includes a membrane clean up unit and a commercially available PEM fuel cell. 


\section{TABLE OF CONTENTS}

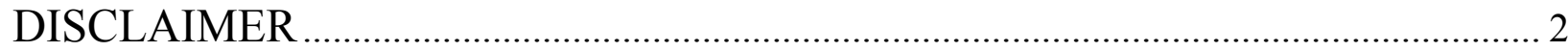

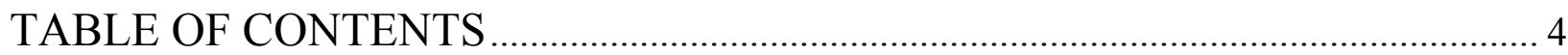

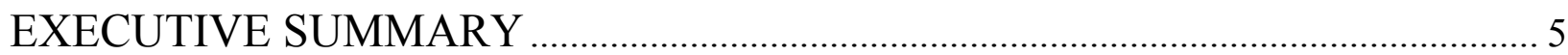

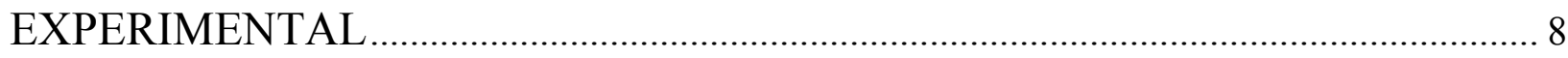

Steam Reformer Transient Response............................................................................... 8

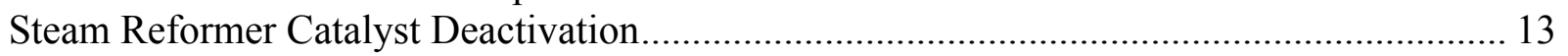

Steam Reformer Degradation Tests Using Bluff Bodies ....................................................... 14

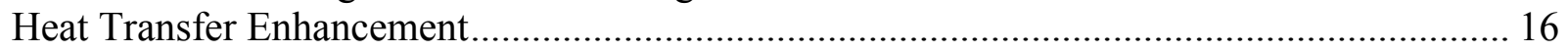

Autothermal Reforming of Coal-Derived Methanol............................................................. 18

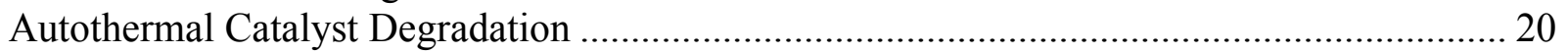

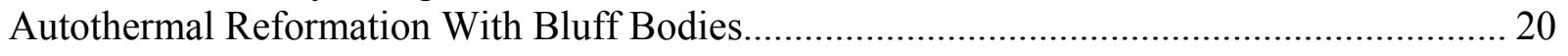

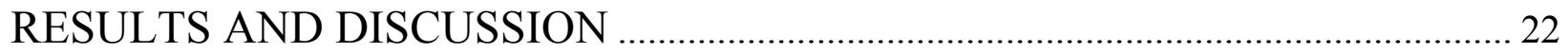

Steam Reformer Transient Response............................................................................. 22

Steam Reformer Catalyst Degradation .................................................................................... 29

Steam Reformer Degradation Tests Using Bluff Bodies.......................................................... 35

Bluff Body Catalyst Degradation With Coal-Derived Methanol ............................................. 37

Bluff Body Catalyst Degradation With Chemical-Grade Methanol........................................... 39

Optimization of Bluff Bodies for Steam Reformation.............................................................. 42

Heat Transfer Enhancement............................................................................................. 44

Autothermal Reforming of Coal-Derived Methanol............................................................... 49

Autothermal Catalyst Degradation ................................................................................... 54

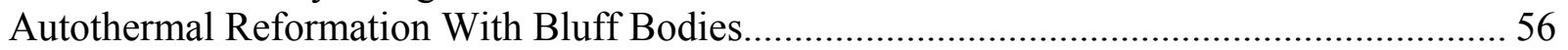

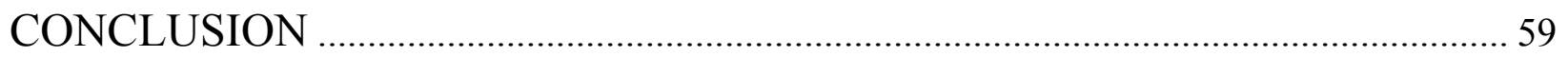

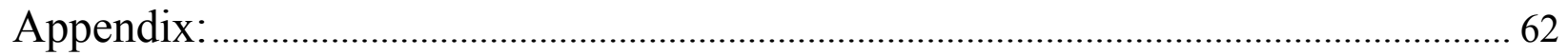

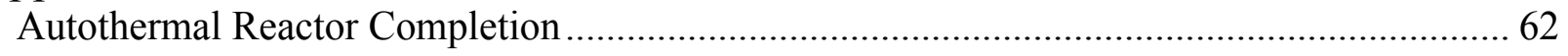

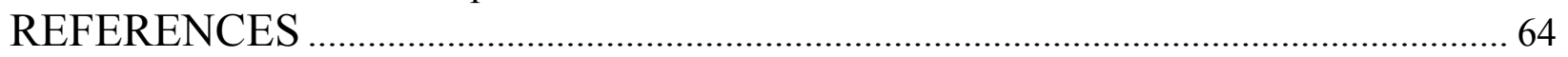




\section{EXECUTIVE SUMMARY}

Hydrogen can be produced from many feedstocks including coal. The objectives of this project are to establish and prove a hydrogen production pathway from coal-derived methanol for fuel cell applications.

This progress report is the eighth report submitted to the DOE reporting on the status and progress made during the course of the project. This report covers the time period of October 1, 2004 - September 30, 2005.

Much progress has been made on the project funded by the Department of Energy during this reporting period. All of the projects are proceeding on or slightly ahead of schedule.

This quarter saw progress in eight areas. These areas are:

1. steam reformer transient response,

2. steam reformer catalyst degradation,

3. steam reformer degradation tests using bluff bodies,

4. optimization of bluff bodies for steam reformation,

5. heat transfer enhancement,

6. autothermal reforming of coal derived methanol,

7. autothermal catalyst degradation,

8. and autothermal reformation with bluff bodies.

Work with quantifying the transient response has been recently completed and analyzed. During quarter six, the transient response of coal-derived methanol was analyzed and compared to the fuel cell grade methanol results found previously. A master's thesis titled, Evaluation Of The Use Of Acoustic Waves For Improving The Transient Response Of Steam Reformers, written by M.J. Beerman was completed based on the results of the research.

We have begun investigating the role of temperature in catalyst deactivation in order to understand how geometry can play such a large role in this important parameter. Tests with quasi-isothermal reactors quantify the large dependence of catalyst degradation on temperature. This reinforces the idea that minimizing temperature gradients within the reactor can be as important to the steam reformation process as fuel purity, if not more so. Work continues on investigating the role of temperature.

Degradation tests have begun using the bluff body packages. As the bluff body set up has shown increased conversion of fuel as noted in past reports, it was expected that the flow disturbers will also have an effect in catalyst degradation rates. The first set of data has been collected regarding the use of coal based methanol with the bluff body set up. The degradation rates are much higher in this reactor than with the previous smaller reactors used for testing catalyst deactivation. In comparison to catalyst degradation due to the differences in fuel type (fuel cell grade vs coal derived methanol) as reported previously, it appears that the effect of reactor geometry on catalyst degradation far outweighs the effect of fuel type. This is an encouraging 
result for those eager to use coal-derived methanol as a hydrogen feed-stock. Data sets collected preliminarily quantify the effect of geometry in catalyst degradation.

Previous reports have concluded that reactor geometry plays a greater factor in methanol reformation than fuel type. Bluff bodies were introduced into the reactor as a passive element to increase the flow path length. The increase in path length increased effective fuel residence in the reactor as well as mixing. The increase in heat transfer through the reactor due to the bluff bodies increased fuel conversion. A study has begun to look at optimizing the design of the bluff bodies to find the maximum potential of the bluff bodies. The inner diameter of the rings was varied as well as the outer diameter of the disks. Larger diameter disks and smaller inner diameter rings result in higher conversions of fuel than previous geometries, but also result in higher pressure drops across the catalyst bed.

We have continued to investigate the role of temperature in catalyst deactivation in order to understand how geometry can play such a large role in this important parameter. Tests with quasi-isothermal reactors quantify the large dependence of catalyst degradation on temperature. This reinforces the idea that minimizing temperature gradients within the reactor can be as important to the steam reformation process as fuel purity, if not more so. Work continues on investigating the role of temperature. This year we have specifically investigated ways to improve heat transfer and to analyze the affect of heat transfer on fuel conversion. Different geometries and the effect of an internal cartridge heater were specifically investigated.

Autothermal reforming of coal-derived methanol has taken place with a low-grade catalyst not specifically designed for reformation but showing acceptable conversion and stability. Initial findings show that reactor performance was similar to fuel cell grade methanol. Analysis of the results is continuing and further tests will be made with a specialty catalyst.

From previous research, it was determined that steam reforming catalysts experienced catalyst degradation for both coal-derived and chemical grade methanol with slightly higher degradation rates from the coal-derived methanol. Similar studies for autothermal reformation have begun using a low-grade catalyst. Because large temperature gradients do not exist between the centerline and the wall of the reactor in autothermal reformation, the results were expected to differ from the steam reforming catalyst data. This is indeed the case in degradation and it appears that autothermal reformation is the preferred method due to a higher temperature and the resulting capability to reform the small quantities of high order hydrocarbon in the coal derived methanol.

Previous research with steam reforming showed that bluff bodies significantly increased fuel conversion due to increased heat transfer. Autothermal reformation using bluff bodies was studied to determine if fuel conversion would improve due to increased mixing of air and fuel to a uniform mixture. According to previous autothermal reformation experimental results, placing the monolith catalyst at different locations in the axial direction resulted in different fuel conversions. When the catalyst sat close to the reactor entrance (Zone 1), the result showed a lower fuel conversion than that sat close to the reactor exit (Zone 4). The result was explained through the following rational. A catalyst close to the reactor exit has more space and time for 
oxygen and methanol fuel mixing to occur. This allows for increased partial oxidation after entering the catalyst bed during the autothermal reaction.

The reformate clean up system design has begun and initial estimates of equipment have been received. The two major design choices are pressure swing absorption (PSA) device and the use of a palladium membrane. The cost of the palladium membrane systems were less expensive than the PSA device, but the reformate will need to be pressurized above 150 psi, as well as heated above $300 \mathrm{C}$. Currently we are deciding on the best device for the flow requirements of the PEM fuel cell, and the capacity of the reformer system.

There are several "spin-off" projects that will continue at the laboratory with further investigations of steam reforming and autothermal reformation although no-longer under the direct support of the DOE Funded efforts in the next year period (Year 3) will focus on the design of the clean-up system and the integration and testing of the PEM system as outlined in the original project schedule. Knowledge from the related reformation projects will be integrated into the final design as it becomes available.

The project has resulted several publications over the past year including 4 Master's theses. These theses include J. Lars Dorr's investigation of autothermal reformation, Michael .J Beerman's investigation of enhancement methods and transient performance, Chang H. Liao's investigation of passive enhancement and Hyung C. Yoon's direct study of steam reforming coal derived methanol. The results of this study have been presented to international meetings of the ASME, and to the IECEC. Further publications in internationally recognized journals are forthcoming. 


\section{EXPERIMENTAL}

The following section describes the experimental methods used and developed during the reporting period for the following areas: steam reformer transient response, steam reformer catalyst deactivation, steam reformer degradation tests using bluff bodies, optimization of bluff bodies, steam reformer heat transfer enhancement, autothermal reforming of coal derived methanol, autothermal catalyst deactivation, and autothermal reformation with bluff bodies.

\section{Steam Reformer Transient Response}

For practical applications of small-scale reformers, transient response is just as important to reactor performance as steady-state conversion. Steam reformation is known to have a relatively slow transient response due to heat transfer limitations, so it is beneficial to understand the behavior of steam reformers under transient flow conditions and find ways to improve the response time. During the third quarter, preliminary experiments were run to evaluate the transient response of a steam reformer using chemical grade methanol.

In quarter seven, the final experiments and analysis in regard to transient response and acoustic enhancement were performed both with chemical grade methanol as well as coal-derived methanol. For a complete summary of work done on improving transient response with acoustic enhancement, please reference the master's thesis completed in May 2005 [1]. The thesis was completed using research supported by the DOE grant at the Hydrogen Production and Utilization Lab at UC Davis.

The experimental set up of the packed reactor with the acoustic equipment can be seen below in Figure 1. An acoustical driver, sealed in an explosion-proof enclosure, was mounted to the bottom of the reactor. The mounting adapter has a cooling water jacket, and a small nitrogen purge to protect the diaphragm of the driver from overheating. A high temperature pressure transducer was mounted near the top of the catalyst bed housing.

To determine the dominant mode in the catalyst bed housing a swept sine wave was introduced into the reactor, and the transfer function taken. An FFT of the transfer function was taken, so that the dominant frequency could be determined. Figure 2 is a plot of the Transfer function magnitudes of Reformer B at room temperature with pelletized catalyst, crushed catalyst, no catalyst, as well as packed with crushed catalyst and bluff bodies. 


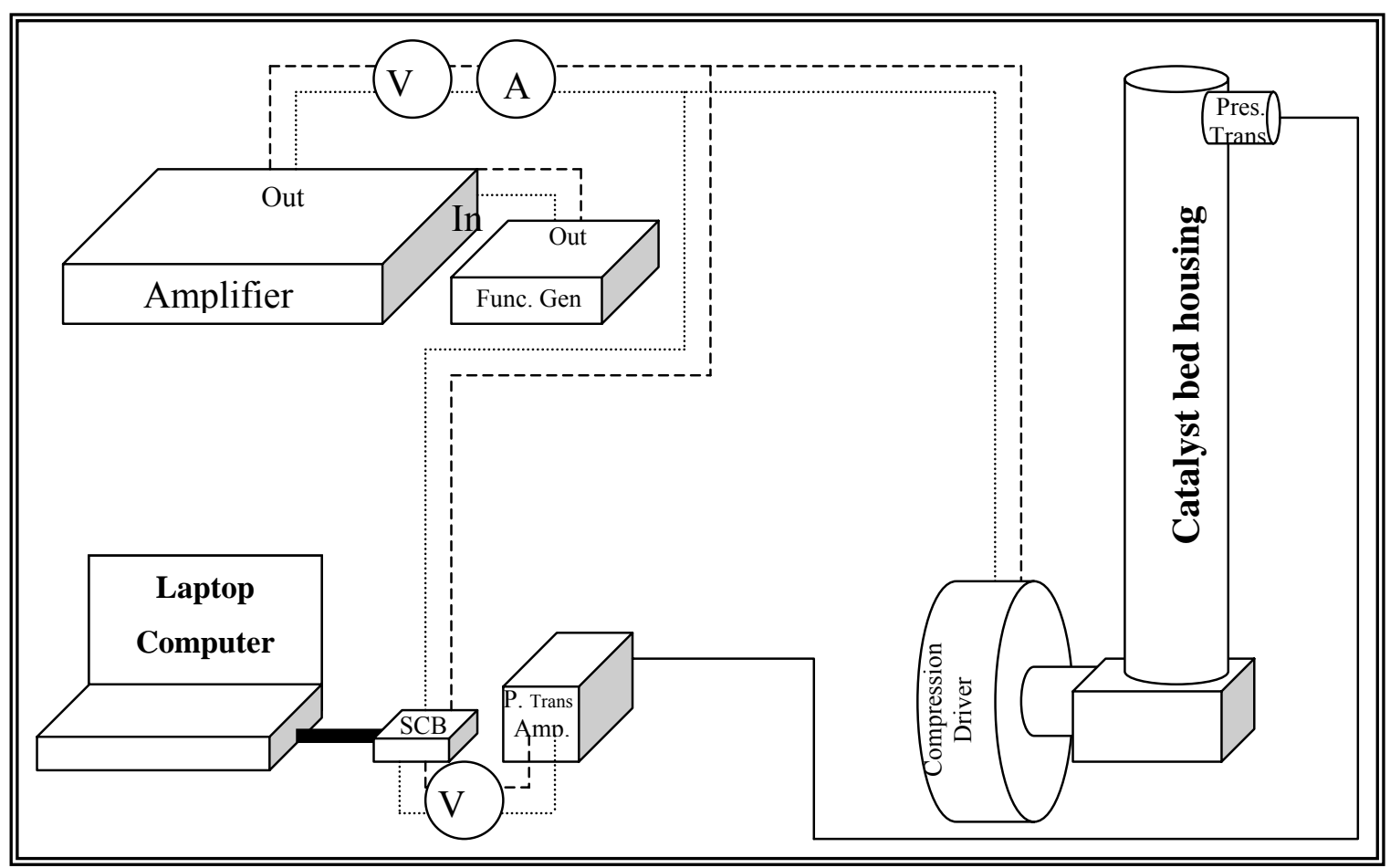

Figure 1: Experimental set up

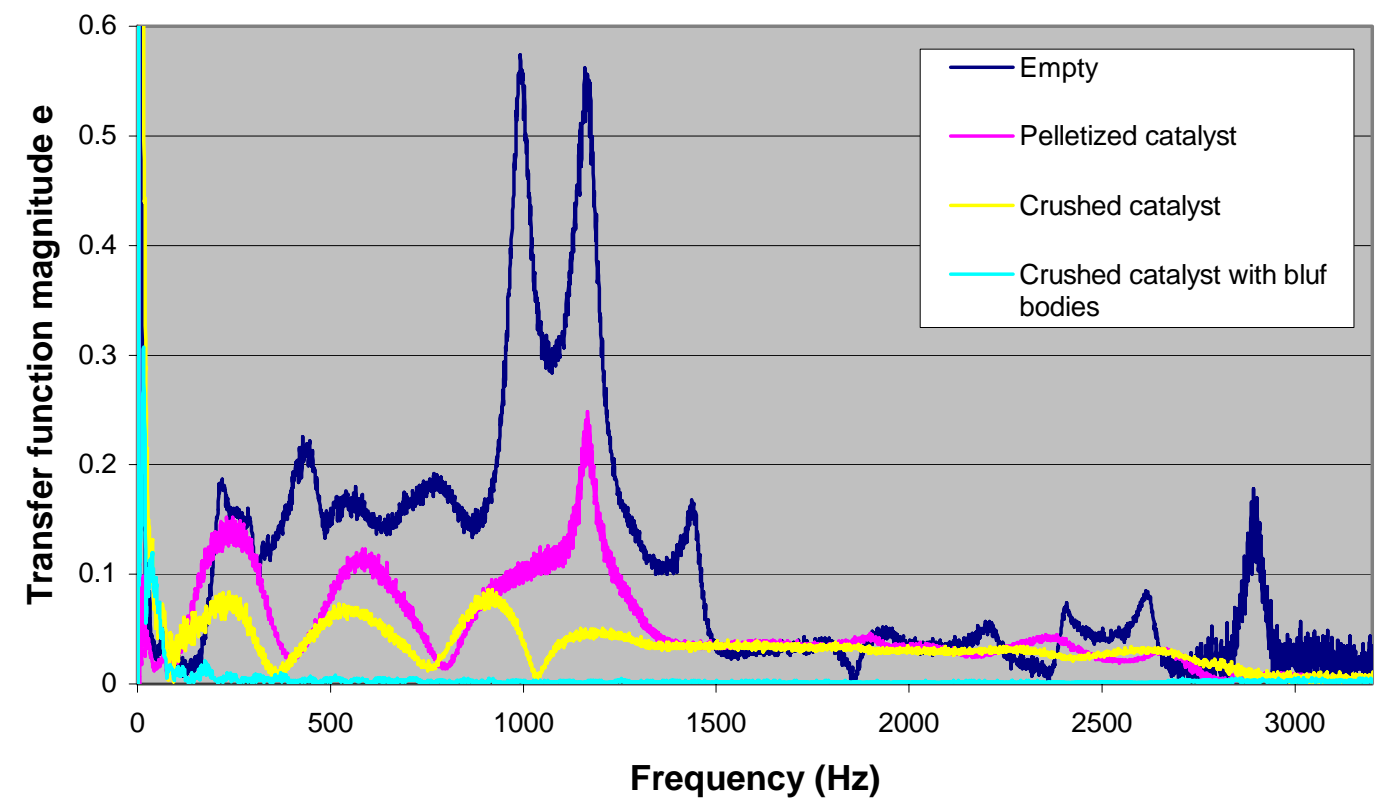

Figure 2: Transfer function magnitude vs. frequency for catalyst bed housing B 
Since the speed of sound varies with temperature and gas composition the optimal frequency was determined at each operational temperature and while reforming. Figure 3 below is a plot of the transfer function magnitude while reforming coal-derived methanol.

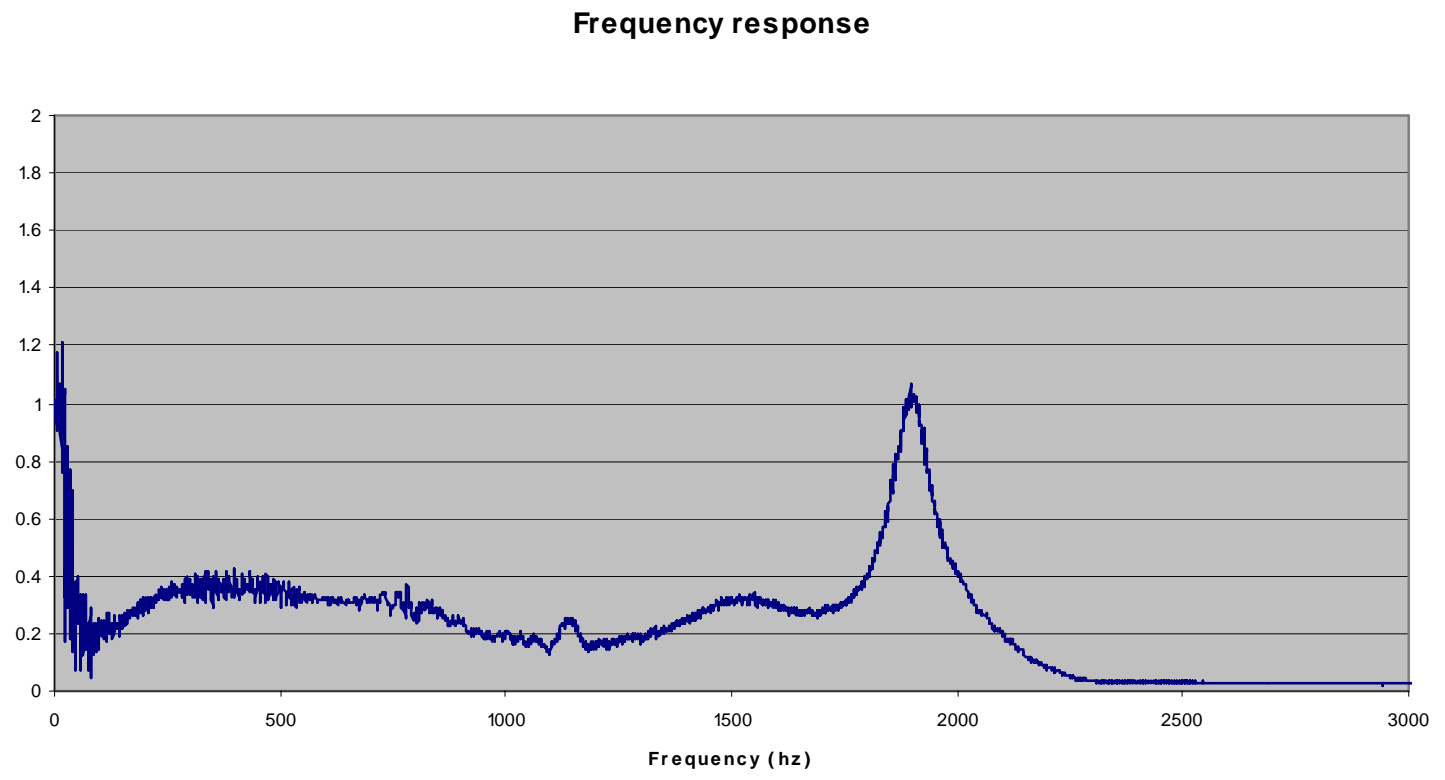

Figure 3: Transfer function magnitude vs. frequency while reforming coal-derived methanol

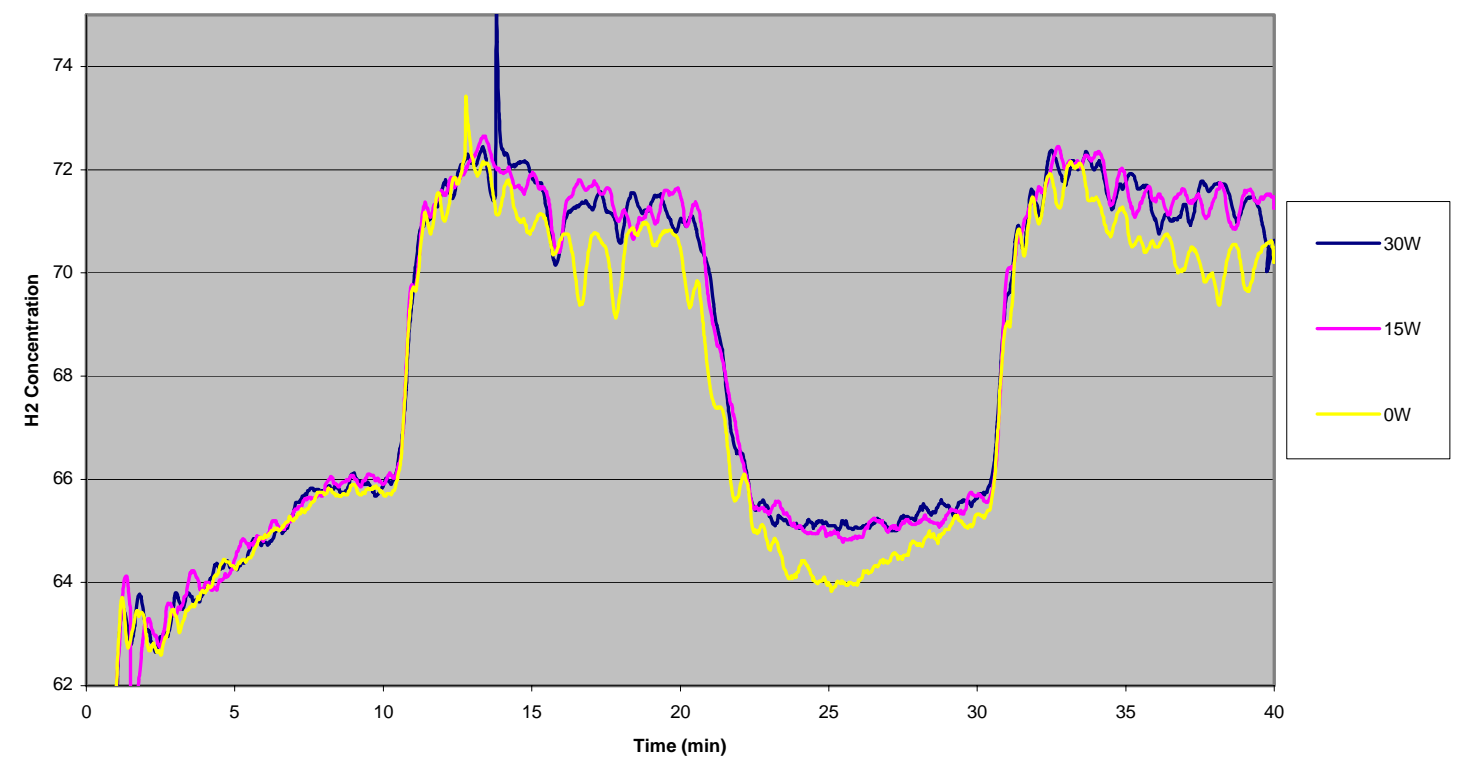

Figure 4: Hydrogen Concentration in product stream from chemical grade methanol 


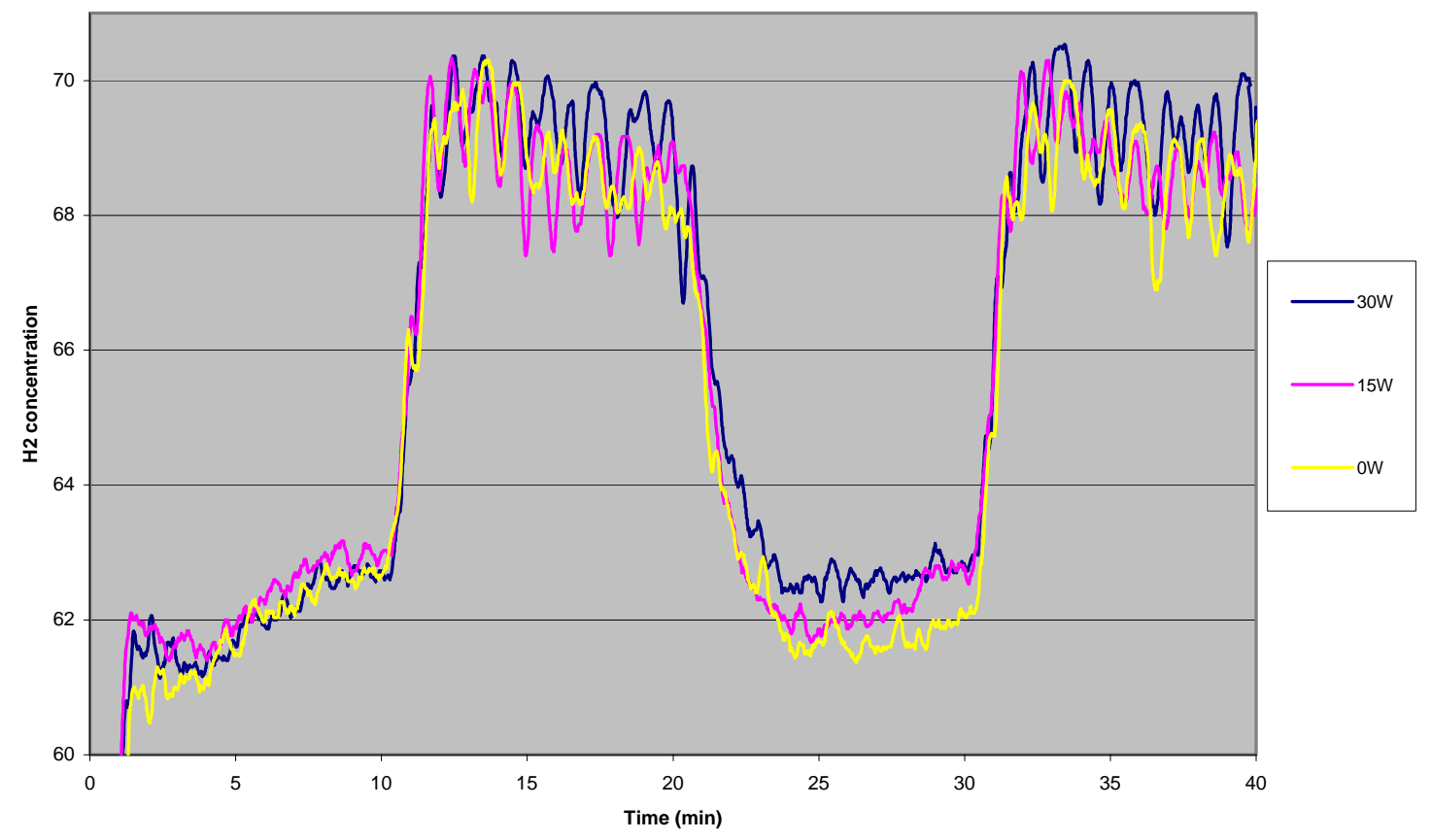

Figure 5: Hydrogen Concentration in product stream from coal-derived methanol

Figures 4 and 5 show the chemical grade methanol gives a slightly higher concentration of hydrogen, with minimal increases due to the addition of acoustical power. Figures 6 and 7 show the reactor temperature as the flow rate changes from low flow to high flow. When the flow rate increases and the centerline temperatures drop immediately we notice that the Zone 4 temperature rises for about a minute before dropping. It has been determined that this is due to the increased flow rate pushing the exothermic water-gas-shift reaction down to Zone 4. 


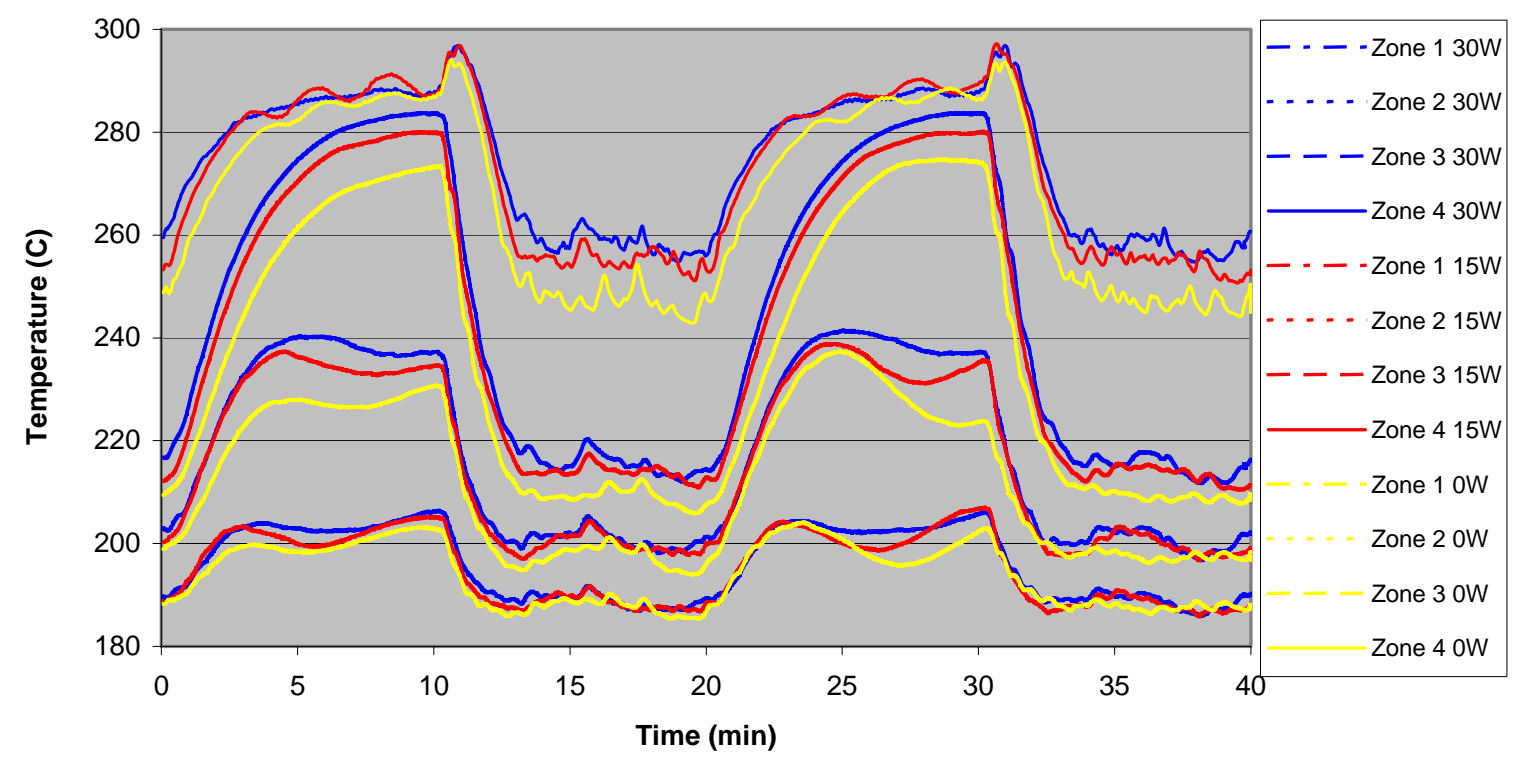

Figure 6: Reactor temperature during two cycles from low flow to high flow with chemical grade methanol (Average of four runs)

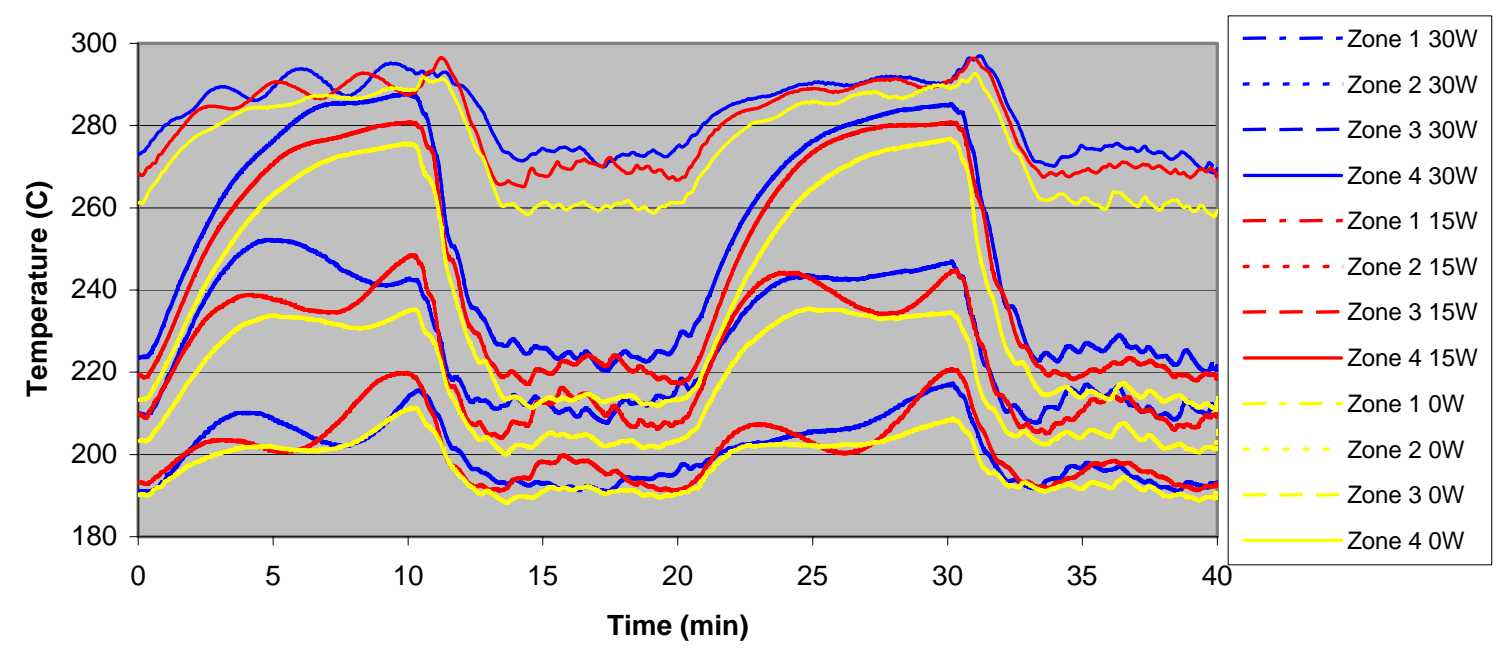

Figure 7: Reactor temperature during two cycles from low flow to high flow with coal-derived methanol (Average of four runs)

Our initial studies which were taken as the reactant flow rate through a steam reformer was cycled between $2.5 \mathrm{ml} / \mathrm{min}$ and $5 \mathrm{ml} / \mathrm{min}(0.0845$ and $0.169 \mathrm{oz} / \mathrm{min})$ were fairly close in conversion percentage making it difficult to clearly see the transient response, so for the second round of experiments the flow rate was varied from $2.5 \mathrm{ml} / \mathrm{min}$ to $7.5 \mathrm{ml} / \mathrm{min}(0.0845 \mathrm{oz} / \mathrm{min}$ to $0.254 \mathrm{oz} / \mathrm{min}$ ), alternating every 10 minutes, which allowed the reactor to just reach steady state 
before the next change in flow rate. The steady-state conversion at $2.5 \mathrm{ml} / \mathrm{min}(0.0845 \mathrm{oz} / \mathrm{min})$ was expected to be $100 \%$. However, the high flow rate of $7.5 \mathrm{ml} / \mathrm{min}(0.254 \mathrm{oz} / \mathrm{min})$ would not be, so a series of baseline steady-state runs were taken to give a benchmark. Since steam reforming is an endothermic reaction the temperature profiles within the reactor tell a good story of how the reactor is responding. By comparing the actual transient conversions to an idealized step function of conversions we can also see how well the reactor responds.

It has been shown that the addition of an acoustic standing wave promotes better heat transfer and thus yields higher conversions [2]. Since the transient response is directly related to heat transfer limitations it was expected that the introduction of a standing wave during the transient experiments would result in a shorter recovery time constant. All of the studies performed include conversions taken with 30 watts of acoustic enhancement, 15 watts of acoustic enhancement as well as with out any acoustic enhancement.

\section{Steam Reformer Catalyst Deactivation}

During the reformation process, the catalyst will slowly lose effectiveness to a point where the methanol conversion drops below an acceptable level and the catalyst must be replaced. Since the catalyst is a major contributor to the cost of a reformer, it is beneficial to be able to estimate how long the catalyst will last. In this study, the rate of catalyst deactivation in steam reformation of methanol is measured under steady-state, isothermal conditions over a range of temperatures and flow rates. The goal is to obtain information that can be used to estimate the lifetime of a non-isothermal catalyst bed from its temperature profile.

During the first phase of the study, the conversion percentage was measured over a 7.5 hour period at intervals of 1.5 hours. All runs were performed with Reactor A containing a mixture of crushed catalyst and inert material. Both the catalyst and inert particles were sieved to be between $0.159 \mathrm{~cm}(1 / 16 \mathrm{in})$ and $0.3175 \mathrm{~cm}(1 / 8 \mathrm{in})$ in diameter. The amount of catalyst used in each run was chosen by estimating the amount required to fully convert $2.0 \mathrm{ml} / \mathrm{min}(0.0676$ $\mathrm{oz} / \mathrm{min}$ ) of premix at the temperature for the run. The range of temperatures studied was from $190^{\circ} \mathrm{C}\left(374^{\circ} \mathrm{F}\right)$ to $350^{\circ} \mathrm{C}\left(662^{\circ} \mathrm{F}\right)$, which covers the range that can occur within a small nonisothermal reactor. The range of flow rates studied was from $2.0 \mathrm{ml} / \mathrm{min}(0.0676 \mathrm{oz} / \mathrm{min})$ to 2.6 $\mathrm{ml} / \mathrm{min}(0.0879 \mathrm{oz} / \mathrm{min})$. It is expected that there is a small range of temperature over which catalyst deactivation is minimized, with an increase in deactivation at temperatures above and below the optimal range. Furthermore, it is expected that flow rate should have at least a secondary effect on deactivation.

In a previous report, an outline for the study on catalyst deactivation in a methanol-steam reformer was described. In this report, the experiments performed and the results are presented herein. 


\section{Steam Reformer Degradation Tests Using Bluff Bodies}

This experiment used Reactor B as a base reactor to investigate the catalyst degradation rate under a passive flow in the catalyst bed. Reactor B was packed with eight packages of bluff bodies using a crushed copper-based catalyst. Chemical-grade methanol was used as the reforming fuel for this degradation experiment. In the coming experiments, reactor B with no bluff body packages will be tested with the same conditions to investigate reactor geometry effects on the catalyst degradation rate. The coal-derived methanol will also be used for further analysis. The crushed catalyst had an average length of $0.25 \mathrm{~cm}(0.098 \mathrm{in})$. A 30-hour experiment was conducted with an 80-minute data point interval to measure the real time methanol conversion. The mass of the catalyst used in the experiment was 250 grams $(.551 \mathrm{lb})$ packed in Reactor B, shown in Figure 8.

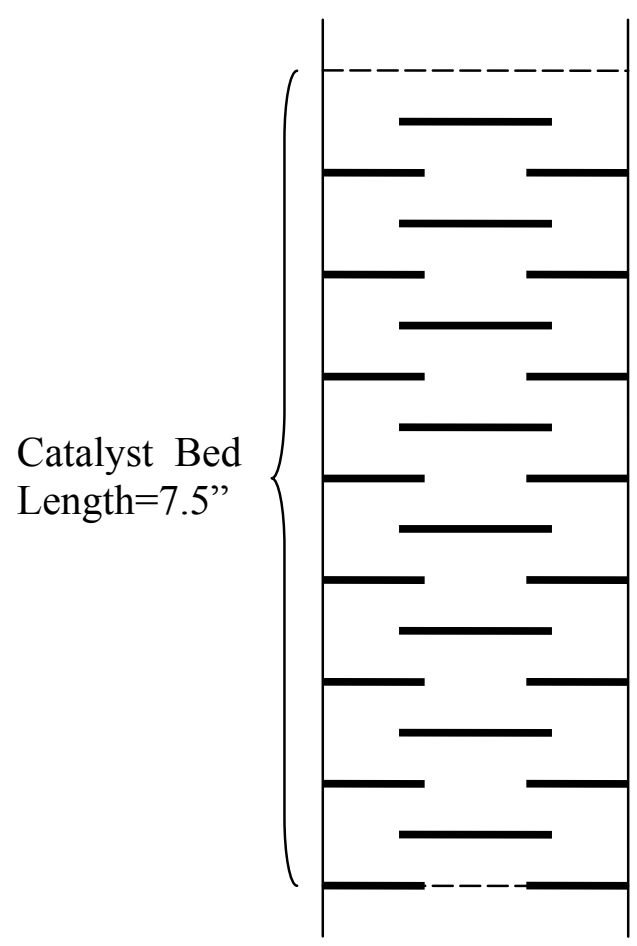

Figure 8: Layout of eight bluff body packages inside Reactor B

Previous experiment results have demonstrated that introducing bluff bodies can significantly improve the steam reforming performance. Therefore, it was expected that bluff bodies might also affect the catalyst degradation rate. This experiment was initiated to investigate and compare the catalyst degradation rates between reactors with bluff body packages and without bluff body packages.

Reactor B was used as a base reactor to investigate the catalyst degradation rate under passive flow in the catalyst bed. Eight packages of bluff bodies were assembled in Reactor B using a crushed copper-based catalyst. Chemical-grade methanol was used as the reforming fuel for this degradation experiment. Reactor B with no bluff body packages was tested with the same 
conditions to compare the bluff body effect on the catalyst degradation rate. The crushed catalyst had an average length of $0.25 \mathrm{~cm}$ (0.098 in). A 30-hour experiment was conducted with an 80-minute data point interval to measure the real time methanol conversion. The mass of the catalyst used in the experiment was 250 grams $(0.551 \mathrm{lb})$ packed in Reactor B.

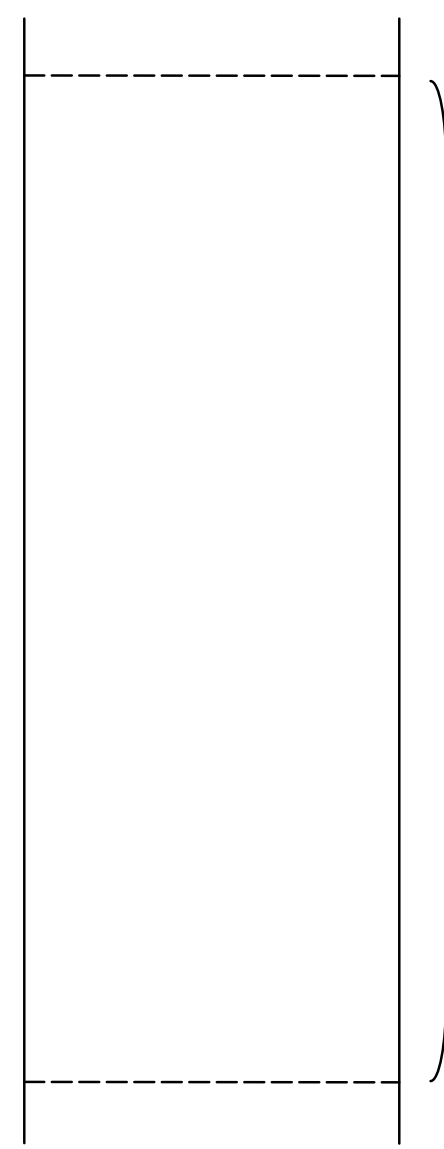

Catalyst Bed Length=7.5"

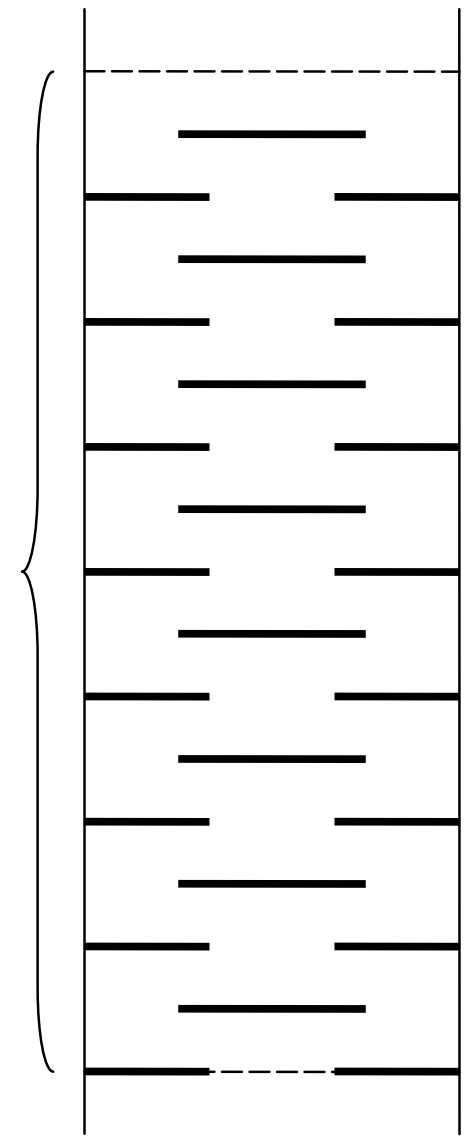

Figure 9: Catalyst degradation test without bluff bodies in Reactor B, run with crushed catalyst and chemical grade methanol

After initial degradation tests were complete, an investigation to the role geometry played in catalyst deactivation was studied. Both chemical grade and coal-derived methanol was tested using different reactor geometries. As mentioned in previous reports, reactor geometry significantly affects catalyst aging regardless of using the same operating conditions (same space velocity and inlet temperature). Reactor geometry dominates catalyst aging because heat and mass transfer can be severely limited as reactor size increases. To analyze the affect geometry has on chemical grade and coal-derived methanol two reactors with different geometries were used. Reactor B is an example of a long reactor and has been set up with eight bluff body packages. The outer diameter and length of Reactor B is 1.66" and 10" respectively. Reactor C was used as smaller sized reactor. The outer diameter and length of Reactor C is 1.05 " and 5" respectively. Reactor B was loaded with $250 \mathrm{~g}$ of crushed catalyst, while Reactor C was loaded with $39 \mathrm{~g}$. The steam to carbon ratio was maintained at a constant 1.5:1 molar ratio. For all the experiments, a 2.5 liquid hourly space velocity associated with premix flow rate was maintained. 
After catalyst degradation tests with and without bluff bodies have been completed using chemical grade methanol, coal-derived methanol will be analyzed. Initial results indicated that the degradation phenomena did not have a significant effect on conversion percentage, but did increase reactor centerline temperature. The experiment using coal-derived methanol and eight bluff body packages was completed to compare the difference in catalyst degradation using chemical grade methanol.

\section{Heat Transfer Enhancement}

The following setup was used to determine the preliminary experimental results of heat transfer enhancement via internal cartridge heater. The purpose of heat transfer enhancement is to increase the percent convergence of coal-derived methanol. The ideal case would be $100 \%$ convergence. Reactor $\mathrm{A}$ is shown below in Figure 10 and reforms methanol using eight band heaters. Reactor $\mathrm{C}$ is shown below in Figure 11 and reforms using two band heaters and an internal cartridge heater. Reactor A and Reactor $\mathrm{C}$ have the same $3 / 4$ " nominal diameter but differ in length. Reactor $\mathrm{C}$, which has an internal cartridge heater, was loaded with $39 \mathrm{~g}$ of crushed catalyst. Reactor A was loaded with $250 \mathrm{~g}$ of pelletized catalyst and a second experiment was conducted using $250 \mathrm{~g}$ of crushed catalyst. For the three previously described cases, contact time has been defined in terms of space velocity and packing density to enable comparison with different experimental results. The same set point was applied in the case of Reactor A regardless of different flow rates. However, the set point of Reactor $\mathrm{C}$ had been changed to minimize thermal gradients inside the reactor. 


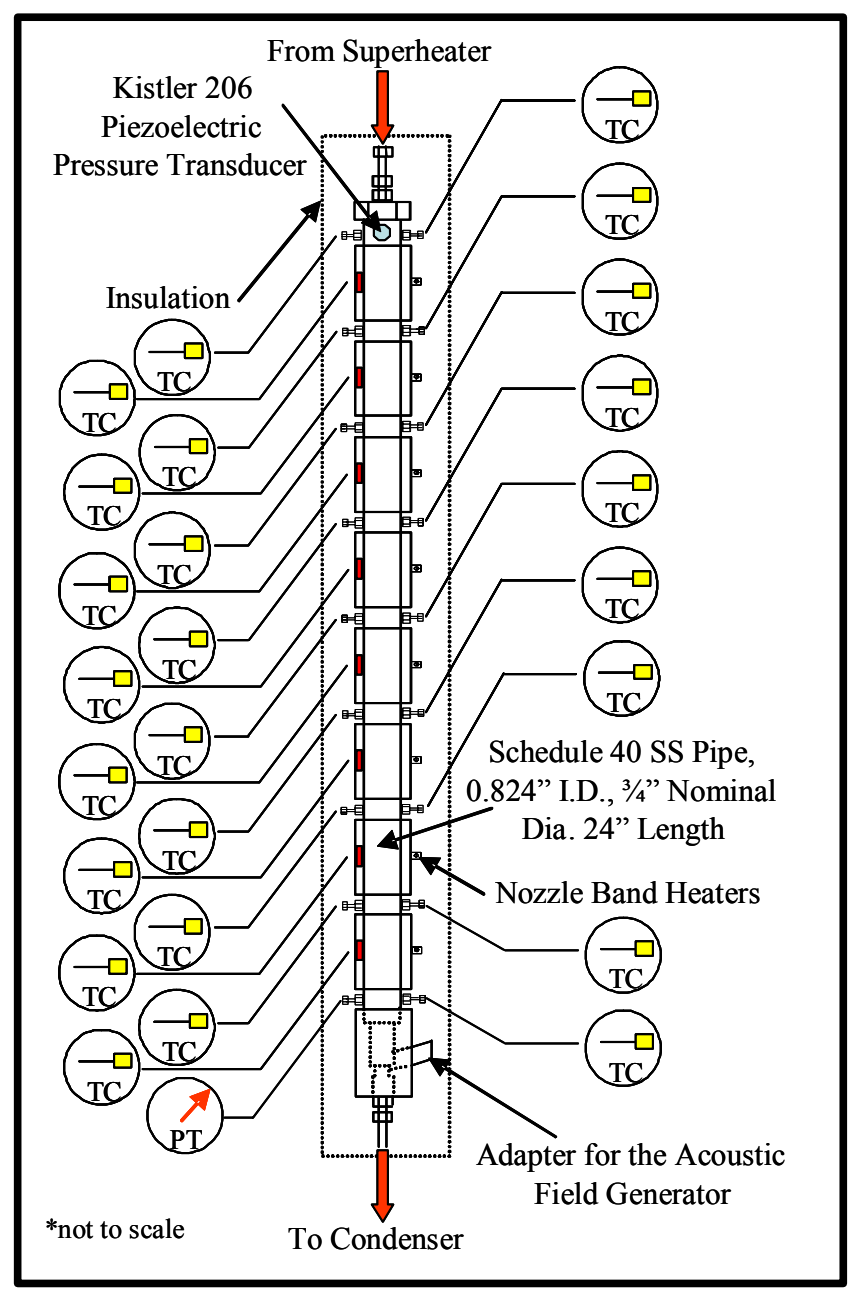

Figure 10: Reactor A Schematic 


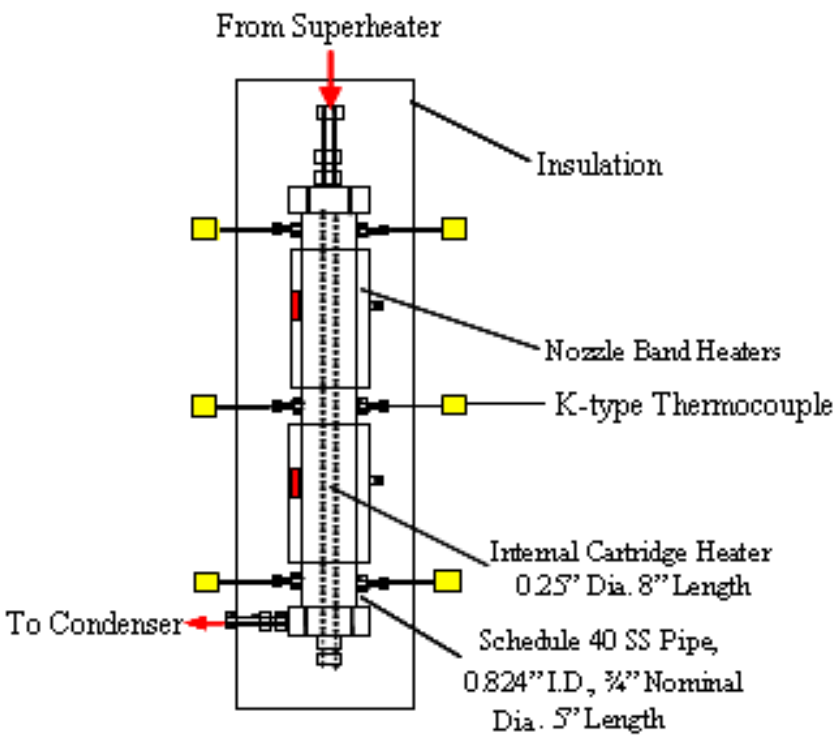

Figure 11: Reactor C Schematic

\section{Autothermal Reforming of Coal-Derived Methanol}

The autothermal reforming of coal-derived methanol test was initiated by using "Urban catalyst." The catalyst used in this experiment was taken from an automotive catalytic converter. A catalytic converter in a car is used to reduce harmful emissions from the engine exhaust. Inside a catalytic converter there are two monolithic catalysts, one located upstream and the other downstream. The one located in the upstream position plays as a reduction catalyst. It contains platinum and rhodium, which helps reduce the NOx emissions. The oxidization catalyst located downstream contains platinum and palladium, which can reduce the unburned hydrocarbon and carbon monoxide by burning them with oxygen. This experiment adopted the oxidization catalyst as an ATR catalyst to test its function as a catalyst for coal-derived methanol. The catalyst was machined into a cylindrical shape with a length of $3.713 \mathrm{~cm}(1.462 \mathrm{in})$ and $3.78 \mathrm{~cm}$ (1.330 in) diameter, shown in Figure 12. 


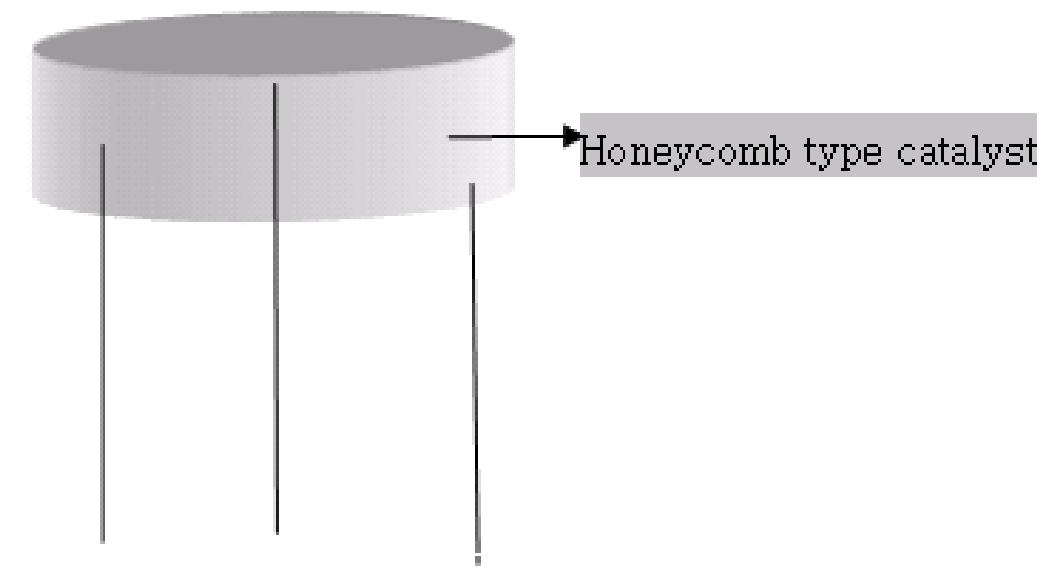

\section{End Cap 3 End Cap 4 Erd Cap 1}

Figure 12: The location of end-cap thermocouples

Mixing effects in steam reforming has already been show to be of great significance to the effectiveness of a reformer. Coal-derived methanol has been set up for autothermal reformation (ATR). Mixing in ATR is much more significant than in steam reformation (SR) because of the addition of oxygen inside the reactor, which through Partial Oxidation (POX) supplies heat, by means of combustion, for the steam reforming reaction. To figure out the effects of mixing as well as find out the optimal location for the placement of the ATR catalyst within the reactor, what we call, "urban catalyst" (catalyst used in vehicle catalytic converters) was put in different locations inside the reactor for preliminary set-up of ATR of coal-derived methanol.

Urban catalysts wafers $3.5 \mathrm{~cm}$ in diameter by $3.4 \mathrm{~cm}$ in length $(1.38$ " $\mathrm{x} 1.34$ ") were placed in Zone 1 and Zone 4 during different runs. Zone 1, as can be seen in Figure 13, is located at top of the reactor so that there is approximately $2.54 \mathrm{~cm}(1$ ") of entry length for mixing of the gases leaving the superheater. On the other hand, Zone 4 is located below the middle of the reactor (approximately $17.8 \mathrm{~cm}$ (7') entry length), which should be enough entry length for complete mixing of the fuel with oxygen, supplying heat through combustion. The Steam/Carbon Ratio was held constant at 1.5:1 for the entire experiment. The Oxygen/Carbon ration was varied from 0.2 up to 0.35 . Liquid hourly space velocity was constantly set at 2 . 


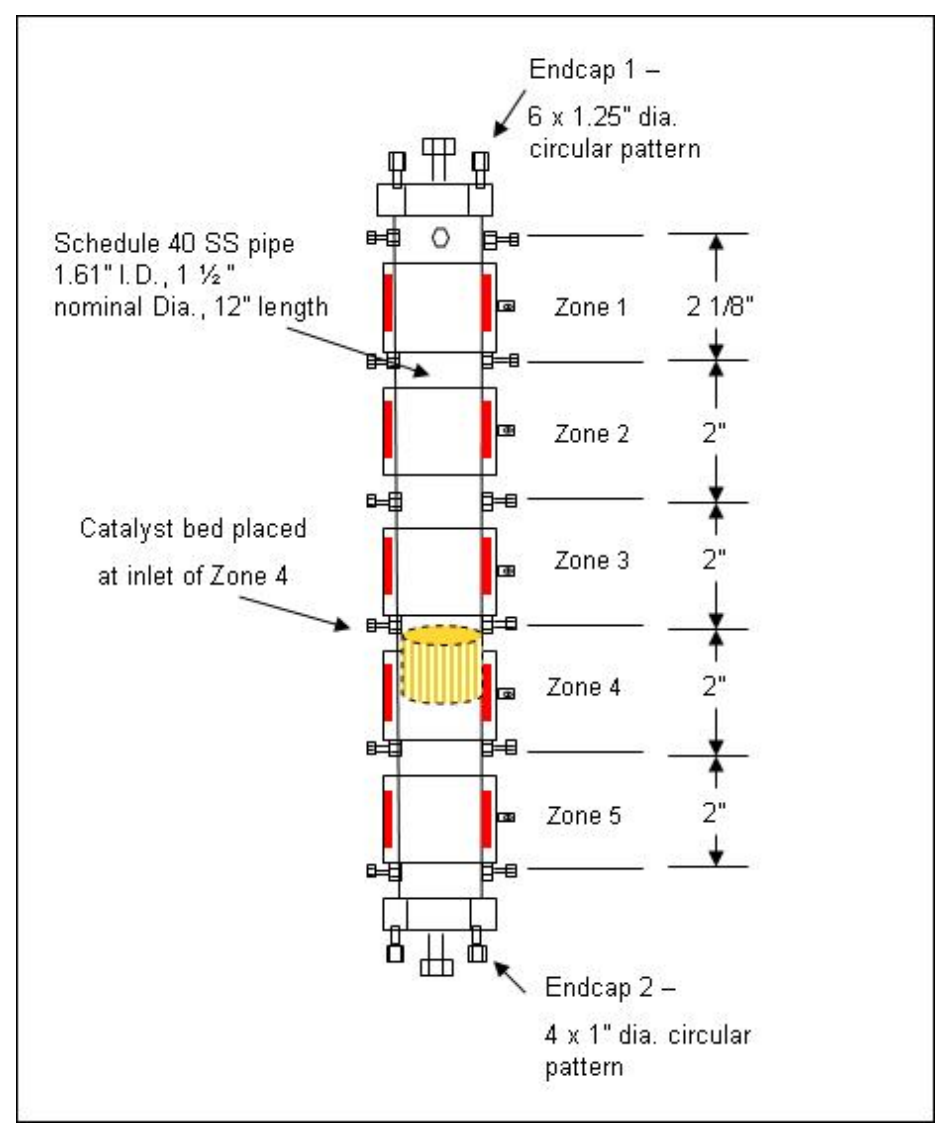

Figure 13: Schematic of ATR Reactor

\section{Autothermal Catalyst Degradation}

Steam reformation catalyst degradation presented limited lifetime issues. To determine the lifetime of the autothermal catalyst, degradation tests similar to the ones performed for steam reformation were completed. The reduction catalyst (upstream catalyst) of a three-way catalytic converter has been used for autothermal reformer degradation tests. The size of reduction catalyst (upstream catalyst) is 1.4 " diameter and 1.45 " Length. This catalyst is mainly composed of platinum and rhodium. Both chemical grade and coal-derived methanol was used for this autothermal reformer degradation test. $\mathrm{O}_{2} / \mathrm{C}$ and $\mathrm{S} / \mathrm{C}$ ratio are adapted at 0.21 and 1.5 respectively. Reactor inlet temperature was maintained at approximately $250 \mathrm{C}^{\circ}$.

\section{Autothermal Reformation With Bluff Bodies}

According to previous autothermal reformation experiment results, placing the monolith catalyst at different locations in the axial direction resulted in different fuel conversions. When the catalyst sat close to the reactor entrance (Zone 1), the result showed a lower fuel conversion than close to the reactor exit (Zone 4). The result was explained through the following rational. A 
catalyst close to the reactor exit has more space and time for oxygen and methanol fuel mixing to occur. This allows for increased partial oxidation after entering the catalyst bed during the autothermal reaction. In this experiment, ring-disk bluff body sets are expected to enhance the mixing more than empty space before the catalyst bed. Therefore, an experiment design depicted in Figure 14 was set up to test the mixing mechanism caused by bluff bodies.

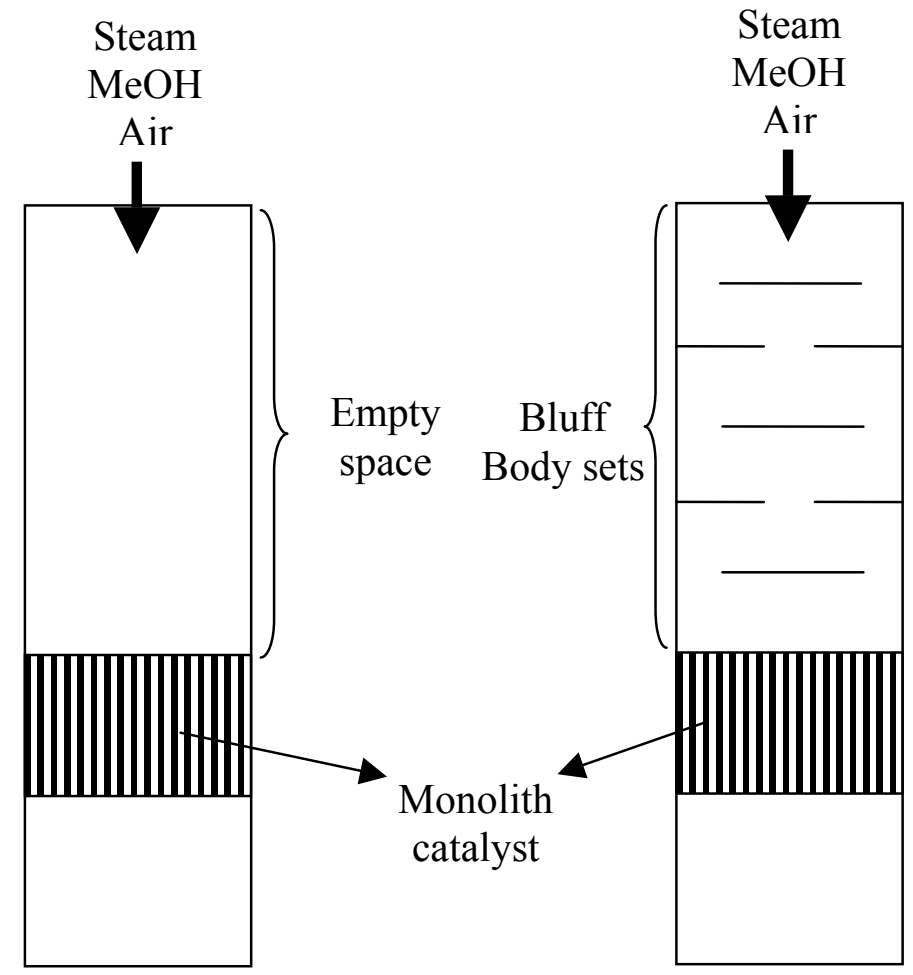

Figure 14: Schematic for ATR reactor with and without bluff body.

Chemical grade methanol at a steam to carbon ratio $(\mathrm{S} / \mathrm{C})$ of 1.5:1 was used as the fuel and tested at different oxygen to carbon ratio to examine corresponding fuel conversion. The GHSV range was 21083 to $21570\left[\mathrm{~h}^{-1}\right]$ for the reactor condition of $250 \mathrm{C}$ and $0.1 \mathrm{MPa}$. The liquid flow rate was set at $9.95 \mathrm{ml} / \mathrm{min}$ (H2O: $4.0 \mathrm{ml} / \mathrm{min}$ and $\mathrm{MeOH}: 5.95 \mathrm{ml} / \mathrm{min}$ ). Water and methanol were separately vaporized before entering to the super heater. The catalyst was taken from a catalytic converter intended for use on automobiles and termed as low-grade, or urban catalyst. Two experiment runs were carried out including the first run without bluff body packages and a second run with bluff body packages. 


\section{RESULTS AND DISCUSSION}

\section{Steam Reformer Transient Response}

In that the acoustics of the reactor varies slightly each time the catalyst bed housing is packed, the dominant frequencies were revaluated for each catalyst packing. Figure 15 shows an example of the transfer function magnitude vs. frequency for the reactor during reduction. Figure 16 shows the transfer function magnitude vs. frequency for the reactor during the reformation of coal-derived methanol.

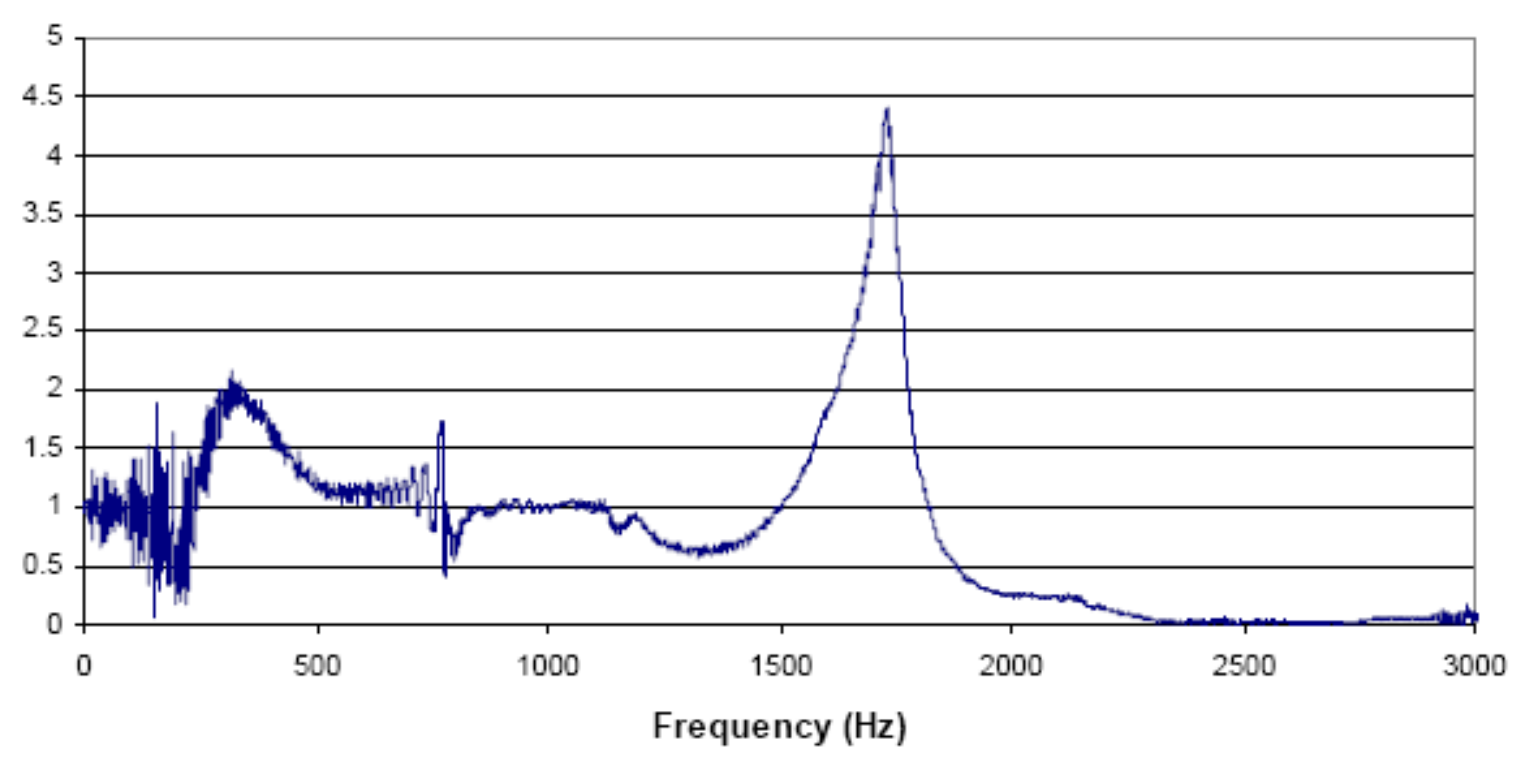

Figure 15: Transfer function magnitude of catalyst bed housing while reducing catalyst 


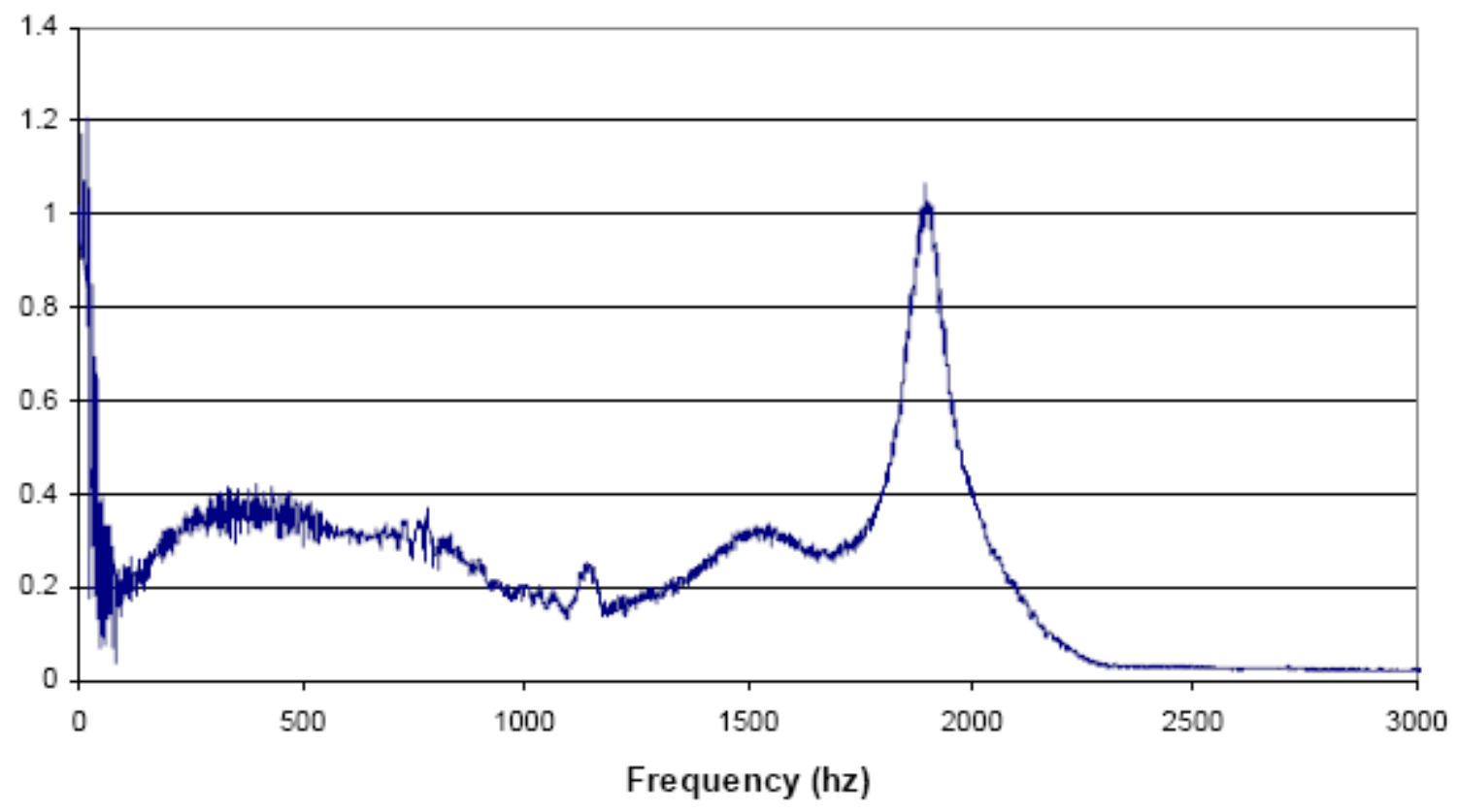

Figure 16: Transfer function magnitude of catalyst bed housing while reforming coal-derived methanol

During reduction the catalyst bed is heated to $200^{\circ} \mathrm{C}\left(392^{\circ} \mathrm{F}\right)$ and is filled with $98.5 \%$ nitrogen, and $1.5 \%$ hydrogen by mass. While reforming the catalyst bed is at a temperature of around $260^{\circ} \mathrm{C}\left(500^{\circ} \mathrm{F}\right)$, and is filled with hydrogen, carbon monoxide, carbon dioxide, methane, as well as unreacted water and methanol. It is clear that the peak between these two operations shifts in frequency due to an increase in temperature and a change in the gas composition by a comparison of the plots below.

For the catalyst bed housing used the dominant mode frequency for the case of the chemical grade methanol was $1935 \mathrm{~Hz}$ while reforming. When the coal-derived methanol was used the dominant mode frequency was found to be $1898 \mathrm{~Hz}$. During operation the temperature and gas compositions do fluctuate. To optimize the influence of the acoustic enhancement a feed back control system would be required to periodically recalculate the optimal frequency and adjust the input. 


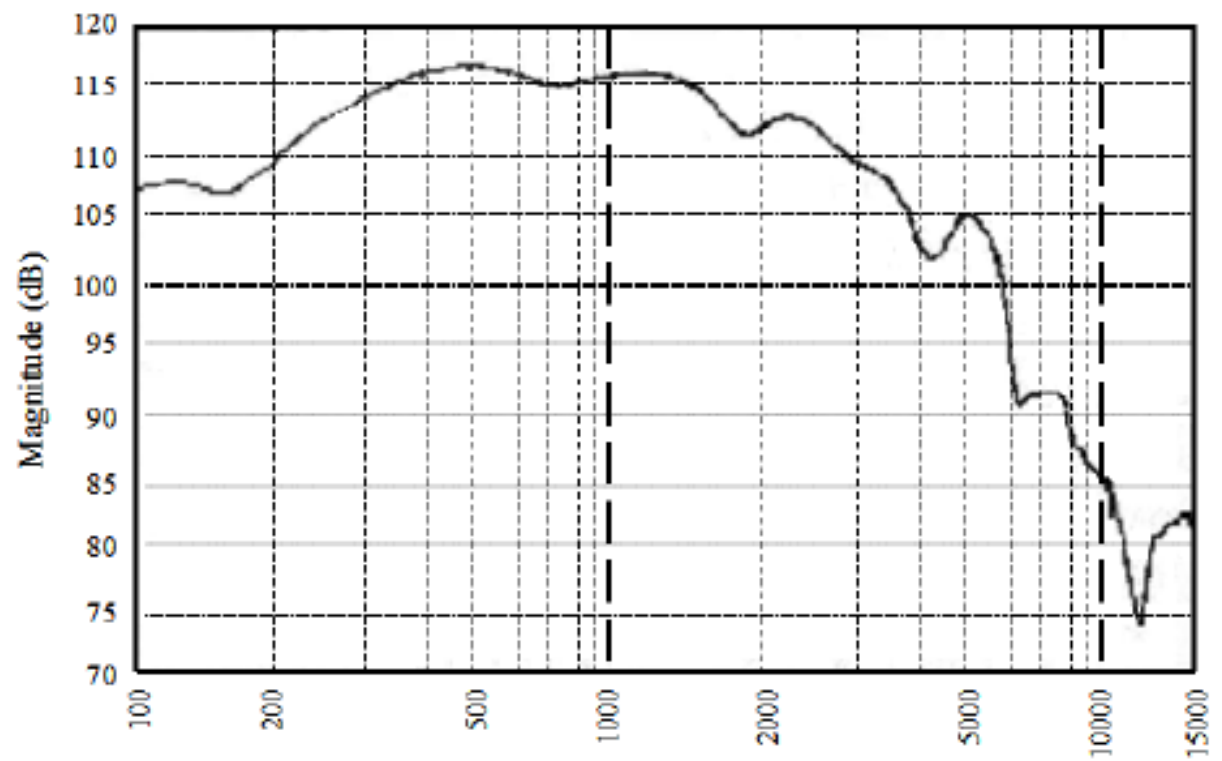

Figure 17: Frequency response of the Atlas PD-60A Driver (Courtesy of Atlas)

In addition to variances in the changing condition of the catalyst bed there is a limitation to the response that can be achieved by a swept sine from the driver while determining the dominant modes. Figure 17 presents the frequency response of the compression driver indicating that tones below $200 \mathrm{~Hz}$, and above $50000 \mathrm{~Hz}$ will be produced with less power. Although there is a limitation as to the range of the modes that can be examined it is not believed that tones outside of this range would yield higher sound pressure levels.

\section{CONVERSION DATA}

The primary output from the experiments was the fuel conversion. The fuel conversions calculated from the transient experiments are tabulated below in Table 1 along with the overall averages and standard deviations. After completion of the initial experiments using the chemical grade methanol it was determined that four data points was not necessary and thus for all remaining reformer settings only three points were collected.

Table 1: Conversions of transient experiments

\begin{tabular}{|c|c|c|c|c|c|c|c|}
\hline \multirow{2}{*}{ Fuel } & \multirow{2}{*}{$\begin{array}{c}\text { Power } \\
\text { Level (W) }\end{array}$} & \multicolumn{4}{|c|}{ Conversion (\%) } & \multirow{2}{*}{$\begin{array}{c}\text { Average } \\
\text { Conversion } \\
(\%)\end{array}$} & \multirow{2}{*}{$\begin{array}{l}\text { Standard } \\
\text { Deviation }\end{array}$} \\
\hline & & Run 1 & Run 2 & Run 3 & Run 4 & & \\
\hline \multirow{3}{*}{$\begin{array}{c}\text { Chemical } \\
\text { Grade } \\
\text { Methanol }\end{array}$} & 0 & 95.48 & 95.4 & 95.75 & 95.63 & 95.57 & 0.156 \\
\hline & 15 & 96.34 & 96.35 & 96.31 & 96.26 & 96.32 & 0.040 \\
\hline & 30 & 97.03 & 96.82 & 96.87 & 96.9 & 96.91 & 0.090 \\
\hline \multirow{3}{*}{$\begin{array}{c}\text { Coal } \\
\text { Derived } \\
\text { Methanol }\end{array}$} & 0 & 96.58 & 95.66 & 94.34 & - & 95.53 & 1.126 \\
\hline & 15 & 96.67 & 95.28 & 96.1 & - & 96.02 & 0.699 \\
\hline & 30 & 97.86 & 97.17 & 96.46 & - & 97.16 & 0.700 \\
\hline
\end{tabular}


As expected we see higher standard deviations for the coal-derived methanol, which is attributed to higher rates of degradation. However, it is apparent that the addition of acoustics to the reformer resulted in greater overall conversion, and created less deviation in the case of both fuels most likely due to lessened thermal gradients. The statistical accuracy of the measured conversions was derived using the student-t distribution. The $95 \%$ and $99 \%$ confidence range was calculated using Equation 1, where $\mathrm{C} \%$ is the percent conversion $\mathrm{t}_{\mathrm{v}, \mathrm{p}}$ is the student- $\mathrm{t}$ distribution, and $\mathrm{S}_{\mathrm{X}}$ is the standard deviation.

$$
C \%=\bar{C} \% \pm t_{v, p} S_{x}
$$

Results of the two confidence levels for the transient experiments can be seen in Table 2 below.

Table 2: Statistical accuracy of transient experiments

\begin{tabular}{|c|c|c|c|c|}
\hline Fuel & $\begin{array}{c}\text { Power Level } \\
\text { (W) }\end{array}$ & $\begin{array}{c}\text { Average } \\
\text { Conversion (\%) }\end{array}$ & $\begin{array}{l}95 \% \text { Confidence } \\
( \pm \%)\end{array}$ & $\begin{array}{l}99 \% \text { Confidence } \\
( \pm \%)\end{array}$ \\
\hline \multirow{3}{*}{$\begin{array}{c}\text { Chemical Grade } \\
\text { Methanol }\end{array}$} & 0 & 95.57 & 0.50 & 0.91 \\
\hline & 15 & 96.32 & 0.13 & 0.24 \\
\hline & 30 & 96.91 & 0.29 & 0.52 \\
\hline \multirow{3}{*}{$\begin{array}{l}\text { Coal Derived } \\
\text { Methanol }\end{array}$} & 0 & 95.53 & 4.84 & 11.17 \\
\hline & 15 & 96.02 & 3.01 & 6.93 \\
\hline & 30 & 97.16 & 3.01 & 6.95 \\
\hline
\end{tabular}

As stated previously in order to provide a comparison for improvements in the transient response steady state runs were performed to yield a base line of comparison. It was expected that the steady state conversions at a flow rate of $2.5 \mathrm{ml} / \mathrm{min}$ would be $100 \%$. Two runs were performed at a flow rate of $2.5 \mathrm{ml} / \mathrm{min}$ without acoustics and verified this assumption. The addition of acoustics can only improve the process so no further runs were performed. A series of runs using a flow rate of $7.5 \mathrm{ml} / \mathrm{min}$ with each of the fuels, and at each of the various acoustical settings were performed. The conversions derived from the steady-state experiments as well as their collected averages and standard deviations are displayed below in Table 3.

Table 3: Conversions of steady state experiments at a flow rate of $7.5 \mathrm{ml} / \mathrm{min}$

\begin{tabular}{|c|c|c|c|c|c|c|c|}
\hline \multirow{2}{*}{ Fuel } & $\begin{array}{c}\text { Power } \\
\text { Level (W) }\end{array}$ & Run 1 & Run 2 & Run 3 & Run 4 & $\begin{array}{c}\text { Average } \\
\text { Conversion } \\
(\%)\end{array}$ & $\begin{array}{c}\text { Standard } \\
\text { Deviation }\end{array}$ \\
\hline \multirow{2}{*}{$\begin{array}{c}\text { Chemical } \\
\text { Grade } \\
\text { Methanol }\end{array}$} & 0 & 92.32 & 91.42 & 91.17 & 90.48 & 91.35 & 0.760 \\
\cline { 2 - 8 } & 15 & 92.96 & 93.88 & 93.7 & 93.34 & 93.47 & 0.407 \\
\hline $\begin{array}{c}\text { Coal } \\
\text { Derived } \\
\text { Methanol }\end{array}$ & 0 & 93.03 & 94.48 & 91.95 & 91.44 & 92.73 & 1.345 \\
\cline { 2 - 8 } & 15 & 94.12 & 92.59 & 91.46 & - & 92.39 & 0.848 \\
\hline
\end{tabular}

There was a severe and unexplainable drop in the conversion of the chemical grade methanol with 30 Watts of acoustical power. Runs two through four were taken directly after one another 
as dictated by the randomization of experiment order. It is possible that this drop is due to a sound pressure level drop in the reactor brought on by a shift in the catalyst bed. The statistical accuracy of the measured conversions of the steady-state experiments was also calculated using the student-t distribution as described above. The results of the accuracy calculations can be seen in Table 4 below.

Table 4: Statistical accuracy of steady state experiments

\begin{tabular}{|c|c|c|c|c|}
\hline \multirow{2}{*}{ Fuel } & \multicolumn{3}{|c|}{$\begin{array}{c}\text { Power Level } \\
(\mathrm{W})\end{array}$} & \multicolumn{3}{|c|}{$\begin{array}{c}\text { Average } \\
\text { Conversion }(\%)\end{array}$} & $\begin{array}{c}\text { ( } \\
( \pm \%)\end{array}$ & $( \pm \%)$ \\
\hline \multirow{2}{*}{$\begin{array}{c}\text { Chemical Grade } \\
\text { Methanol }\end{array}$} & 0 & 91.35 & 2.42 & 4.44 \\
\cline { 2 - 5 } & 15 & 93.47 & 1.30 & 2.38 \\
\hline \multirow{2}{*}{$\begin{array}{c}\text { Coal Derived } \\
\text { Methanol }\end{array}$} & 30 & 92.73 & 4.28 & 7.85 \\
\cline { 2 - 5 } & 0 & 92.39 & 2.70 & 4.95 \\
\cline { 2 - 5 } & 15 & 94.26 & 0.90 & 1.66 \\
\hline
\end{tabular}

Table 5: Calculation of the ratio of variance of conversion to standard deviation for transient experiments

\begin{tabular}{|c|c|c|c|c|c|}
\hline \multicolumn{6}{|c|}{ Transients } \\
\hline & $\begin{array}{c}\text { Power } \\
\text { Level (W) }\end{array}$ & $\begin{array}{c}\text { Average } \\
\text { Conversion } \\
(\%)\end{array}$ & $\begin{array}{l}\text { Standard } \\
\text { Deviation }\end{array}$ & $\begin{array}{c}\text { Measured } \\
\text { Conversions } \\
(\%)\end{array}$ & $\mathrm{d} / \sigma \sigma$ \\
\hline \multirow{12}{*}{$\begin{array}{l}\text { Chemical } \\
\text { Grade } \\
\text { Methanol }\end{array}$} & \multirow{4}{*}{0} & \multirow{4}{*}{95.57} & \multirow{4}{*}{0.156} & 95.48 & 0.55 \\
\hline & & & & 95.4 & 1.06 \\
\hline & & & & 95.75 & 1.19 \\
\hline & & & & 95.63 & 0.42 \\
\hline & \multirow{4}{*}{15} & \multirow{4}{*}{96.32} & \multirow{4}{*}{0.040} & 96.34 & 0.62 \\
\hline & & & & 96.35 & 0.87 \\
\hline & & & & 96.31 & 0.12 \\
\hline & & & & 96.26 & 1.36 \\
\hline & \multirow{4}{*}{30} & \multirow{4}{*}{96.91} & \multirow{4}{*}{0.090} & 97.03 & 1.39 \\
\hline & & & & 96.82 & 0.95 \\
\hline & & & & 96.87 & 0.39 \\
\hline & & & & 96.9 & 0.06 \\
\hline \multirow{9}{*}{$\begin{array}{c}\text { Coal } \\
\text { Derived } \\
\text { Methanol }\end{array}$} & \multirow{3}{*}{0} & \multirow{3}{*}{95.53} & \multirow{3}{*}{1.126} & 96.58 & 0.94 \\
\hline & & & & 95.66 & 0.12 \\
\hline & & & & 94.34 & 1.05 \\
\hline & \multirow{3}{*}{15} & \multirow{3}{*}{96.02} & \multirow{3}{*}{0.699} & 96.67 & 0.94 \\
\hline & & & & 95.28 & 1.05 \\
\hline & & & & 96.1 & 0.12 \\
\hline & \multirow{3}{*}{30} & \multirow{3}{*}{97.16} & \multirow{3}{*}{0.700} & 97.86 & 1.00 \\
\hline & & & & 97.17 & 0.01 \\
\hline & & & & 96.46 & 1.00 \\
\hline
\end{tabular}


After evaluating the standard deviation and statistical accuracy of the steady state and transient conversion data the validity of the data was questioned due to a larger standard deviation than had been expected. Chauvenet's criterion was thus used to test the validity of the measured data. The criterion specifies that a reading may be rejected if the probability of obtaining the particular deviation from the mean is less than $1 / 2 \mathrm{n}$, where $\mathrm{n}$ is the number of data samples. For the data series where four data points were collected the ratio of the maximum acceptable deviation to standard deviation is 1.54 , and for three data point sets that ratio would be 1.38. Table 5 shows the calculated ratios of the variance in the percent conversion from the mean to the standard deviation $\left(d_{i} / \sigma\right)$ for the transient experiments.

\section{TRANSIENT RESPONSE EVALUATION}

To provide a baseline of comparison for the transient response an approximated average conversion that would be expected from a perfectly responding reformer was calculated. This was done for each of the acoustical and fuel purity settings using Equation 1 the baseline data presented above, where $t$ is the time between changes in flow $(10 \mathrm{~min}), \overline{\% C}_{2.5, \mathrm{SS}, \mathrm{a}}$ is the percent conversion at a steady state flow rate of $2.5 \mathrm{ml} / \mathrm{min}$ for each of the individual acoustical settings (determined to be $100 \%$ ), and $\overline{\% C}_{7.5, \mathrm{SS}, \mathrm{a}}$ is the percent conversion at a steady state flow rate of $7.5 \mathrm{ml} / \mathrm{min}$ for each of the individual acoustical settings (taken from Table 3 ).

$$
\overline{\% C}_{\text {idioal }}=\frac{2 t \overline{\%}_{2.5,5 S, a}+2 t \overline{\%}_{7,5,55, a}}{4 t}
$$

These idealized conversions are displayed in Table 6 where the difference between the idealized conversions and the actual conversions is also tabulated. It was expected that the difference between the actual and idealized averages would decrease incrementally as acoustical power was added. However, from the data presented below this is not the case.

\begin{tabular}{|c|c|c|c|c|}
\hline Fuel & $\begin{array}{c}\text { Power } \\
\text { Level (W) }\end{array}$ & $\begin{array}{c}\text { Average } \\
\text { Conversion } \\
(\%)\end{array}$ & $\begin{array}{c}\text { Idealized } \\
\text { Conversions }\end{array}$ & Difference \\
\hline \multirow{3}{*}{$\begin{array}{l}\text { Chemical } \\
\text { Grade } \\
\text { Methanol }\end{array}$} & 0 & 95.57 & 95.67 & 0.11 \\
\hline & 15 & 96.32 & 96.74 & 0.42 \\
\hline & 30 & 96.91 & 96.36 & -0.54 \\
\hline \multirow{3}{*}{$\begin{array}{c}\text { Coal } \\
\text { Derived } \\
\text { Methanol }\end{array}$} & 0 & 95.53 & 96.20 & 0.67 \\
\hline & 15 & 96.02 & 97.13 & 1.12 \\
\hline & 30 & 97.16 & 97.88 & 0.71 \\
\hline
\end{tabular}

The importance of further advancements in fuel reformer technology was set forth if fuel cell vehicles are to see commercial use. Improvements in the transient response of steam reformers was identified as an important goal that will aid in bridging the gap between traditional IC engine and fuel cell powered vehicles. The use of acoustic pressure waves as a method of enhancing transient response time was investigated. In order to evaluate the improvement gained an adapter 
was fitted to the bottom of a catalyst bed housing which connected an acoustic compression driver to the system. The flow rate of the reformer was varied from $2.5 \mathrm{ml} / \mathrm{min}$ to $7.5 \mathrm{ml} / \mathrm{min}$ as a square wave with a period of 20 minutes. The frequency of the dominant standing wave was determined and introduced into the reformer at two different power levels. Fuel purity was also evaluated to determine if methanol derived from coal would have varied transient effects. The data collected evaluated the response by a comparison of averaged conversion over two cycles, which was then compared to the calculated average conversion of a perfectly responding reformer. In addition to an evaluation of the conversions, analysis of the catalyst bed temperature fluctuations was made.

The addition of a resonating acoustic standing wave proved to enhance overall conversion of the fuel, but was inconclusive with respect to an increase in transient response for either methanol grade. However, an analysis of the temperature fluctuations inside the catalyst bed shows lessened thermal gradients across the diameter of the catalyst bed indicating an increase in the heat transfer rate coefficient. Upon further analysis of the temperature readings of the exterior and interior catalyst bed walls it was determined that the temperature slope set point of the control scheme was limiting the heat flux into the catalyst bed thus hindering the improved response that was expected.

From the data collected it is evident that the addition of a resonating acoustic wave inside of the catalyst bed of a steam reformer does result in increased heat transfer and thus should shorten the time constant of the transient response. Although the acoustic enhancement causes an increase in heat transfer it is important that the temperature controls scheme of the steam reformer be adjusted to take full advantage of the improvement. The experiments utilizing coal-derived methanol showed a similar transient response to that of the chemical grade methanol. There were larger temperature fluctuations observed inside the catalyst bed during the experiments with coal-derived methanol, and an increased rate of catalyst deactivation that made it difficult to show the improvements in response time accomplished by the addition of the acoustic standing wave.

\section{RECOMMENDATIONS}

The results of this study suggest that acoustics can be one method for improving transient response times of steam reformers, but there is much more work that needs to be done if small scale reformers are to become widely used. It is believed that the dominant effect of the acoustic wave is that of an increased, and oscillatory, flow velocity yielding better heat transfer. In addition to heat transfer the pressure wave may also have a substantial impact on the mass transfer of the system moving reactants and reformate in and out of catalyst sites. Experiments should be run to quantify the contribution of both of these mechanisms of acoustic enhancement to steam reformation. Since the frequency and length of the reformer is known the pressure and velocity nodes and antinodes can be easily determined. By comparing conversions with catalyst alternately placed at these nodes or antinodes, the magnitude of the contributions can be observed.

Just as important as the heat transfer within the catalyst bed is the heat supplied externally to the wall. Too much heat at the wall can sinter the catalyst; whereas too little heat in the center of the 
bed can cause coking. Improved heat transfer helps to reduce these gradients and simplify controls. Also observed was that during low flow operation the catalyst bed temperatures rose driving the water-gas shift reaction in the opposite direction. Further work needs to be done on temperature control schemes for steam reformers to optimize heat flux during transients, and optimize the wall temperatures so that sintering at the wall and coking in the center is avoided. The current catalyst bed employs the use of 14 thermocouples for the thermal controls although a commercialized reformer might only be afforded one or two. Therefore it is important that the operation of the reformer be well characterized with respect to the heat requirements per location for a given reactor geometry and flow rate.

Fluctuations in the sound pressure level of the catalyst bed were observed during reforming with the addition of acoustics. This was due to changes in temperature and gas composition. It is expected that a greater impact from the acoustics could be achieved if a feed back control were employed to periodically calculate the transfer function magnitudes with respect to the catalyst bed conditions and adjust the frequency accordingly. Aside from the active method of increasing heat transfer by the super-position of an acoustic wave there are other passive forms that should be evaluated under transient operation. Work has been performed in the Hydrogen Production and Utilization Lab using bluff bodies (alternating disk and rings) as a passive method of increasing conversion. There are also studies planned for evaluating operation of the steam reformer with the placement of a twisted tape down the central axis of the catalyst bed. It has been shown that by crushing the catalyst pellets and increasing the available surface area that greater conversion is achieved due to the greater availability of catalyst sites. These simple methods could all serve to greatly improve the transient response.

Further transient analysis of the coal derived methanol is called for to determine why the temperature fluctuations are greater (albeit slightly) than those observed by the chemical grade methanol. In particular it would be interesting to analyze the reformate gas composition to determine if there are any other reactions taking place that might contribute to the temperature change. With the contribution from this and ongoing research it is expected that we will see fuel cell vehicles come to commercialization more expeditiously.

\section{Steam Reformer Catalyst Degradation}

The initial steam reforming catalyst deactivation data has been collected. Table 7 shows some interesting trends in catalyst deactivation. Figure 17 shows the methanol conversion rate normalized to the amount of catalyst in the reactor. Using linear regression, the rate of deactivation was determined. Figure 18 shows the rate of deactivation normalized to the initial rate of conversion. Based on current data, the best operating temperature to maximize catalyst lifetime is around $290 \mathrm{C}\left(554^{\circ} \mathrm{F}\right)$, where the deactivation rate is $0.37 \%$ per hour. Lower operating temperatures increase the deactivation rate to $1.35 \%$ per hour at $250 \mathrm{C}\left(482^{\circ} \mathrm{F}\right)$. Higher operating temperatures also increase the deactivation rate, but to a much greater extent. 
Table 7: Data from catalyst deactivation study

\begin{tabular}{|l|l|l|l|l|l|l|l|l|}
\hline Temp & Cat $(\mathrm{g})$ & \multirow{2}{*}{$\begin{array}{l}\text { Flow } \\
(\mathrm{C})\end{array}$} & & \multicolumn{6}{|l|}{ Conversion after X hours online } \\
\cline { 4 - 9 } & & $(\mathrm{ml} / \mathrm{min})$ & 0 & 1.5 & 3 & 4.5 & 6 & 7.5 \\
\hline 250 & 14 & 2.6 & $88.0 \%$ & $86.1 \%$ & $84.1 \%$ & $82.8 \%$ & $80.7 \%$ & $79.1 \%$ \\
\hline 270 & 13 & 3.2 & $83.8 \%$ & $82.0 \%$ & $81.2 \%$ & $80.1 \%$ & $79.2 \%$ & $78.0 \%$ \\
\hline 290 & 5.4 & 2.6 & $67.6 \%$ & $68.6 \%$ & $69.0 \%$ & $67.7 \%$ & $67.8 \%$ & $65.7 \%$ \\
\hline 310 & 3.6 & 2.6 & $71.5 \%$ & $69.2 \%$ & $68.2 \%$ & $66.4 \%$ & $65.0 \%$ & $63.3 \%$ \\
\hline 350 & 2.7 & 2.6 & $65.9 \%$ & $58.2 \%$ & $53.0 \%$ & $48.7 \%$ & $45.5 \%$ & $42.6 \%$ \\
\hline
\end{tabular}

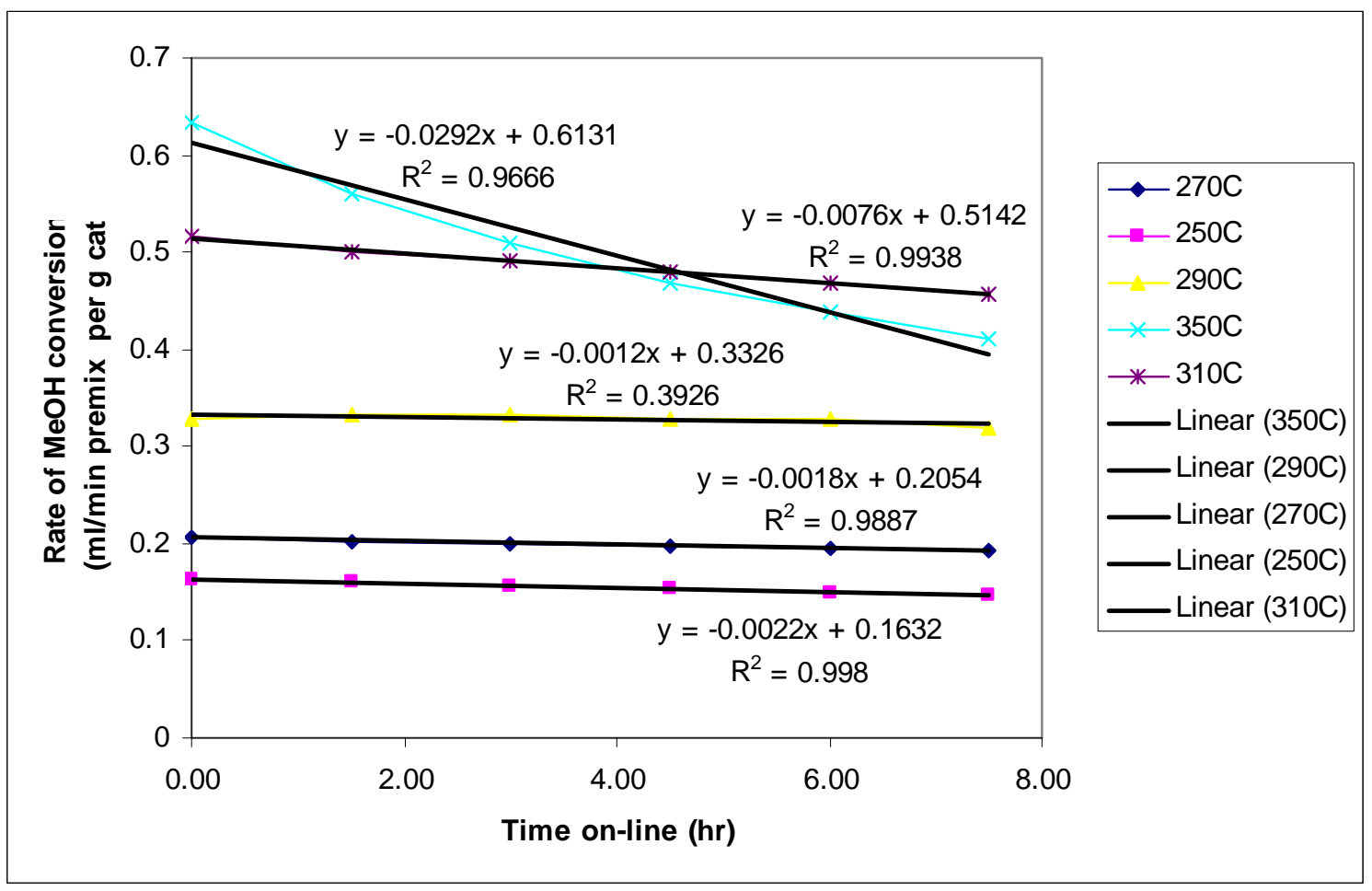

Figure 17: Change in methanol conversion over time 


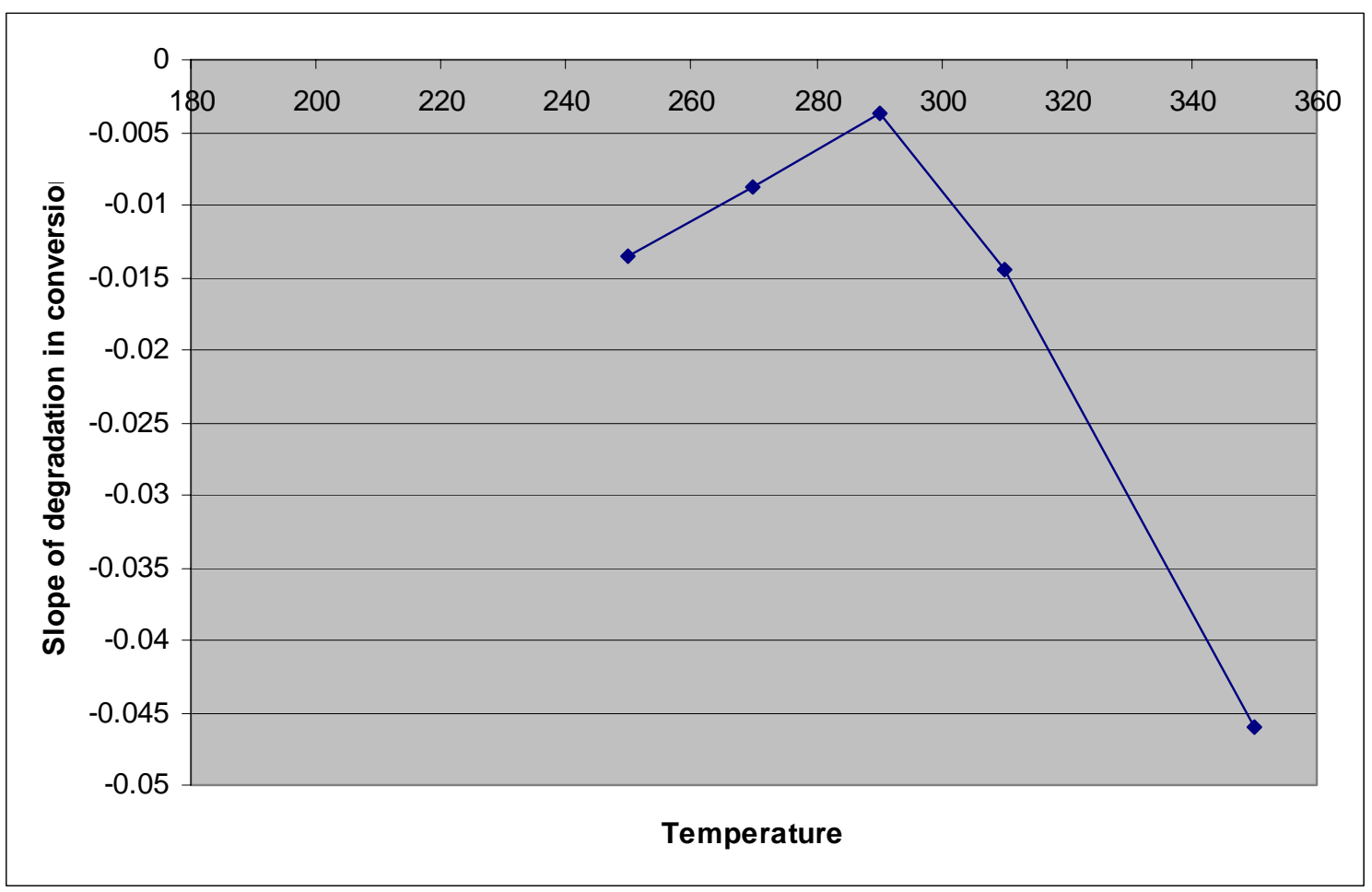

Figure 18: Decrease in catalyst effectiveness at various temperatures

The following is the results of additional experiments to further characterize the effects of both temperature and flow rate on catalyst deactivation.

Table 8: Experimental conditions

\begin{tabular}{|c|c|c|}
\hline $\begin{array}{c}\text { Temperature } \\
\left({ }^{\circ} \mathbf{C}\right)\end{array}$ & $\begin{array}{c}\text { Catalyst loading } \\
\text { (g) }\end{array}$ & $\begin{array}{c}\text { Premix flow rate } \\
\text { (ml/min) }\end{array}$ \\
\hline 210 & 28.3 & 2.6 \\
\hline 250 & 14 & 2.6 \\
\hline 270 & 13 & 3.2 \\
\hline 290 & 5.4 & 2.6 \\
\hline 310 & 3.6 & 2.6 \\
\hline 350 & 2.7 & 2.6 \\
\hline
\end{tabular}


Table 9: Conversion vs. time online at various reactor temperatures

\begin{tabular}{|c|c|c|c|c|c|c|}
\hline & \multicolumn{5}{|c|}{ Conversion at given temperature } \\
\hline Time online (hrs) & $\mathbf{2 1 0}^{\circ} \mathbf{C}$ & $\mathbf{2 5 0}^{\circ} \mathbf{C}$ & $\mathbf{2 7 0}^{\circ} \mathbf{C}$ & $\mathbf{2 9 0}^{\circ} \mathbf{C}$ & $\mathbf{3 1 0}^{\circ} \mathbf{C}$ & $\mathbf{3 5 0}^{\circ} \mathbf{C}$ \\
\hline 0 & $61.87 \%$ & $88.03 \%$ & $83.79 \%$ & $67.63 \%$ & $71.47 \%$ & $65.86 \%$ \\
\hline 1.5 & $60.65 \%$ & $86.05 \%$ & $82.03 \%$ & $68.63 \%$ & $69.21 \%$ & $58.22 \%$ \\
\hline 3 & $59.05 \%$ & $84.12 \%$ & $81.15 \%$ & $68.96 \%$ & $68.16 \%$ & $53.01 \%$ \\
\hline 4.5 & $57.84 \%$ & $82.75 \%$ & $80.11 \%$ & $67.66 \%$ & $66.36 \%$ & $48.69 \%$ \\
\hline 6 & $56.20 \%$ & $80.72 \%$ & $79.15 \%$ & $67.83 \%$ & $64.96 \%$ & $45.48 \%$ \\
\hline 7.5 & $56.76 \%$ & $79.05 \%$ & $78.01 \%$ & $65.72 \%$ & $63.30 \%$ & $42.56 \%$ \\
\hline
\end{tabular}

Table 10: Initial activity and change in activity at different reactor temperatures

\begin{tabular}{|c|c|c|c|}
\hline $\begin{array}{c}\text { Temperature } \\
\mathbf{(} \mathbf{C})\end{array}$ & $\begin{array}{c}\text { Initial activity } \\
\text { (ml/min premix } \\
\text { per g catalyst) }\end{array}$ & $\begin{array}{c}\text { Decrease in activity } \\
\mathbf{( m l / m i n} \text { premix } \\
\text { per hr online) }\end{array}$ & $\begin{array}{c}\text { Decrease in activity } \\
\text { relative to initial rate } \\
\mathbf{( \% / h r ~ o n l i n e ) ~}\end{array}$ \\
\hline 210 & 0.06 & 0.0007 & $1.20 \%$ \\
\hline 250 & 0.16 & 0.0022 & $1.35 \%$ \\
\hline 270 & 0.21 & 0.0018 & $0.88 \%$ \\
\hline 290 & 0.33 & 0.0012 & $0.37 \%$ \\
\hline 310 & 0.52 & 0.0075 & $1.45 \%$ \\
\hline 350 & 0.63 & 0.0292 & $4.60 \%$ \\
\hline
\end{tabular}




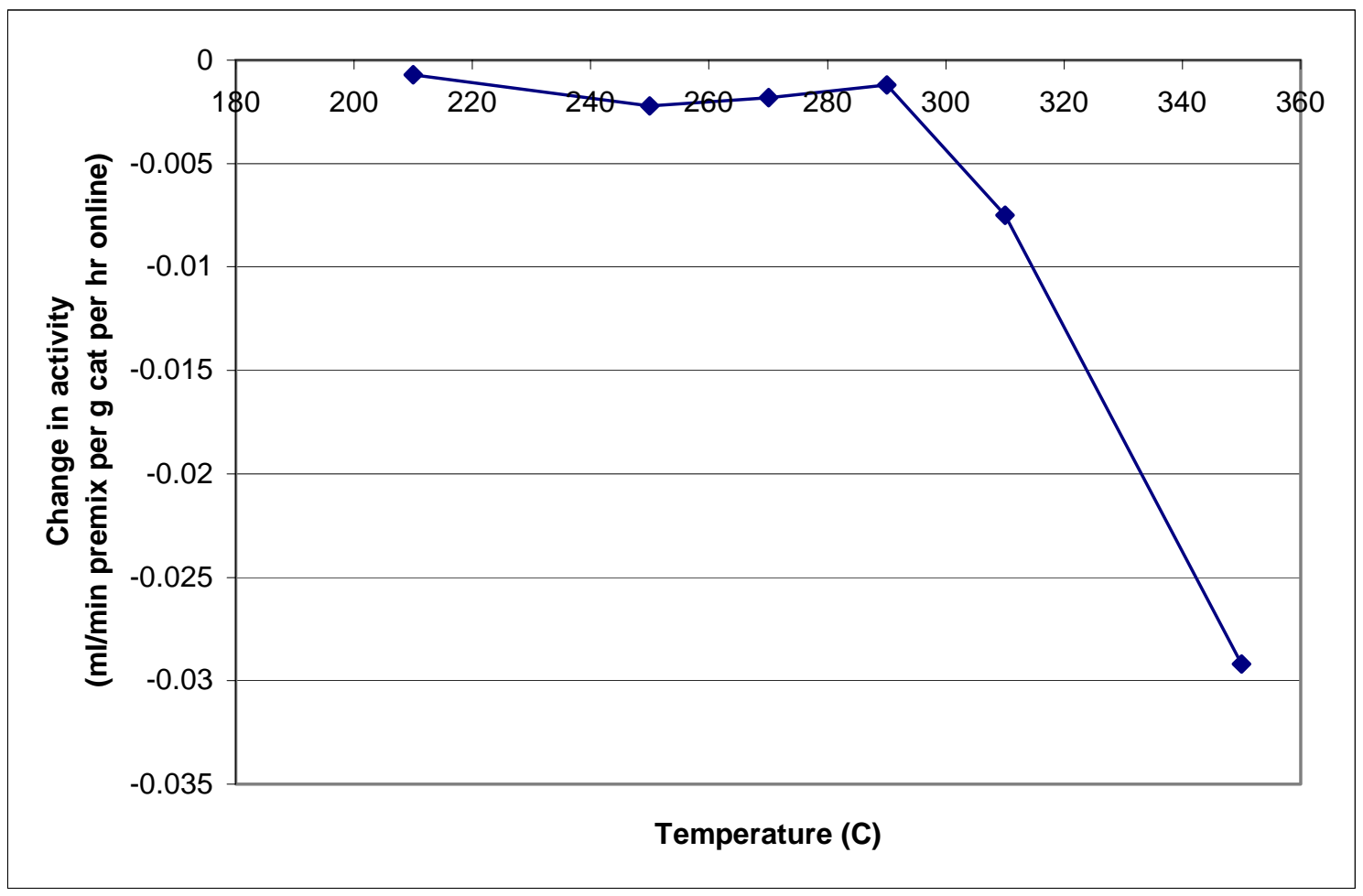

Figure 18: Change in activity vs. temperature

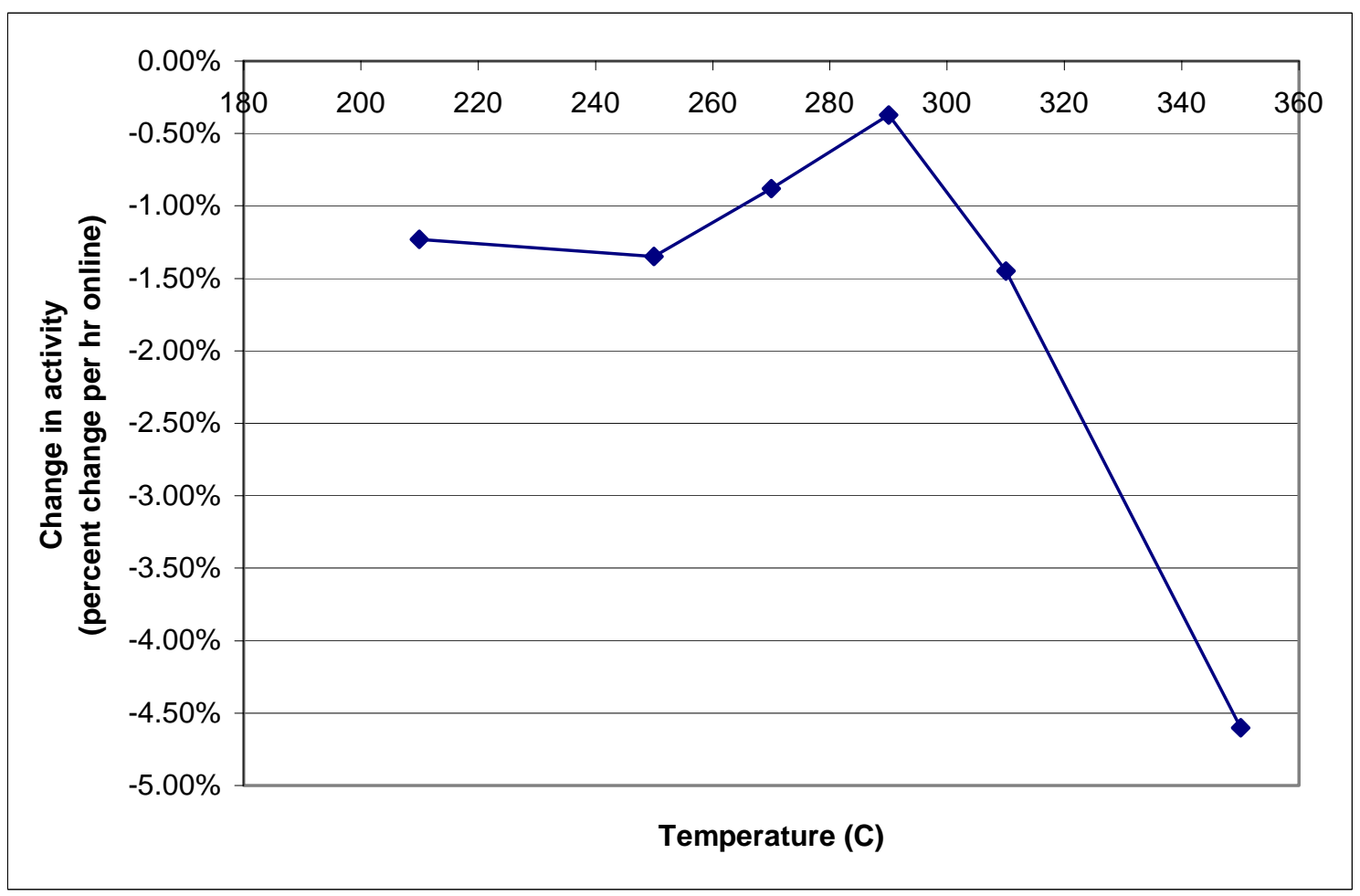

Figure 19: Relative decrease in activity from initial rate 
As expected, initial catalyst activity is highly dependent on temperature. In fact, based on these measurements, only 31 grams $(0.068 \mathrm{lb})$ of catalyst should be necessary for full conversion at $250^{\circ} \mathrm{C}\left(482^{\circ} \mathrm{F}\right)$ and $5 \mathrm{ml} / \mathrm{min}(0.169 \mathrm{oz} / \mathrm{min})$ of premix. Compare this to the $250 \mathrm{grams}(0.551 \mathrm{lb})$ that are required for full conversion in a non-isothermal reactor. Furthermore, there is a narrow temperature band where catalyst deactivation is slowest. Below the optimal temperature range, deactivation relative to the initial activity is somewhat greater. This is likely due to fouling caused by accumulation of carbon compounds on the catalyst surface. Above the optimal temperature range, deactivation is very much greater. This is likely due to rapid sintering, where the catalyst surface area decreases due to agglomeration of metal catalyst particles and degradation of catalyst support material. Surface analysis is needed to precisely determine the processes causing the deactivation. These initial results emphasize the need for better temperature control of the reactor and reduced temperature gradients within the catalyst bed. Further experiments in this area will look at the effect of flow rate and reactant/product concentration on catalyst deactivation. Additionally, the reactor will be run in differential mode in order to collect data suitable for use in a catalyst deactivation model.

As shown in Figure 20, the degradation rate of coal-derived methanol was greater than that of chemical grade methanol for both reactors, in terms of fuel. However, reactor geometry apparently has a much greater affect on percent convergence than the affect of fuel type. Even though Reactor B has been loaded with nearly six times more crushed catalyst than Reactor C, the degradation rate of Reactor B was much larger than Reactor C. Consequently, it can be concluded that reactor geometry has a greater affect on catalyst aging than fuel impurities.

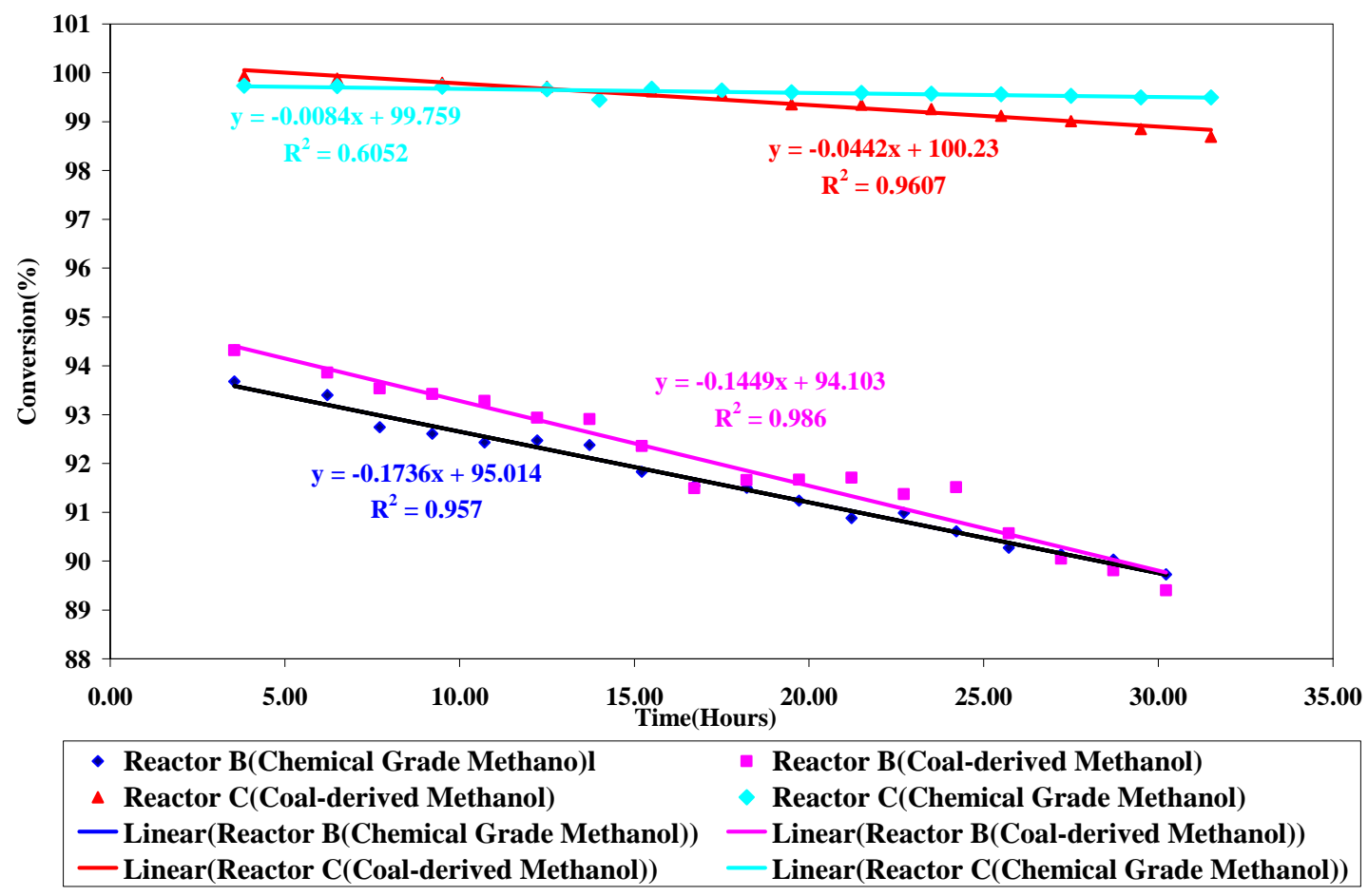

Figure 20: Catalyst degradation both coal-derived and chemical grade methanol for different geometries. 


\section{Steam Reformer Degradation Tests Using Bluff Bodies}

For the degradation test using bluff bodies, three categories of tests were completed. Reactor geometry was testing using Reactor $\mathrm{C}$ with an internal cartridge heater, and compared to the results of using Reactor $\mathrm{B}$ with bluff body packages. Steam reformation catalyst degradation tests using bluff bodies was completed with both coal-derived and chemical grade methanol.

\section{Steam Reforming Geometry}

Catalyst degradation tests associated with different reactor geometries were initiated using chemical grade methanol, which is to be compared with similar experiments using coal-derived methanol. This test was performed on Reactor B and included bluff bodies. The different geometry of the reactors might cause different degradation rates due to different heat and mass transfer limitations. Through this degradation test, we expected to be able to construct an experimental degradation matrix in terms of limitations associated with different reactor geometry, such as aspect ratio and different zones of the catalyst being active within the catalyst bed. Therefore, this result is extremely important from the standpoint of the design of an optimized steam reforming reactor to be used for fuel cell applications. This experiment was performed using the fixed dependant variables of space velocity $[2.5(1 / \mathrm{hr})]$ and inlet temperature $\left[250^{\circ} \mathrm{C}\left(482^{\circ} \mathrm{F}\right)\right]$ in order to allow for a comparison with previous degradation results. At this time, chemical grade methanol was used with de-ionized water at a 1.5:1 steam carbon ratio.

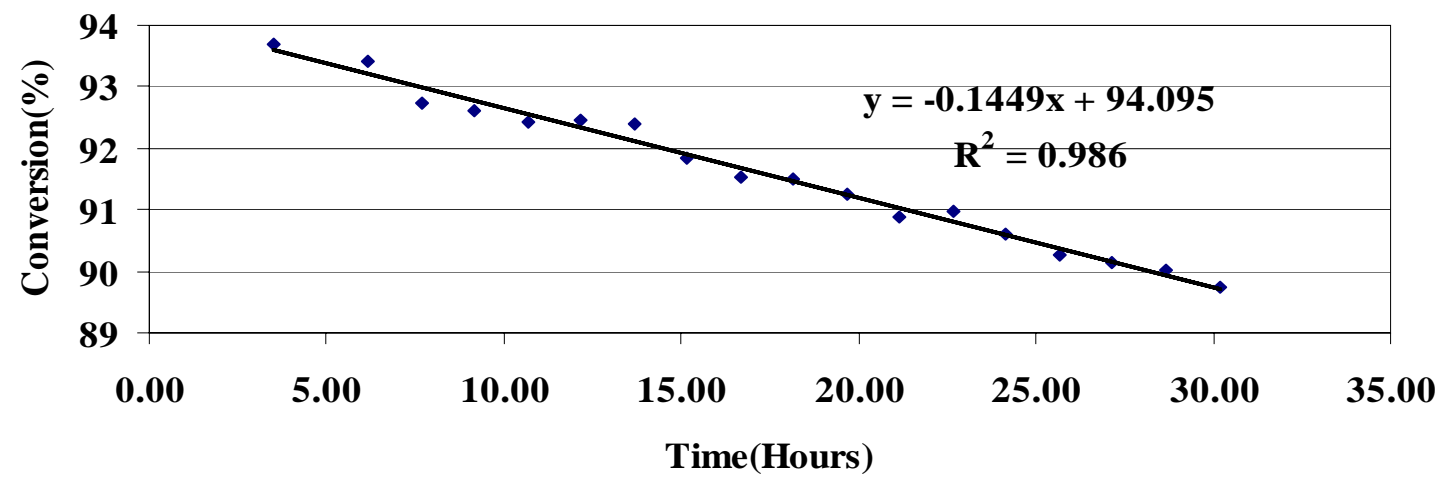

- Conversion(\%) — Linear (Conversion(\%))

Figure 21: Catalyst degradation test in Reactor B using bluff bodies 


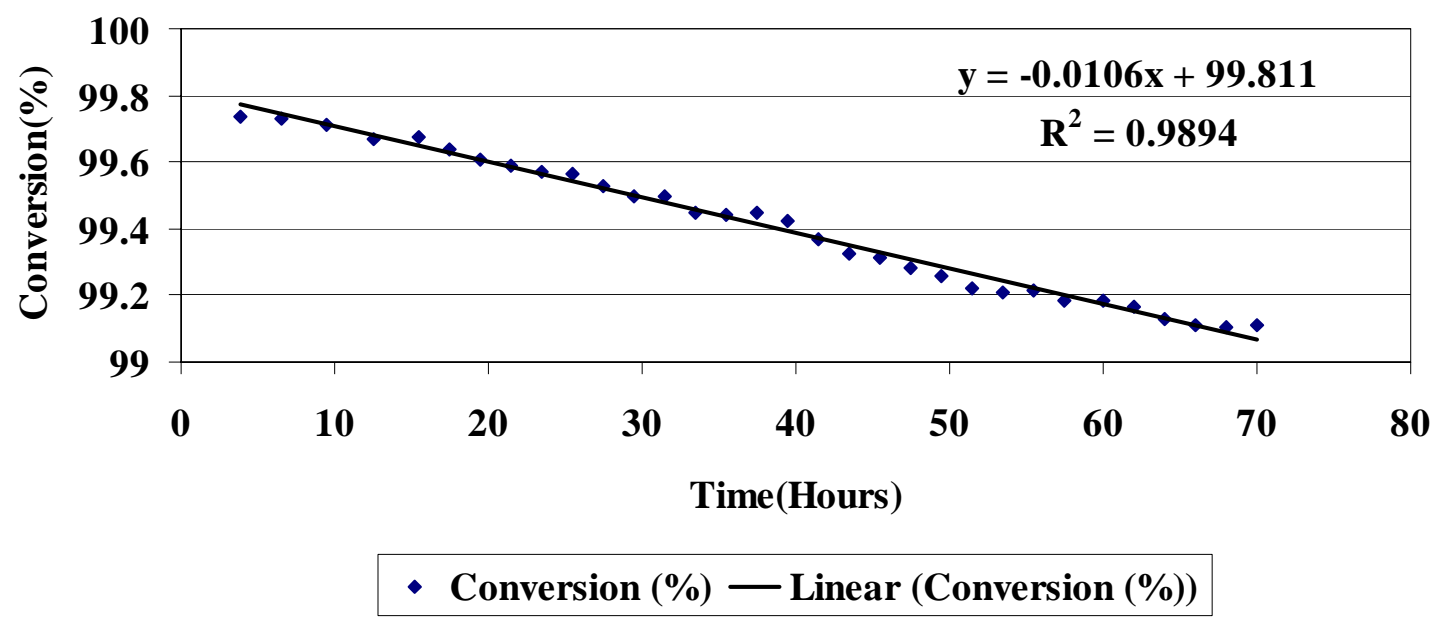

Figure 22: Catalyst degradation test in Reactor $\mathrm{C}$ using internal cartridge heater

As seen in Figure 21 a $-0.1449 \%$ per hour degradation rate was shown in Reactor B with bluff bodies. The above results are compared to previous data, which was performed on Reactor $\mathrm{C}$ with an internal cartridge heater as shown in Figure 22. The degradation rate of Reactor B was almost ten times greater than that of Reactor $\mathrm{C}$ even though $250 \mathrm{~g}(.551 \mathrm{lb})$ of crushed catalyst [39g $(.086 \mathrm{lb})$ of crushed catalyst loaded in Reactor C] was loaded in Reactor B with bluff bodies.

In the previous annual report, it was confirmed that bluff bodies enhance the steam reforming reaction due to the promotion of heat transfer as well as mass transfer associated with passive mixing effects. In other words, passive enhancement mixing using bluff bodies can also increase the methanol overall conversion compared to a non-bluff body reactor. We also confirmed that active enhancement of heat and mass transfer using an internal cartridge heater also can promote increases in overall conversion as well as decreases in catalyst degradation. However, in the degradation test of Reactor B (passive enhancement) showed the weakness of degradation compared to Reactor $\mathrm{C}$ (active enhancement using the cartridge heater). Reactor $\mathrm{B}$ had a larger amount of catalyst than Reactor $\mathrm{C}$ thereby also having more catalytic active space than Reactor C. In other words, more reactive space through radial and axial directions can lead to the aggravation of heat and mass transfer limitations because heat is only supplied from the exterior heat band. Consequently, even though passive enhancement using bluff bodies promoted heat and mass transfer, it might not be enough to supply the heat demand in Reactor B for long-term operation.

If bluff bodies were used in a small diameter reactor such as Reactor A, it might have a more profound effect than bluff bodies in Reactor B. In contrast, the heat requirement areas for steam reforming reaction of Reactor $\mathrm{C}$ were much smaller than those of Reactor $\mathrm{B}$ because of its diameter and length (aspect ratio). Furthermore, an internal cartridge heater was placed in the center of the reactor so that heat was supplied from both the interior and the exterior of the catalyst bed. 
In summary, we confirmed that different reactor geometry is a large factor that contributes to catalyst degradation. Better heat and mass transfer through smaller axial and radial length can suppress the catalyst degradation rate in terms of durability of the catalyst.

In comparison to catalyst degradation due to the differences in fuel type (fuel cell grade vs coal derived methanol) as reported previously, the effect of reactor geometry on catalyst degradation far outweighs the effect of fuel type. This is an encouraging result for those eager to use coalderived methanol as a hydrogen feed-stock. Future work is necessary to further quantify the effect of geometry in catalyst degradation.

\section{Bluff Body Catalyst Degradation With Coal-Derived Methanol}

Two 30-hours runs without bluff bodies and one 30-hours run with bluff body packages have been taken to compare the catalyst degradation rates. The fuel conversions versus experiment running time are shown in Figures 23 and 24. Figure 23 indicates the catalyst inside the Reactor B without bluff body packages degraded 0.14 and 0.1503 conversion percents per hour for two runs. Comparing to the 0.1449 conversion percents per hour shown in Figure 24 with eight bluff body packages inside the reactor, the experiment result showed that the bluff body packages did not have effects on the catalyst degradation rate in conversion percentage.

Chemical Grade MeOH w/o bluff body packs

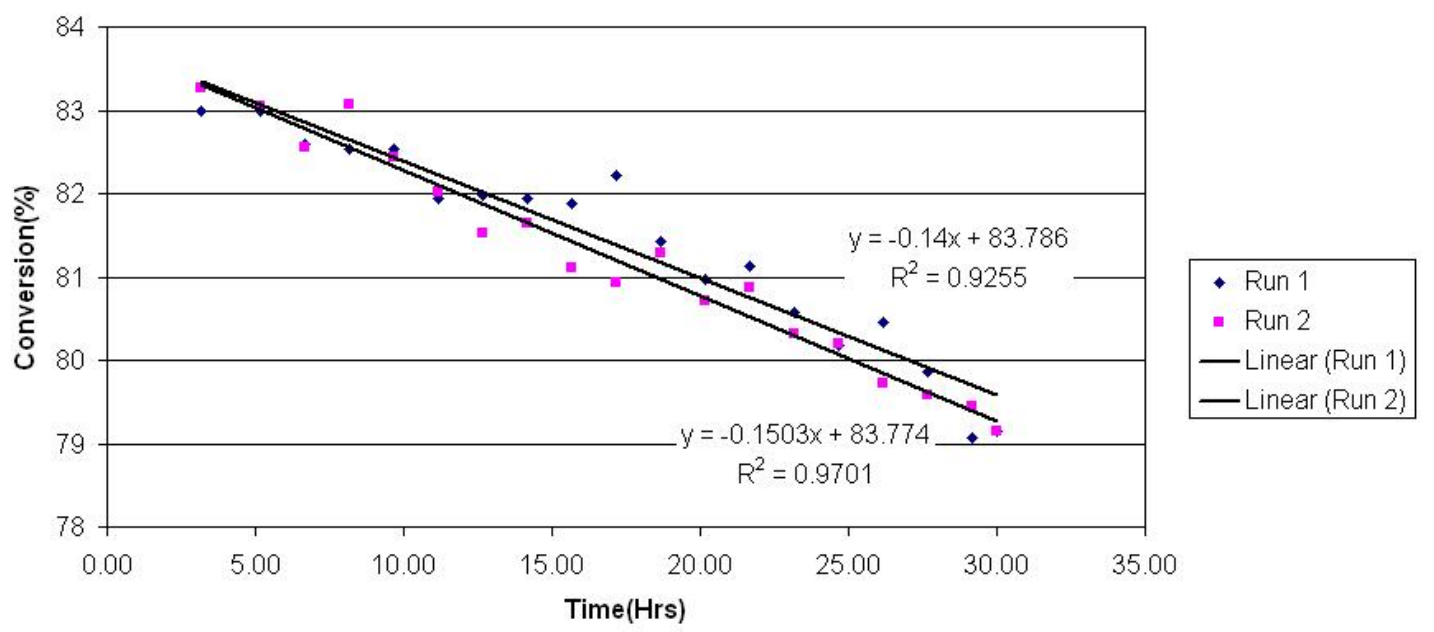

Figure 23: Conversion vs. time without bluff body in Reactor B 


\section{Degradation Test with bluff body}

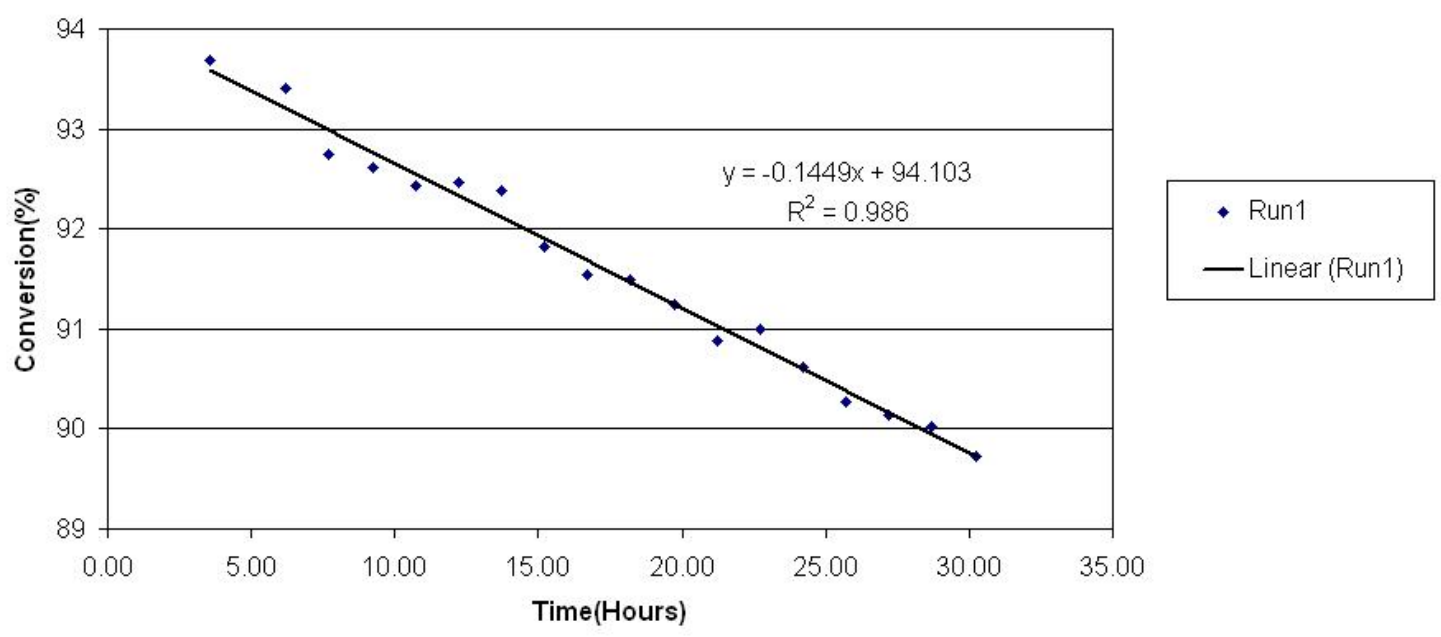

Figure 24: Conversion vs. time with 8 packs of bluff bodies in Reactor B

Catalyst Degradation Test w/ Bluff Body

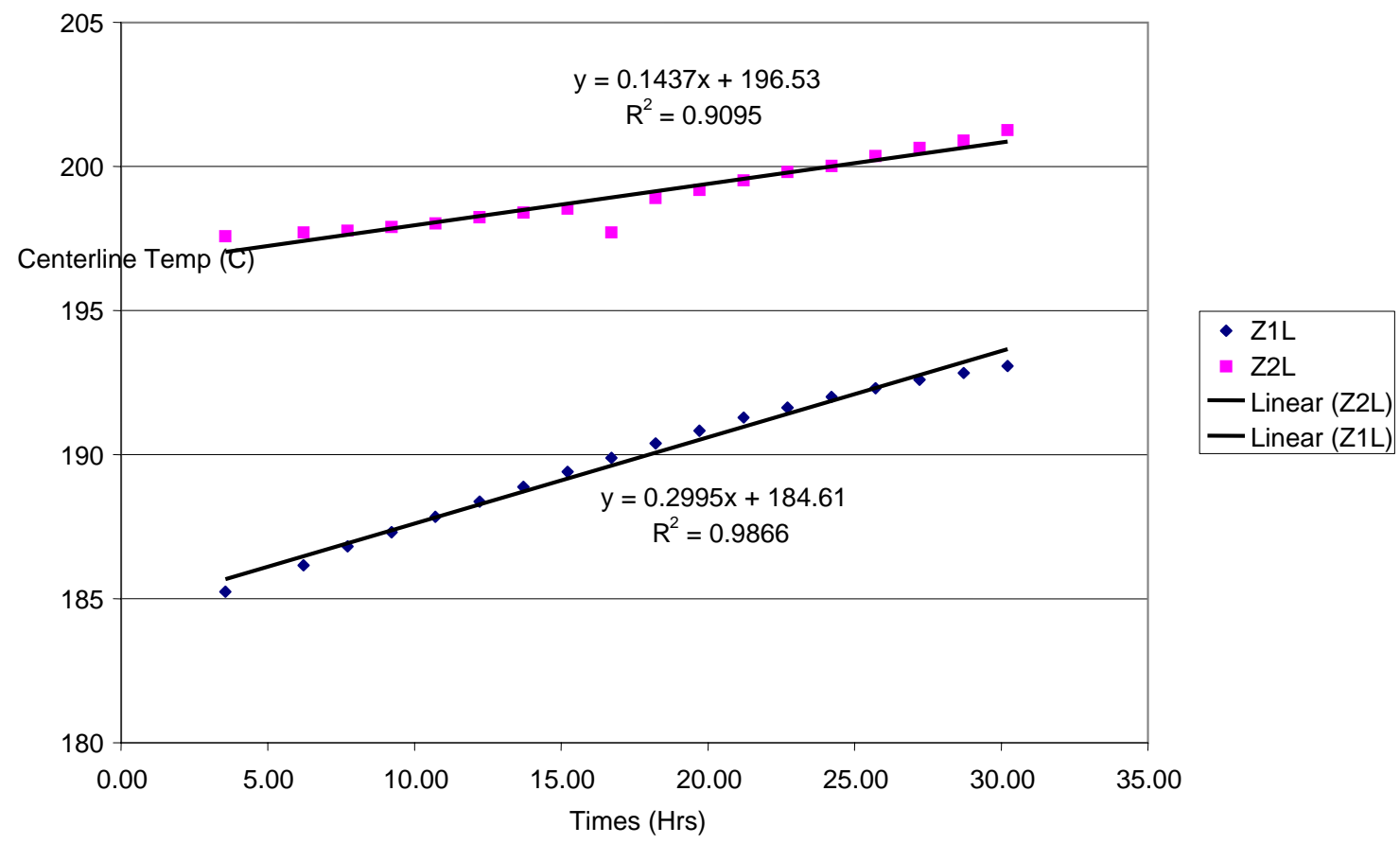

Figure 25: Centerline temperatures at Zone 1 and Zone 2 vs. time, with bluff bodies 
Catalyst Degradation Test w/o Bluff Body

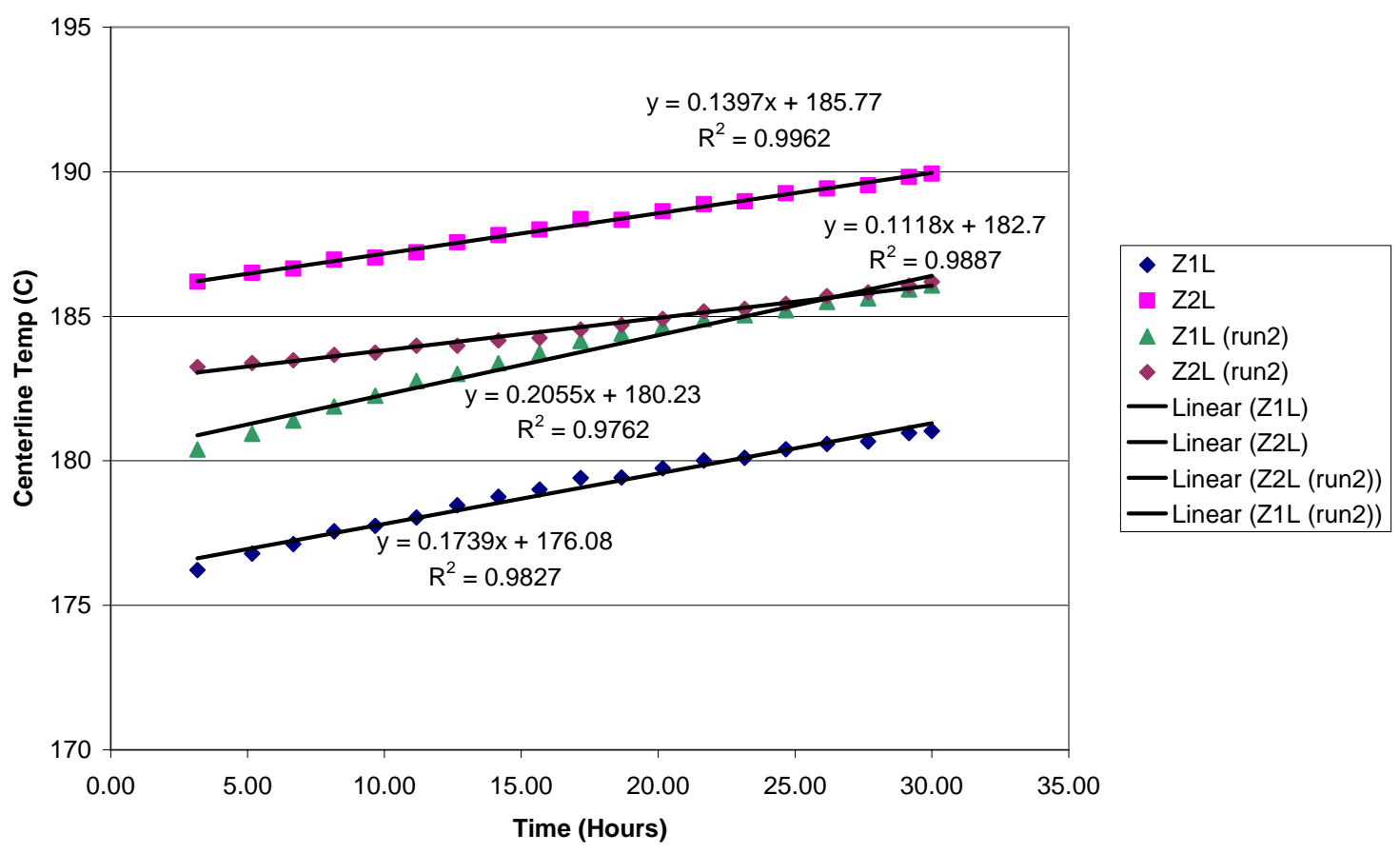

Figure 26: Centerline temperatures at Zone1 and Zone2 vs. time, without bluff bodies

However, by showing the centerline temperatures at Zone 1 (upstream) versus experiment time, the bluff bodies' effect on catalyst degradation rate can be seen. The catalyst degradation can be represented in the temperature increase of the catalyst due to the endothermic nature of the reaction process. In Figure 25, the slope of the linear regression line shows that the temperature increase rate at Zone 1 of the condition with bluff bodies is $0.2995^{\circ} \mathrm{C}$ per hour. In Figure 26, the average temperature increase rate of the two runs is $0.1897^{\circ} \mathrm{C}$ per hour $\left(0.2055\right.$ and $0.1739^{\circ} \mathrm{C} / \mathrm{hr}$ respectively). This result shows that the bluff body experiment had a higher temperature increase rate, which implies a higher catalyst degradation rate.

The catalyst degradation might not be shown in the conversion vs. time chart because the catalyst degradation starts from upstream in the reactor. As time goes by, the degradation moves downstream inside the reactor, but the overall catalyst reforming capacity still overrides the catalyst degradation level.

\section{Bluff Body Catalyst Degradation With Chemical-Grade Methanol}

A 30-hour run with a premix flow rate of $12.5 \mathrm{ml} / \mathrm{min}$ (2.5 LHSV-M) was conducted using chemical-grade methanol and eight bluff body packages. The fuel conversion vs. running time data was collected and shown in Figure 27, along with the results from the coal-derived methanol. 
Fuel Conversion vs. running time

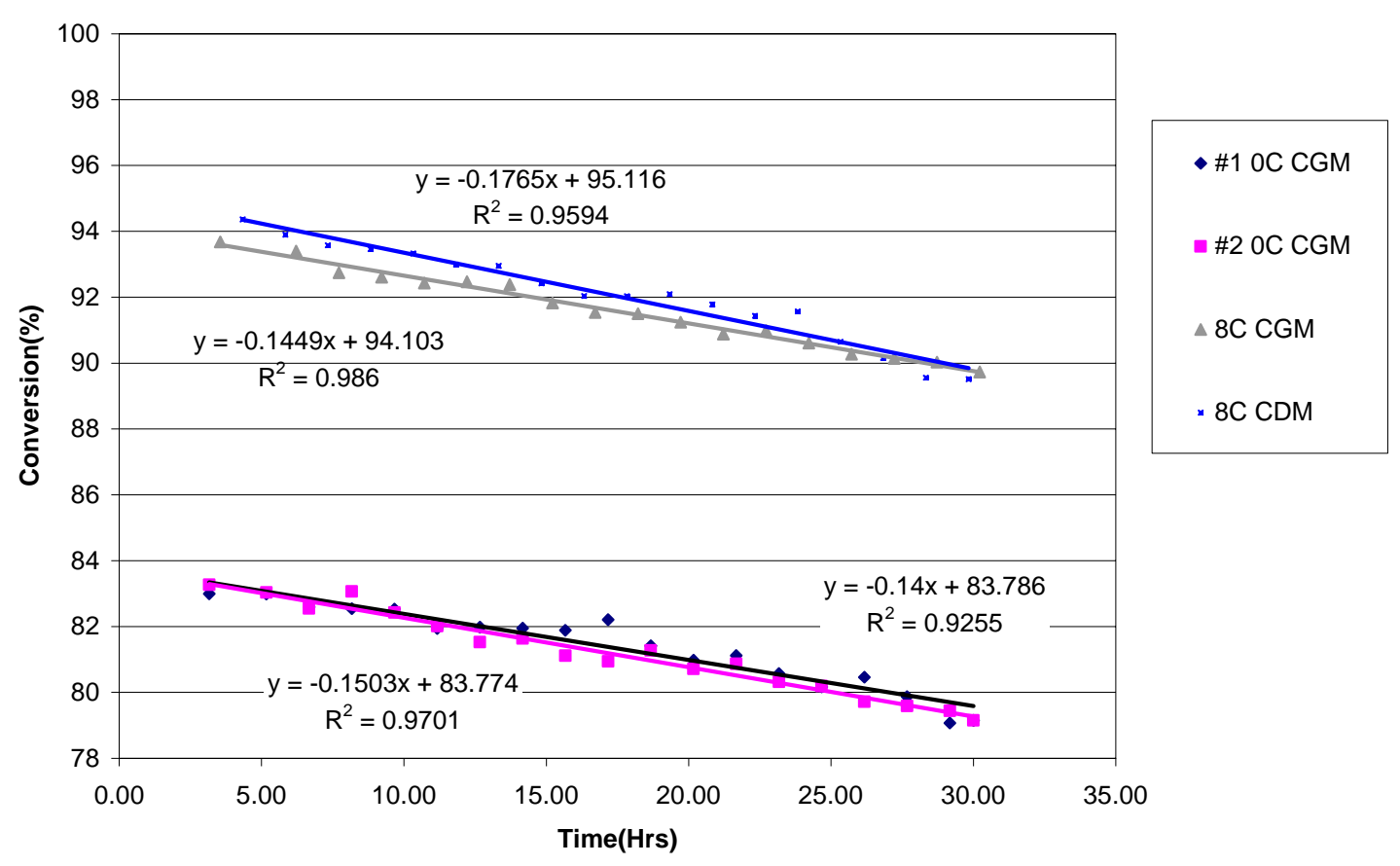

Figure 27: Fuel conversion percentage vs. running time with and without bluff bodies using chemical-grade methanol (CGM) and coal-derived methanol (CDM)

The initial fuel conversion of coal-derived methanol was larger than that of chemical grade methanol due to different hydrocarbon concentrations in the two methanol fuels. More detail of the different hydrocarbon concentrations in the two fuels was discussed in the first annual report. As expected, the degradation rate for coal-derived methanol $(-0.1765 \% / \mathrm{hr}$ with blue line $)$ is larger than that for chemical grade methanol $(-0.1449 \% / \mathrm{hr}$ gray line $)$.

Table 11 shows the degradation rates for the two methanol fuels and reactor geometries:

Table 11: degradation rates (conversion \% per hour) with different methanol fuels and reactor geometries

\begin{tabular}{|c|c|c|}
\hline & $\begin{array}{c}\text { Chemical Grade } \\
\text { Methanol }\end{array}$ & Coal Derived Methanol \\
\hline Reactor B (0C) & -0.1452 & N/A \\
\hline Reactor B (8C) & -0.1449 & -0.1765 \\
\hline Reactor C (internal cartridge heater) & -0.02196 & -0.1065 \\
\hline
\end{tabular}

The data showed the degradation rate of Reactor B loaded with eight bluff body packages was 6.6 times larger $(0.1449 / 0.02196)$ than the degradation rate of Reactor $C$ with chemical grade methanol. The degradation rate of Reactor B (8C) using coal-derived methanol was 1.2 times $(0.1765 / 0.1449)$ greater than Reactor B (8C) using chemical grade methanol. Again the reactor geometry was demonstrated to outweigh the fuel option effects on catalyst degradation. In contrast, the fuel option had a larger effect on the degradation rate $(0.1765 / 0.1449=1.22)$ of Reactor $(8 \mathrm{C})$ than that of bluff bodies $(0.1452 / 0.1449=1.002)$ on Reactor B. 
In Figure 28, the centerline temperature inside the reactor again shows the catalyst degradation rate difference between CGM and CDM.

Degradation test w/ bluff bodies

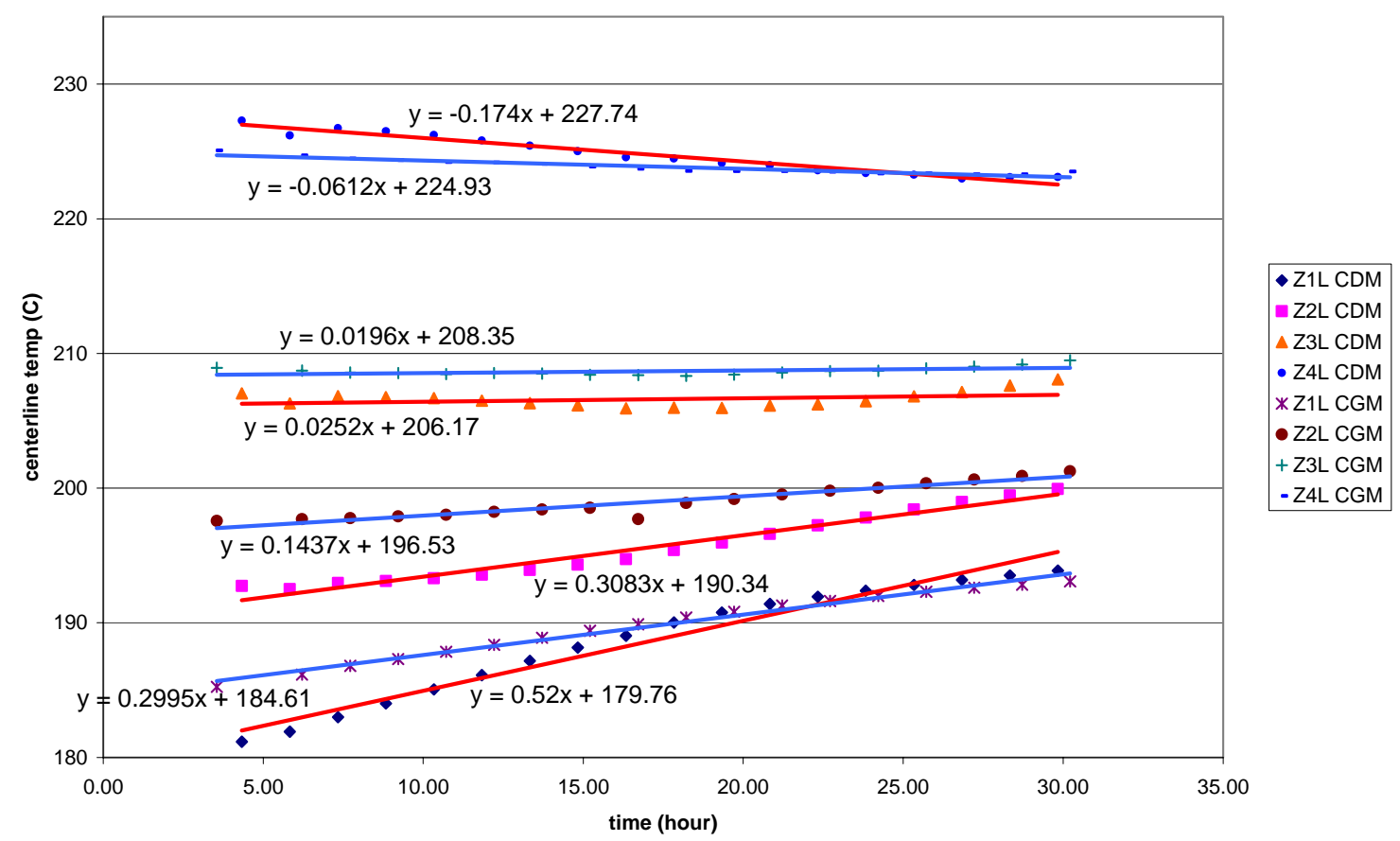

Figure 28: Centerline temperatures vs. running time at different axial positions with 8 packs of bluff bodies using CGM and CDM.

The red lines represent the data trend line for coal-derived methanol and the blue lines represent the data trend lines for chemical grade methanol. As expected, the slopes of the red lines at Zone 1 and Zone 2 are about 1.5 to 2 times greater than that of the blue lines. This again indicates that the higher hydrocarbon concentrations in the coal-derived methanol might cause a faster deactivation rate compared to chemical grade methanol.

The experiment with reactor B (0C) using coal derived methanol will be taken in the future to give a more comprehensive comparison among the effects of different methanol fuels and reactor geometry. Additionally, the reactor operating temperature is expected to have an important influence on degradation rate. To investigate the effect, the set-point temperature will be set at a higher value. 


\section{Optimization of Bluff Bodies for Steam Reformation}

It was expected that the ring's inner diameter and disk's diameter of a ring-disk bluff body set could largely affect the stream pathway in the packed bed. Therefore, in this experiment different bluff body sizes were tested to investigate the relationship between bluff body geometry and fuel conversion. Two other sizes (BB1 \&BB9) of ring-disk bluff body sets were manufactured with different inner ring and outer disk diameters tabulated in Table 12 and plotted in Figure 29.

Table 11: Configuration of different size ring-disk bluff body set

\begin{tabular}{|l|l|l|}
\hline Experiment Configuration & I.D. of Ring $(\mathrm{mm})$ & Dia. of Disk $(\mathrm{mm})$ \\
\hline BB1 & Small & Large \\
\hline BB5 (original experiment) & Medium & Medium \\
\hline BB9 & Large & Small \\
\hline
\end{tabular}

Note: Images are Actual Size
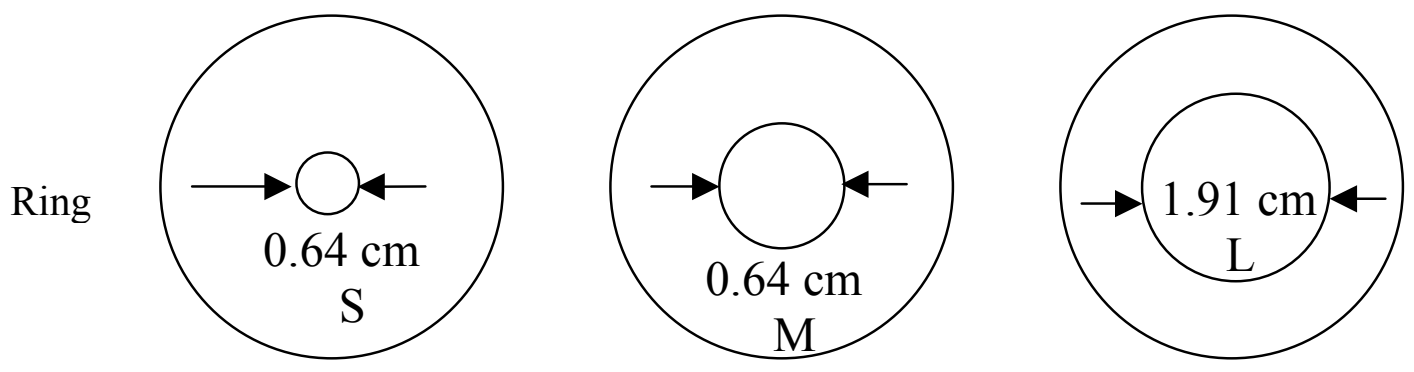

Disk
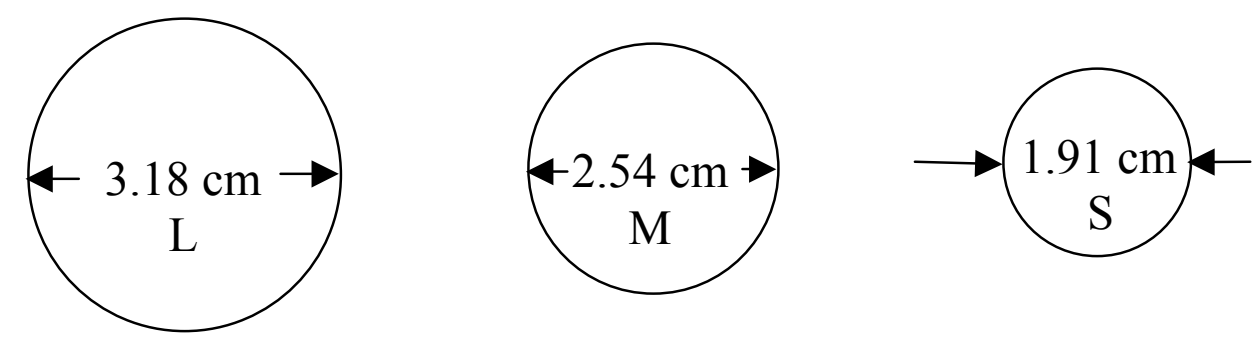

Figure 29: Different sizes of ring-disk bluff body set

The fuel conversion and temperature profiles of experiment configuration: BB1, BB5 (original size) and BB9 were shown in Figure 30 and Figure 31. Comparing to the baseline of BB5 bluff body run, the conversion chart shows a better enhancing performance on using BB1 than on BB9. The results were expected, because a larger diameter disk brings the bulk stream closer to the hot wall for better heat transfer. A smaller inner diameter ring guides the hotter bulk stream back to the narrower vent at centerline. A smaller I.D. ring and larger disk also drive the stream passing path length, effectively increasing the catalyst reaction region. The results in Figure 30 show that a $99 \%$ fuel conversion rate can be maintained when fuel flow rate is increased from 1.0 to 2.0 LHSV-M. This value represented a significant increase in hydrogen yield (hydrogen generating capacity) comparing to the run without bluff body packages. An observed 67\% increase over the original run (BB5) by simply changing the diameters of the rings and disks. On 
the contrary, BB1 with a larger I.D. ring and smaller disk noted decreased performance in fuel conversion than BB5. This effect occurred because the disturbance in flow path was less, therefore mixing and heat transfer was decreased.

To understand which component of bluff body set (disk or ring) plays the main mechanism in bluff body enhancement, the following experiments is going to test using only disks and/or only rings inside the catalyst bed to analyze its performance.

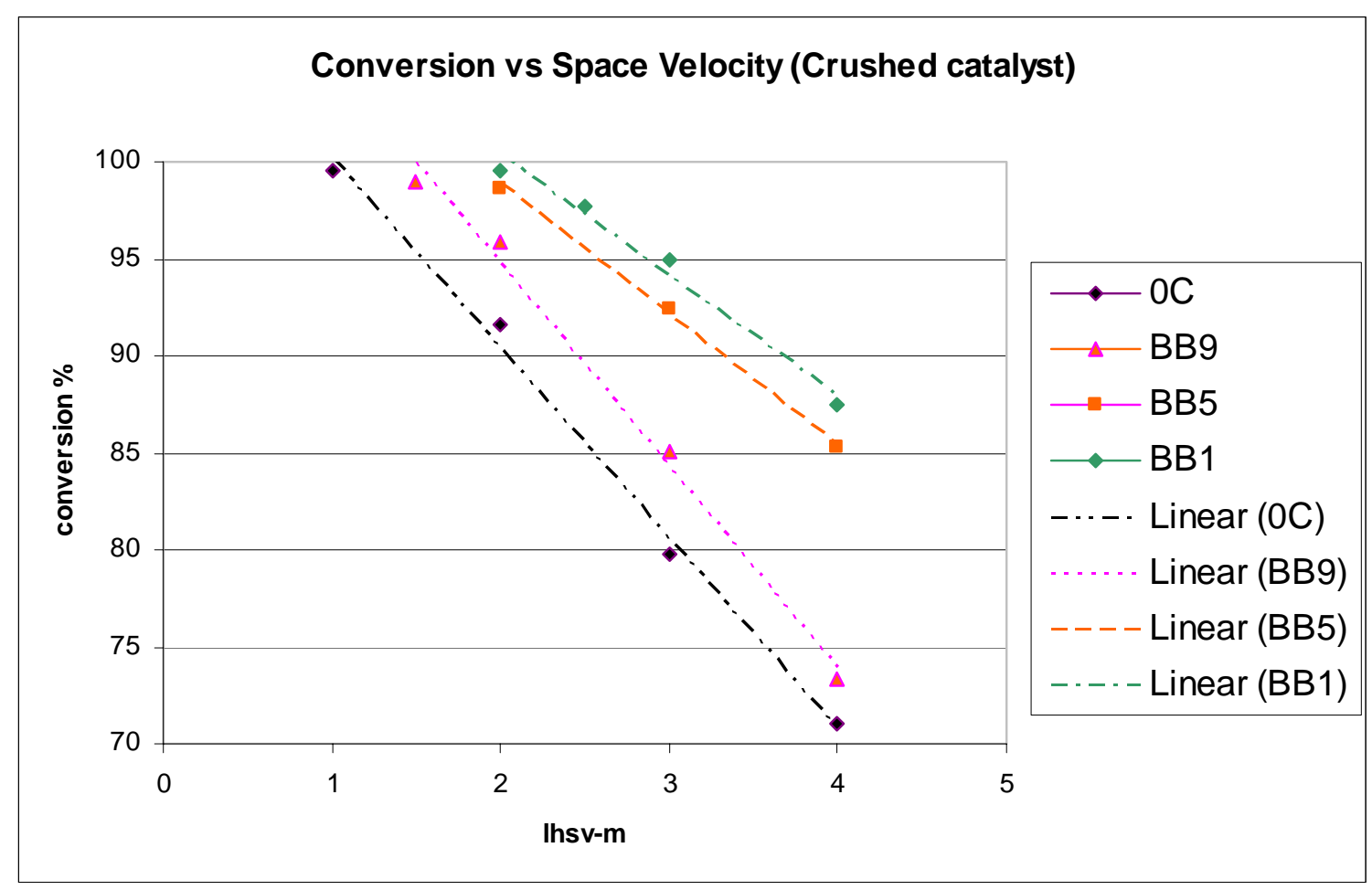

Figure 30: Fuel conversion versus space velocity for different sizes of ring-disk bluff body set 


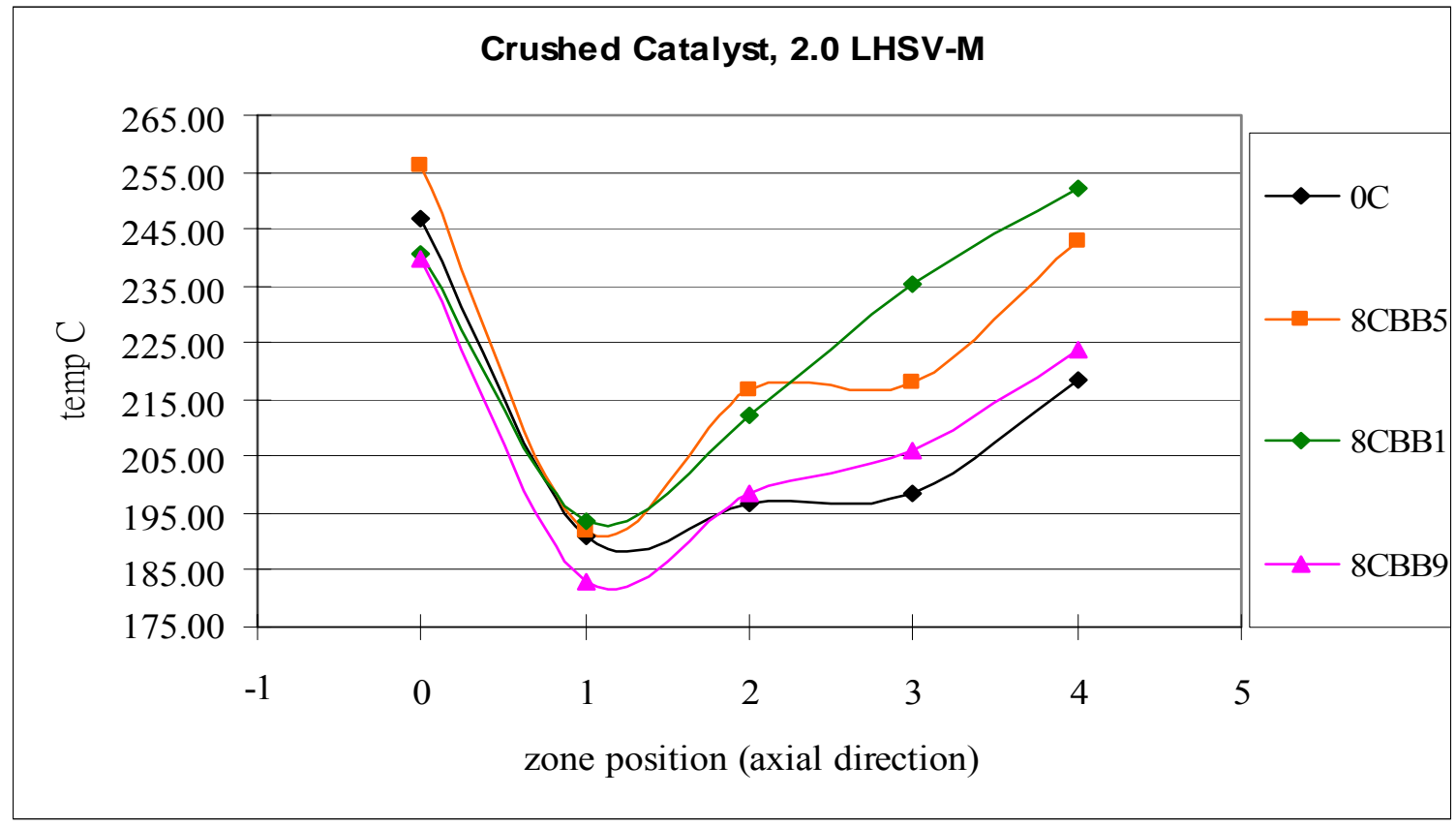

Figure 31: Centerline temperature profile in axis direction for different sizes of ring-disk bluff body set

\section{Heat Transfer Enhancement}

One of the greatest challenges in methanol steam reformation is overcoming the heat transfer limitations associated with the endothermic reaction. The large temperature gradients formed along the reactor walls should be ideally decreased as much as possible. Passive mixing and internal heating elements are two methods that have been investigated to reduce the large temperature gradients typically occurring the reactor. The use of bluff bodies has significantly improved heat transfer and the current research is shown in other sections. A swirl tape enhancement is the second passive enhancement studied so far and is included in this section. The results from internal heating elements on a small reactor, Reactor C, are shown bellow.

\section{Internal Heating Elements}

From a quick observation of the results shown in Figure 32, conclusions can be made about heat transfer enhancement and percent conversion. Reactor C, loaded with crushed catalyst, obviously reached greater conversion than Reactor A, loaded with pelletized catalyst. In the lower flow rate case, Reactor A, loaded with crushed catalyst, had better conversion than Reactor C. However, after around 0.0025 contact time, the conversion of Reactor $\mathrm{C}$ showed much greater conversion percentage than Reactor A. . 


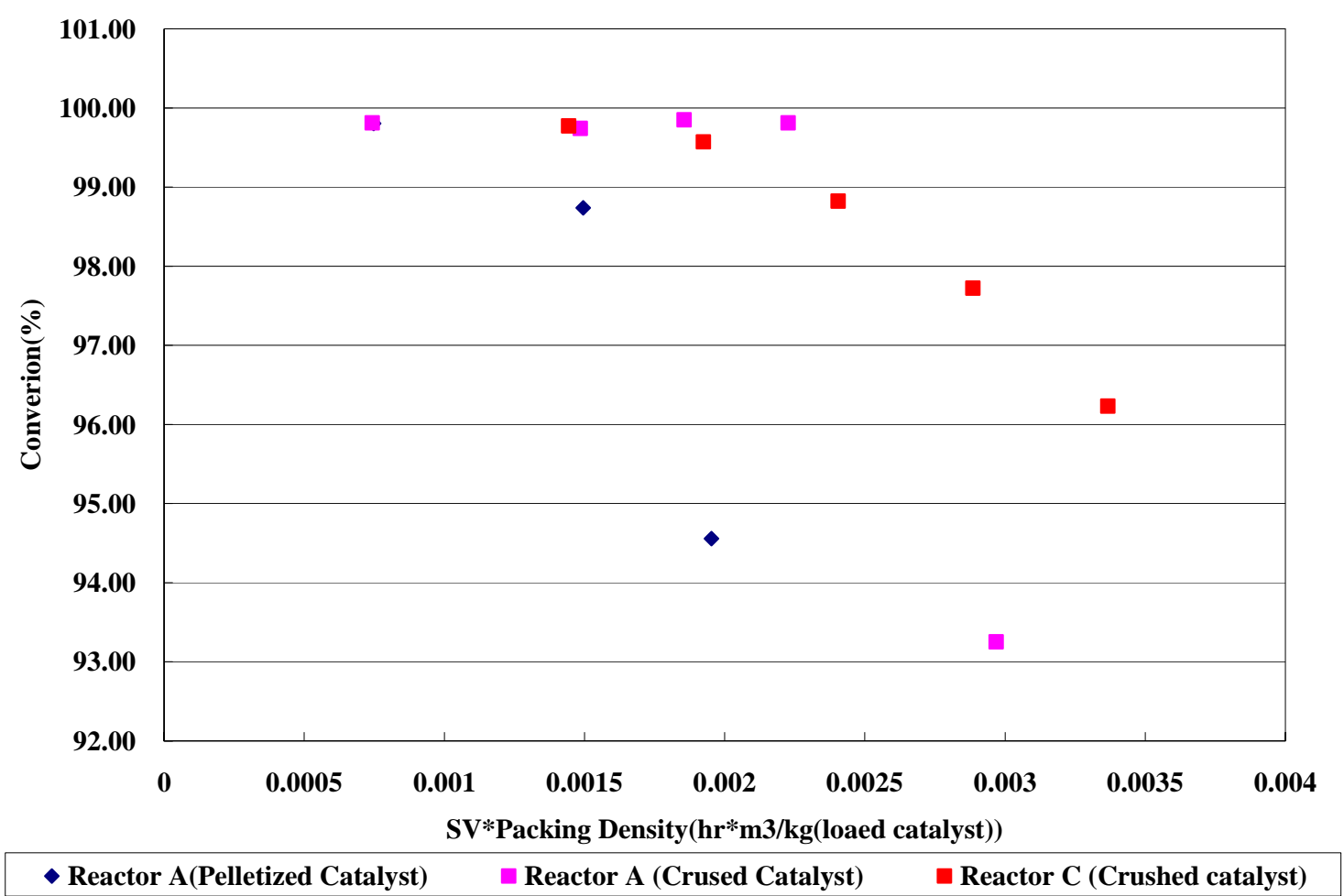

Figure 32: Conversions of methanol in case of Reactor A and Reactor C

Heat and mass transfer limitations are well-known drawbacks occurring from hydrogen production via steam reformation. Another significant problem is the condensation of bulk gas onto the solid phase catalyst. This effect of condensation can grow gradually as flow rate increases. It can also develop severe thermal gradients inside the reactor. For example, when LHSV-M increased, the cold region along the centerline due to the condensation of bulk gas increased in length, as shown in Figure 33. Additionally, the cold region can be formed from the endothermic methanol reduction. However, condensate formation due to heat transfer limitations had a much greater effect than the endothermic chemical reaction on the cold region formation. 
1.02-LHSV-M 99.8\% 2.05 LHSV-M 98.65\% 3.07 LHSV-M 92.71\% 4.09 LHSV-M 89.39\%
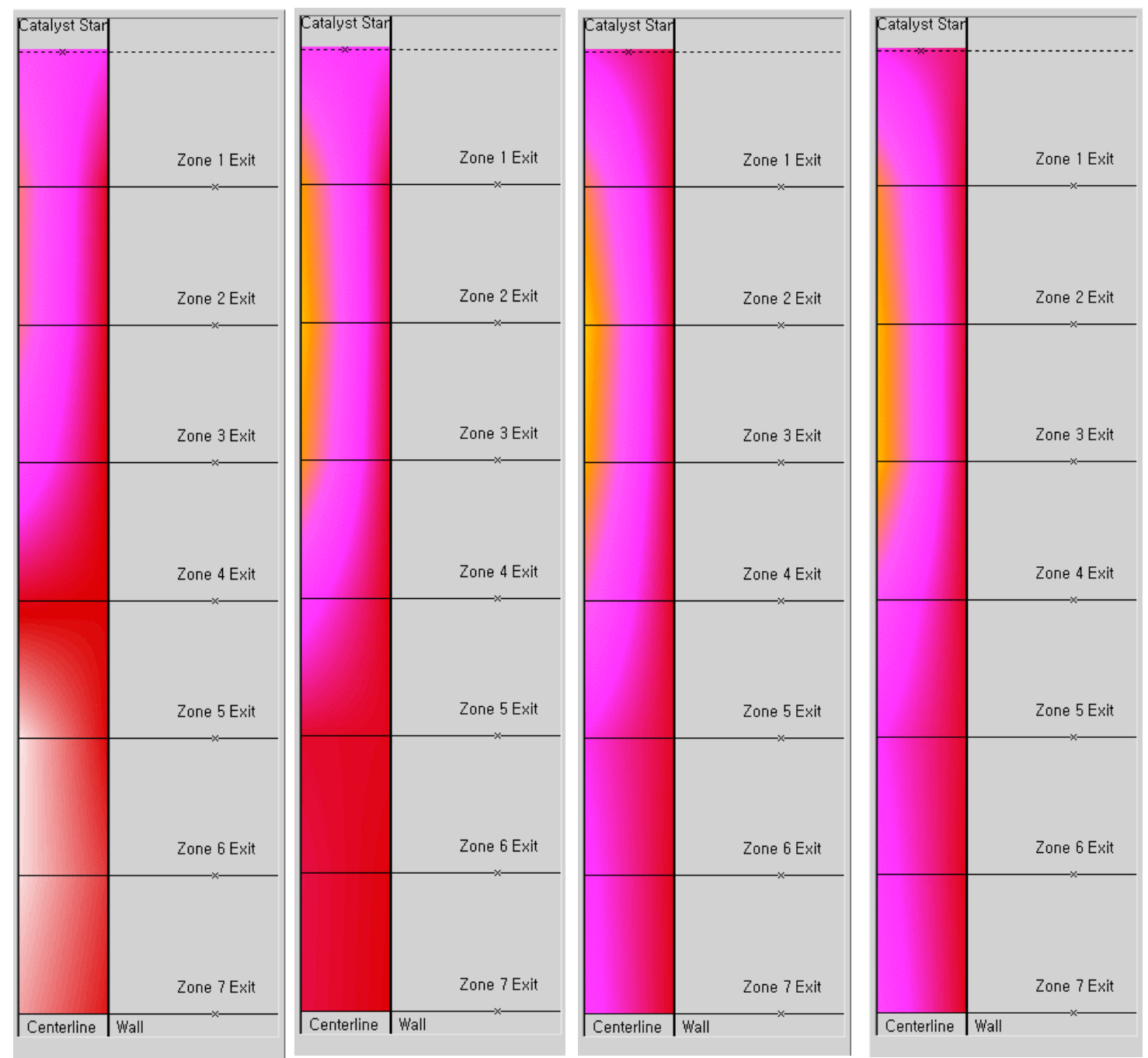

Figure 33: Temperature profile in the Reactor A with pellitized catalyst

Thermal and concentration gradients also developed proportionally inside Reactor A. The concentration of hydrogen is much greater along the reactor centerline due to the endothermic nature of methanol reformation and heat is supplied externally from outside the reactor. For the 1 and 2 LHSV-M cases, the centerline temperature become closer to the wall temperature after Zones 3 and 4, respectively. The previously described result occurred from mass transfer. In the 1 LHSV-M case, the centerline temperatures of Zones 6 and 7 are much hotter than the inside of the wall. Hydrogen mass transfer (i.e. products) due to the hydrogen concentration gradients in the reactor caused this result, because mass transfer can directly affect heat transfer. However, heat transfer cannot directly affect mass transfer. 


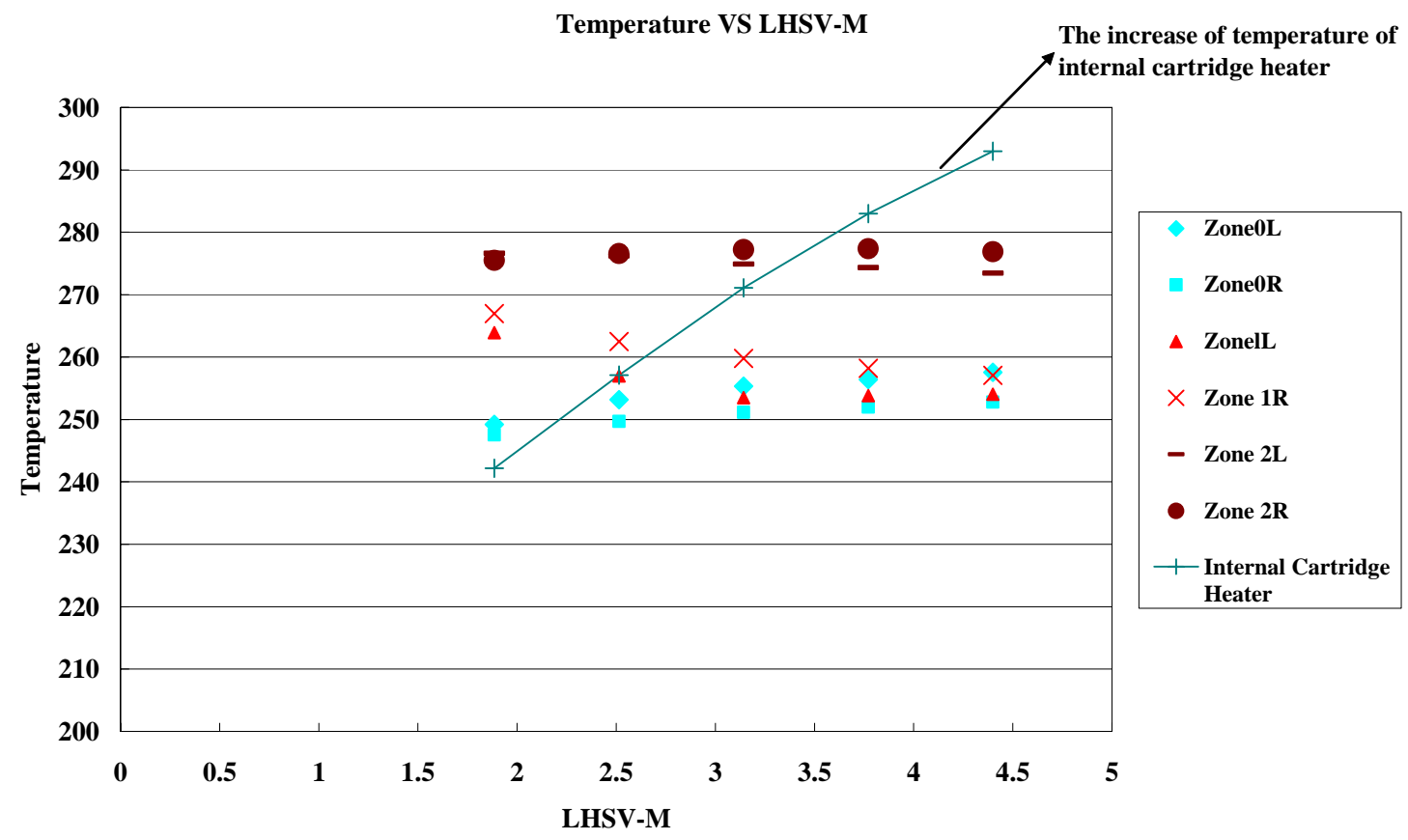

Figure 34: Averaged temperatures of different zones in Reactor C

As shown in Figure 34, the bulk gas condensation affected the internal cartridge heater temperature. To maintain a temperature difference of less than $5 \mathrm{C}^{\circ}$ between the inside wall and centerline, the internal cartridge heater set-point temperature was intentionally increased as LHSV-M was increased.

\section{Swirl Method}

In this investigation, a swirl tape used as a pathway disturber placed inside catalyst packed Reactor B was carried out to test its' enhancement ability in steam reforming processes. The swirl tape was constructed using a 316 stainless steel sheet and twisted one half revolution. The schematic of the swirl tape inside catalyst packed is shown in Figure 35.

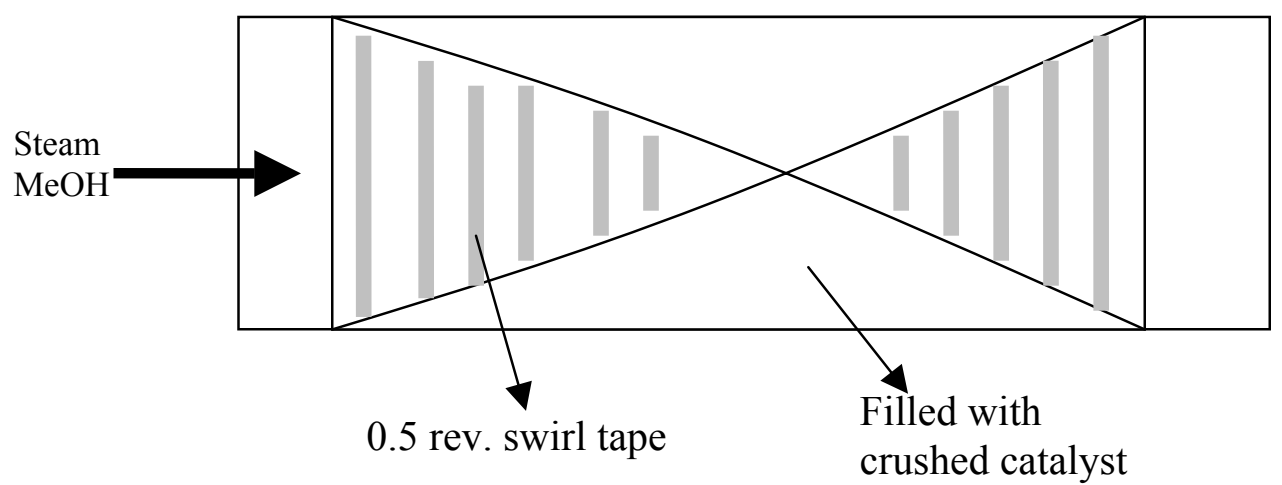

Figure 35: Schematic of 0.5 revolution swirl tape inside reactor bed 
The other experiment conditions were set identically as the bluff body run for 250 grams of crushed FCRM-2 steam reforming catalyst using chemical grade methanol.

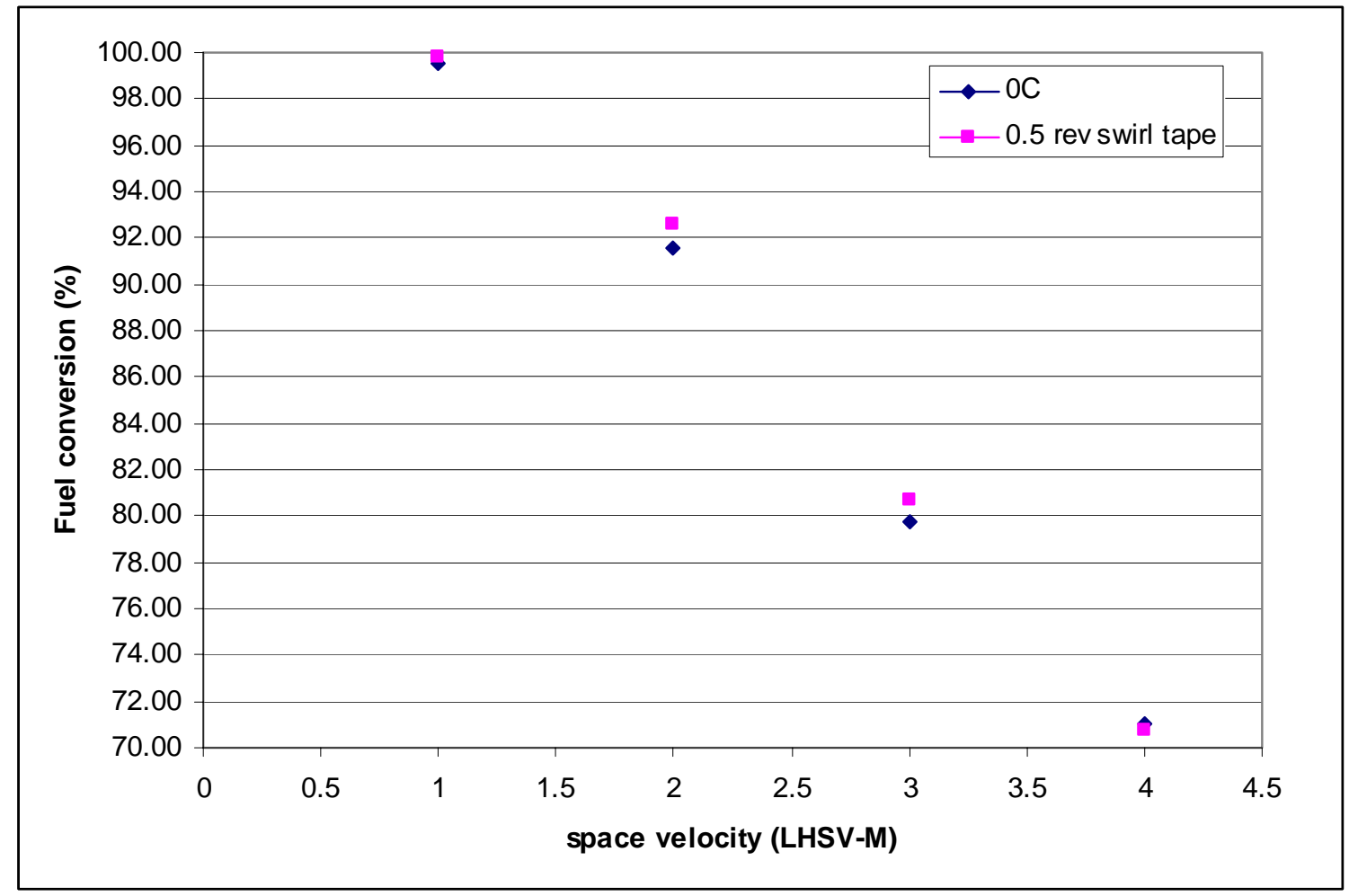

Figure 36: Fuel conversion versus space velocity for experiments with (black) and without swirl tape (pink)

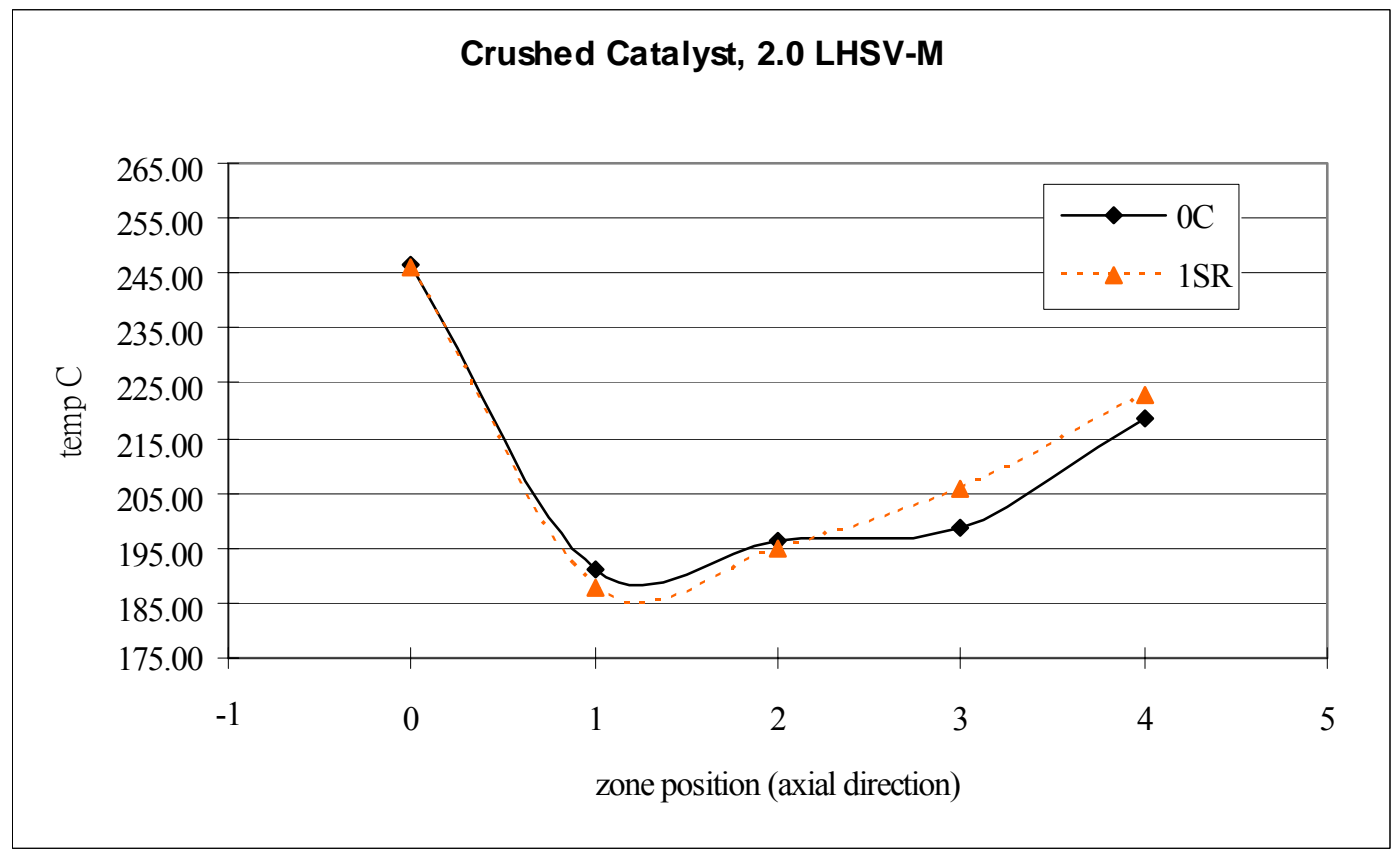

Figure 37: Centerline temperature profile in axial direction 
It was expected that the swirl tape could create an outward component flow in radial direction to bring the stream to the hot wall zone, thus enhancing the fuel conversion. However from the experimental results displayed in Figure 36, the fuel conversion increased by about one percent. This increase is not considered significant. In Figure 37, even though the swirl tape helped conduct heat into the centerline of the catalyst bed, the increased heat transfer might not be large enough assist the endothermic reaction occurring near the centerline. More over, one half-swirl revolutions swirl was too small and downward stream velocity was not large enough to force the stream flow outward in the radial direction to the hot wall region.

\section{Autothermal Reforming of Coal-Derived Methanol}

Autothermal reforming of Coal derived methanol has taken place. The catalyst was wrapped with insulation and placed at Zone 4 of the ATR reactor as shown in Figure 38.

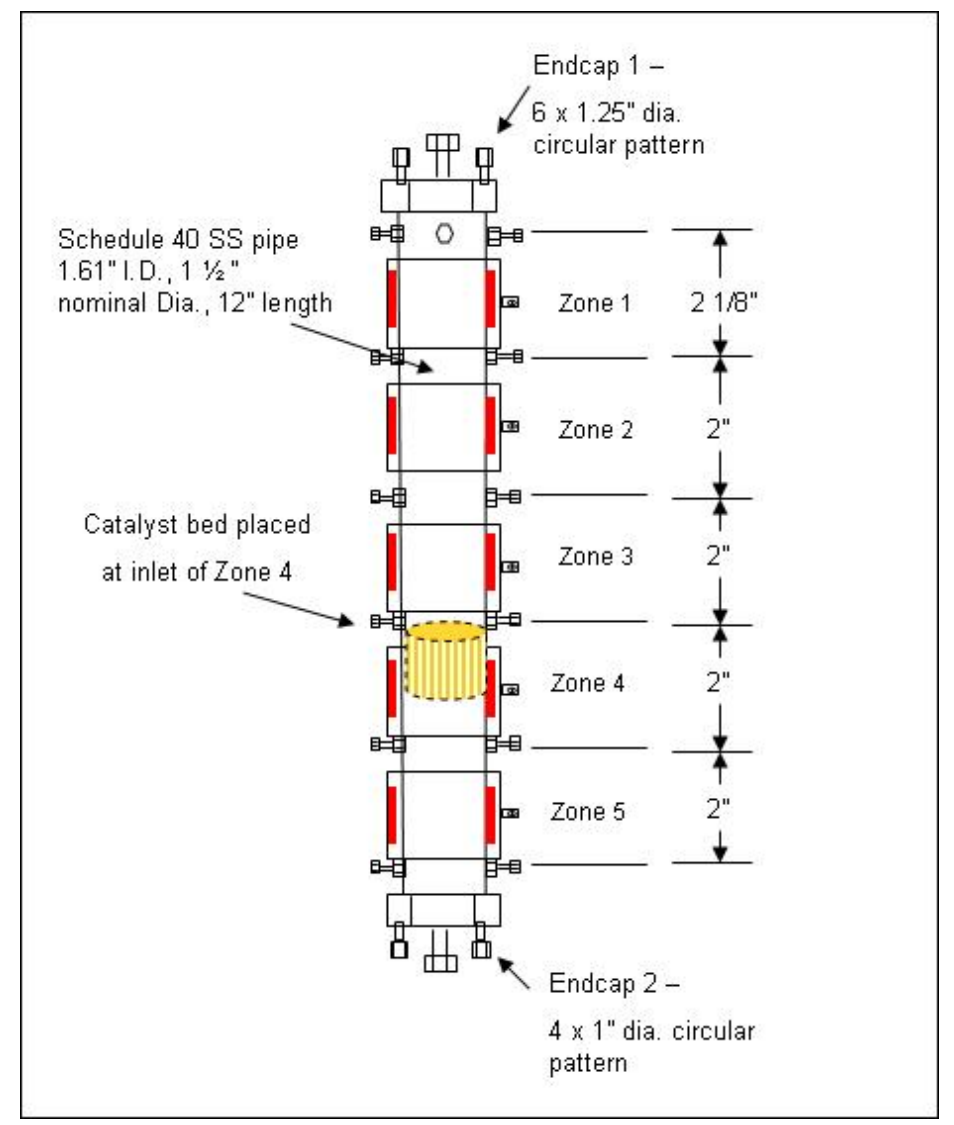

Figure 38: Location of monolithic catalyst inside ATR reactor

Different gas hourly space velocities (GHSV) were applied based on different $\mathrm{O}_{2} / \mathrm{C}$ ratios. The GHSV and $\mathrm{O}_{2} / \mathrm{C}$ ratio were calculated via the developed ATR model, which uses the premix flow rate and airflow rate into the reactor and the operating pressure of the experiment as inputs. Since the premix used for the experiment was fixed with a steam/carbon ratio with $1.5: 1$, the carbon mole number was fixed through out the experiment run by fixing the premix flow rate 
into the ATR reactor. By changing the airflow rate into the reactor, the $\mathrm{O}_{2}$ mole number was increased thus the $\mathrm{O}_{2} / \mathrm{C}$ ratio increased. As shown in Figure 39, as GHSV and $\mathrm{O}_{2} / \mathrm{C}$ ratio increased, methanol percent conversion was linearly increased.

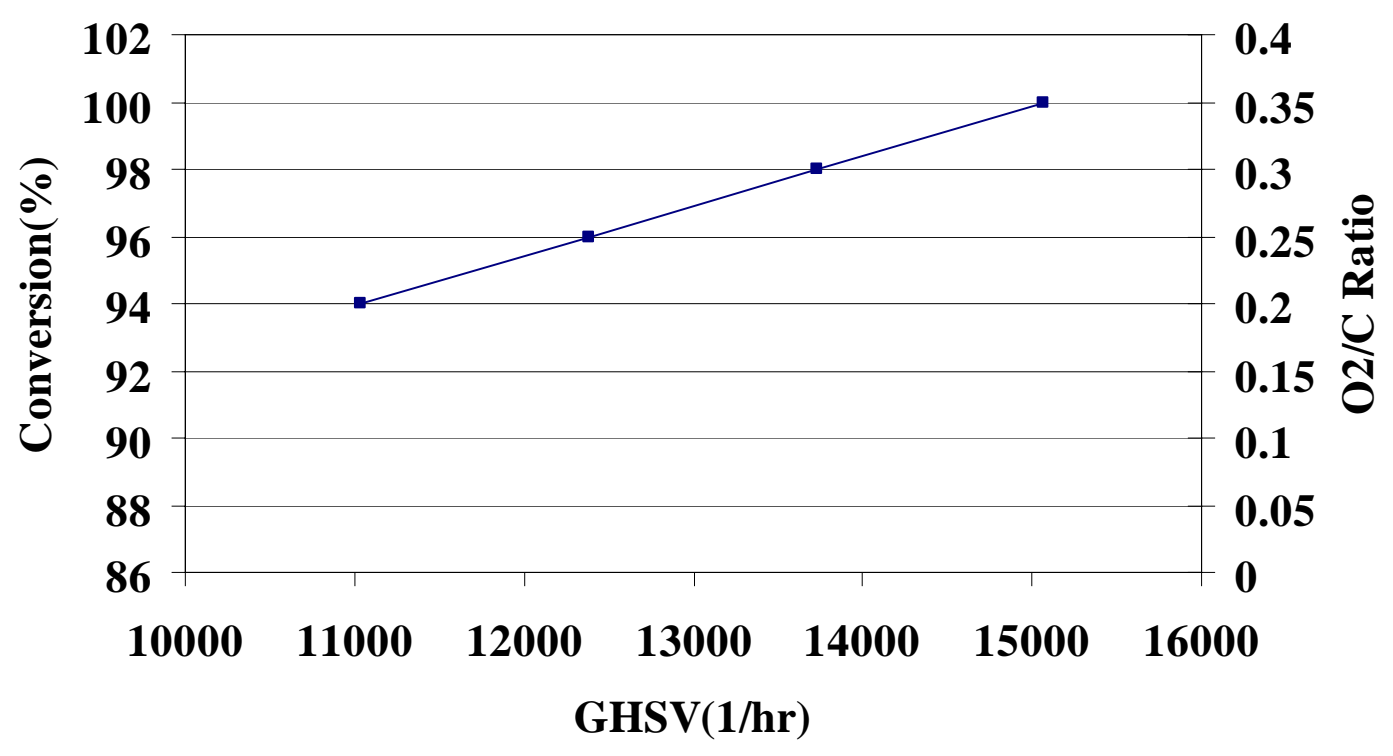

\section{- Coal-derived Methanol}

Figure 39: Autothermal reforming of coal-derived methanol varying $\mathrm{O}_{2} / \mathrm{C}$ ratios at a flow rate of $8.5 \mathrm{ml} / \mathrm{min}$

The $\mathrm{O}_{2} / \mathrm{C}$ ratio was increased up to 0.4 causing the catalyst to sinter, because higher $\mathrm{O}_{2}$ can bring higher temperature caused by combustion of $\mathrm{O}_{2}$ and $\mathrm{CH}_{3} \mathrm{OH}$. 


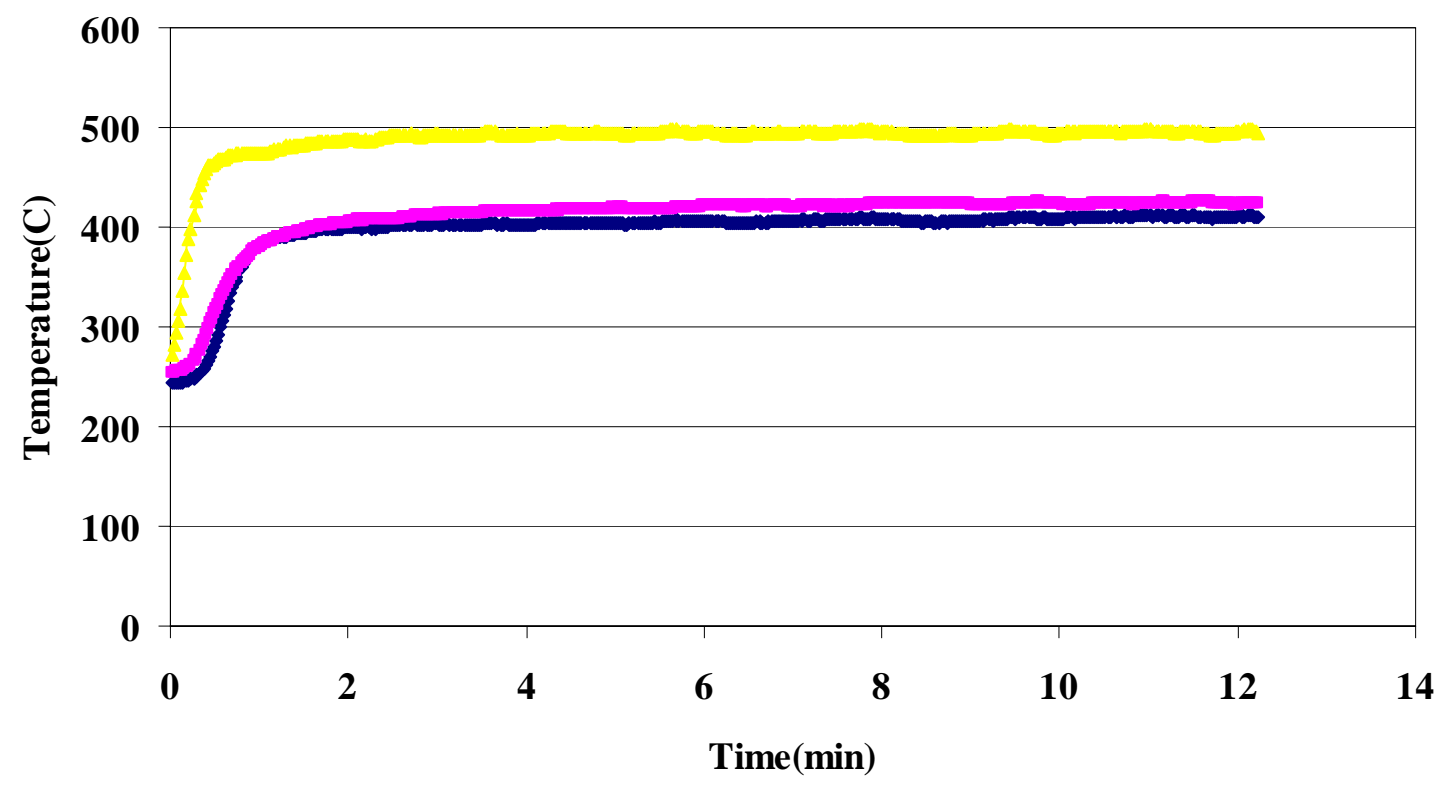

$\rightarrow$ End cap $1 \rightarrow$ End cap $3 \rightarrow$ End cap 4

Figure 40: Temperature profile inside the urban catalyst at different locations $\left(\mathrm{O}_{2} / \mathrm{C}=0.2\right)$

Light-off was confirmed by the end-cap thermocouples located inside the catalyst as seen in Figure 40. Light-off occurred near the top surface of the catalyst. The temperature was increased from $250 \mathrm{C}^{\mathrm{o}}\left(482^{\circ} \mathrm{F}\right)$ to $500 \mathrm{C}^{\mathrm{o}}\left(932^{\circ} \mathrm{F}\right)$ at the top surface. In the middle and bottom zones of the catalyst, the temperature was increased less than approximately $150 \mathrm{C}^{\circ}\left(302^{\circ} \mathrm{F}\right)$ due to endothermic reaction. In other words, heat generated from light-off was consumed for the steam reforming reaction as well as methanol decomposition inside the catalyst. That is why the temperature decreased at each end cap location.

Figure 41 represents the methanol conversion associated with different $\mathrm{O}_{2} / \mathrm{C}$ ratios. The conversion of methanol using urban catalyst located at Zone 4 was higher than when it was placed at Zone 1. This indicates that mixing effects of fuel with oxygen should be significantly considered especially for ATR experiments. These preliminary results can lead us to find the optimal location of catalyst placement to enable complete mixing in our ATR reactor. Catalyst placement in different reaction zones will be repeated to compare with the current initial results 


\section{ATR experiment using urban catalyst}

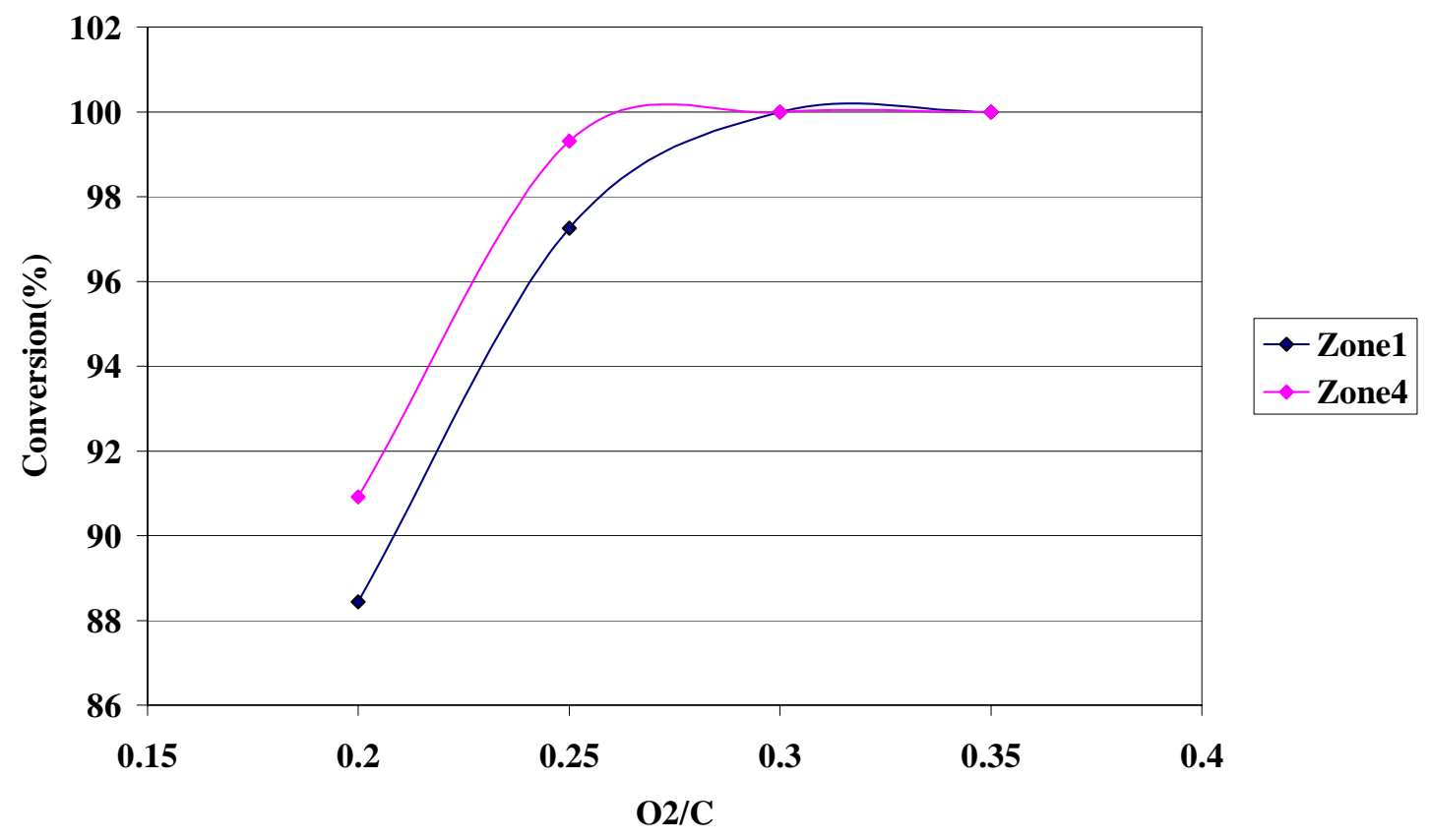

Figure 41: Methanol conversion associated with different $\mathrm{O}_{2} / \mathrm{C}$ ratio

Figure 42 represents hydrogen concentrations at $\mathrm{O}_{2} / \mathrm{C}$ ratios of 0.2 and 0.25 . SR hydrogen concentrations that have been performed in the lab are consistently above $70 \%$. However, due to the combustion wave from the oxygen and fuel, hydrogen concentrations fluctuated $\pm 10 \%$ from the average in ATR. Moreover, ATR hydrogen concentrations were always below $50 \%$, because nitrogen from the air, which is left after combustion, dilutes the gas concentration. A portion of fuel is also used up for combustion in order to sustain a deflagration wave. As expected, Zone 4, which has a greater mixing area for the fuel and oxygen, shows much higher concentrations of hydrogen than Zone 1 in the case of $\mathrm{O}_{2} / \mathrm{C}=0.2$. At $0.25 \mathrm{O}_{2} / \mathrm{C}$, the difference of hydrogen concentrations decreased because the increment of oxygen flow rate as well as partial pressure of oxygen gases enhances the mixing of the fuel with oxygen. 


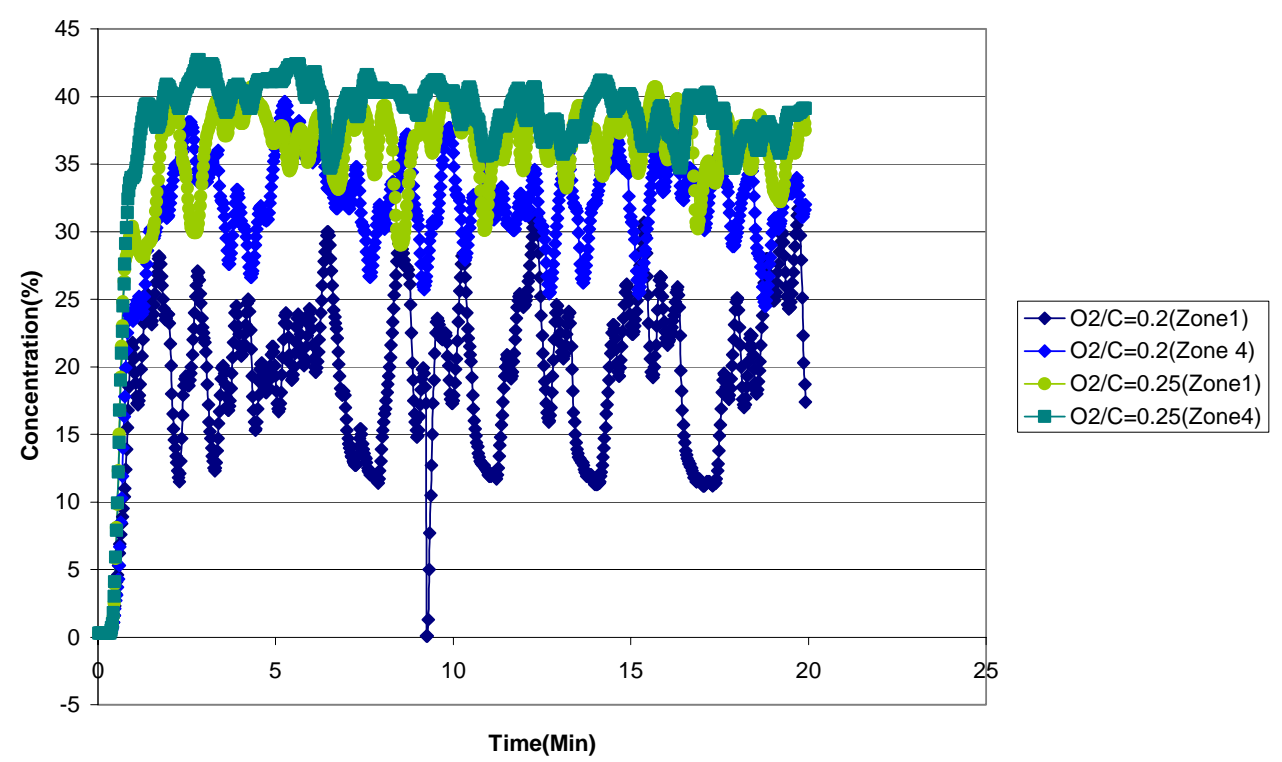

Figure 42: Hydrogen concentration differences for variance in $\mathrm{O}_{2} / \mathrm{C}$ ratios and zones

Hydrogen Concentration

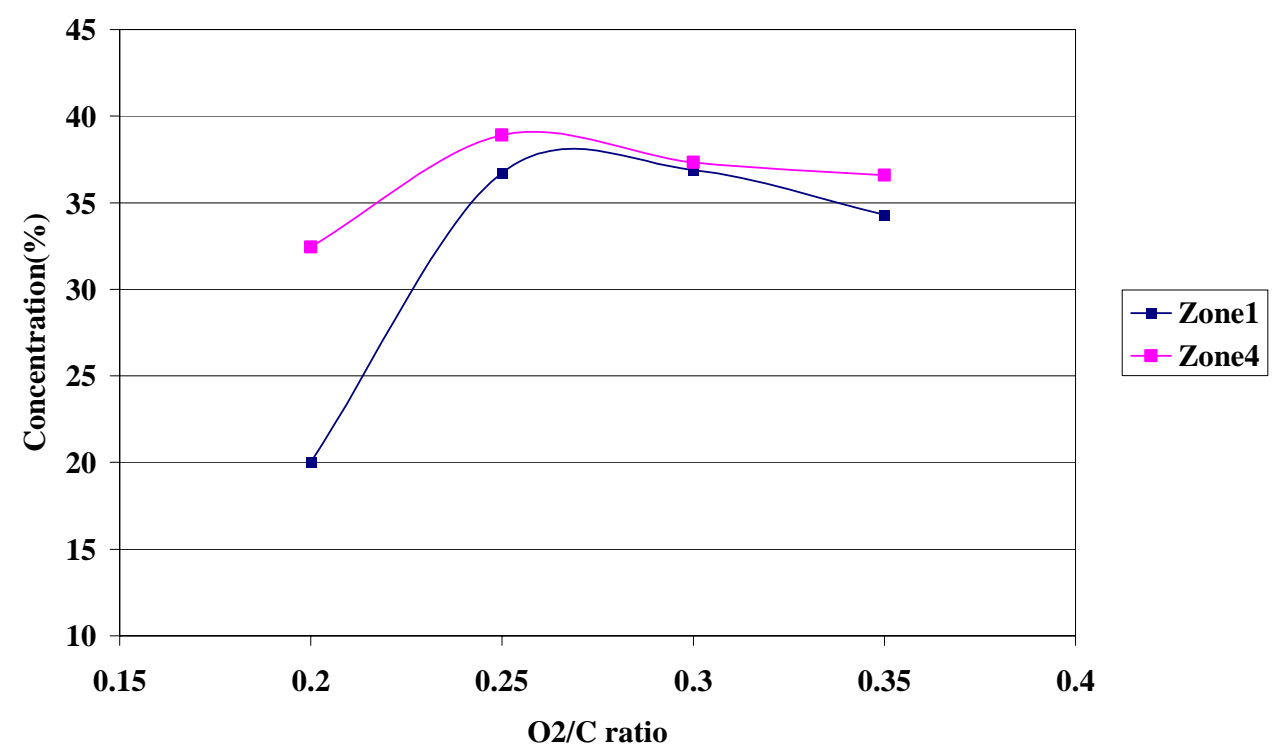

Figure 43: Averaged hydrogen concentration differences for variance in $\mathrm{O}_{2} / \mathrm{C}$ ratios and zones

Figure 43 represents the averaged hydrogen concentration differences in the case of varying both $\mathrm{O}_{2} / \mathrm{C}$ ratio and zone placement of the catalyst. Theoretically, the optimal $\mathrm{O}_{2} / \mathrm{C}$ ratio in the case of equilibrium is around 0.23 . There is always the possibility of carbon formation below 0.2 $\mathrm{O}_{2} / \mathrm{C}$ ratio. Mixing effects should be considered to find out the optimized $\mathrm{O}_{2} / \mathrm{C}$ because maximum averaged hydrogen concentration at different zones shifted a little bit left when the catalyst moved from Zone 1 to Zone 4 . In the case of Zone 1 placement, the averaged maximum 
hydrogen concentration was shown at an $\mathrm{O}_{2} / \mathrm{C}$ of around 0.275 . For Zone 4 placement, the averaged maximum hydrogen concentration was shown around $0.25 \mathrm{O}_{2} / \mathrm{C}$. Therefore, the effects of mixing fuel with oxygen can significantly affect the overall efficiency of ATR.

\section{Autothermal Catalyst Degradation}

The reduction catalyst (upstream catalyst) of a three-way catalytic converter has been used for autothermal reformer degradation tests. The size of reduction catalyst (upstream catalyst) is 1.4" diameter and 1.45" Length. This catalyst is mainly composed of platinum and rhodium. Both chemical grade and coal-derived methanol was used for this autothermal reformer degradation test. $\mathrm{O}_{2} / \mathrm{C}$ and $\mathrm{S} / \mathrm{C}$ ratio are adapted at 0.21 and 1.5 respectively. Reactor inlet temperature was maintained at approximately $250^{\circ} \mathrm{C}$. As shown in Figure 44, when air valve is opened, fuel with air initially lights off at the top of catalyst in much less than 1 minute. The catalyst light off is noted by the large increase in catalyst temperature from $250^{\circ} \mathrm{C}$ to $600{ }^{\circ} \mathrm{C}$.

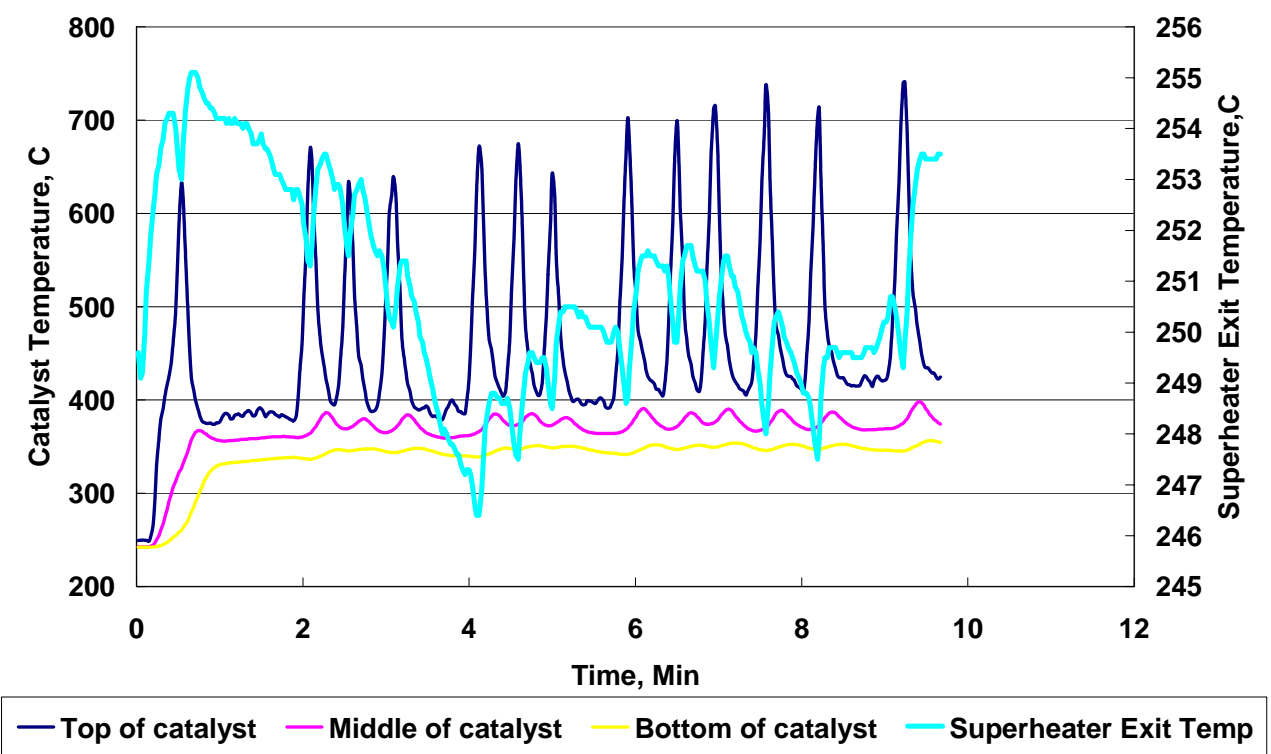

Figure 44:The Initial Light-Off inside the ATR reactor

The top of the catalyst observed temperature fluctuations due to rich fuel combustion and lean fuel combustion cycles originally caused by fuel vaporization cycles. As shown in Figure 45, even though reactor temperature exit (Red) stayed between $249.5 \mathrm{C}^{\circ}$ and $251.5 \mathrm{C}^{\circ}$, it made the fluctuation of light-off temperatures over $300 \mathrm{C}^{\mathrm{o}}$. Increasing temperature of the vaporizer 1 exit (yellow) indicates rich fuel region. Similarly, a decreasing temperature of vaporizer 1 exit represents lean fuel region due to less fuel vaporized. The top of the catalyst temperature variations matches well with vaporizer 1 exit temperature variations. The fuel vaporizes using an internal cartridge heater by turning on and off cyclically. When the heater in vaporizer 1 is turned on, a burst of methanol vapor is released until the heater is turned off. The concentration of methanol vapor varies while the air flow rate is constant. This was not as much of a problem for steam reformation because maintaining a specific $\mathrm{O} 2 / \mathrm{C}$ ratio was not relevant. This problem should be corrected for degradation tests because it could lead to sintering of catalyst. 


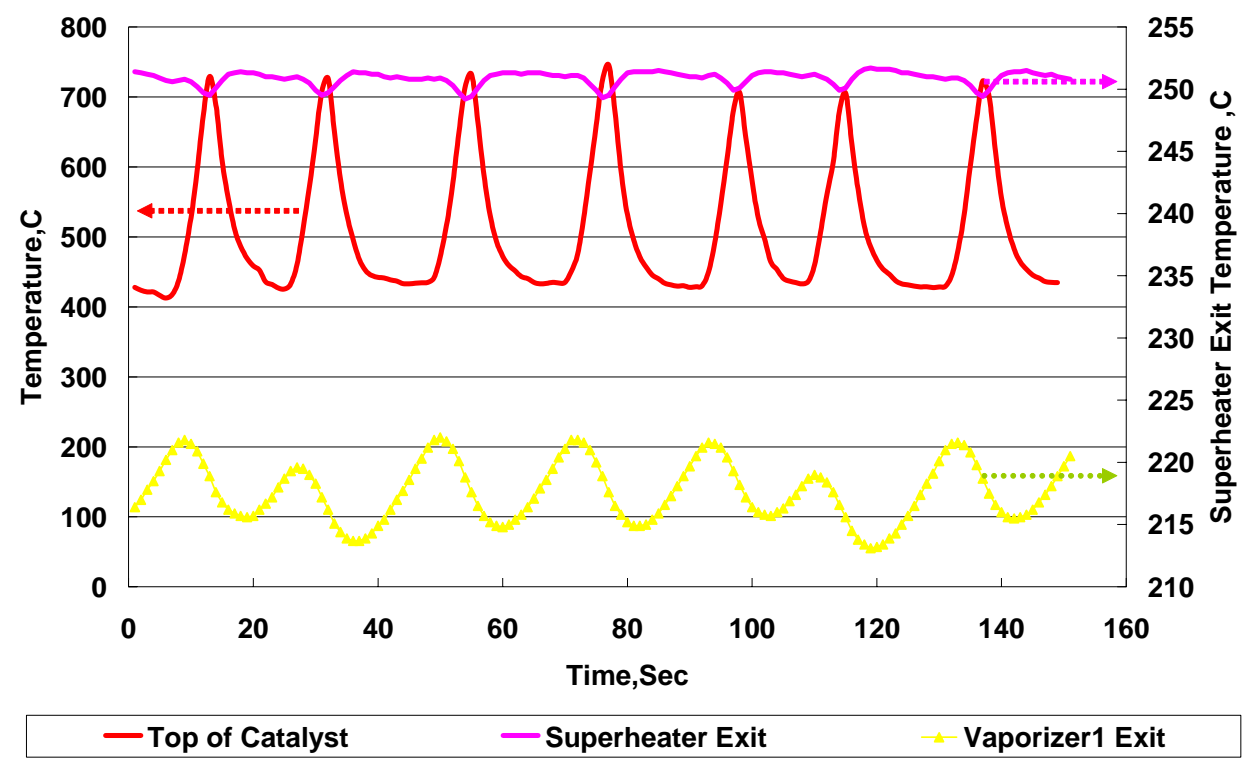

Figure 45: The Variation of Superheater Exit Temperature and Top of Catalyst Temperature

This temperature fluctuation lead to the hydrogen concentration change shown in Figure 46. Hydrogen concentration variation could match well with the temperature fluctuation between the top and the middle catalyst. This means that the dominant area of hydrogen production is located between the top and the middle of the catalyst.

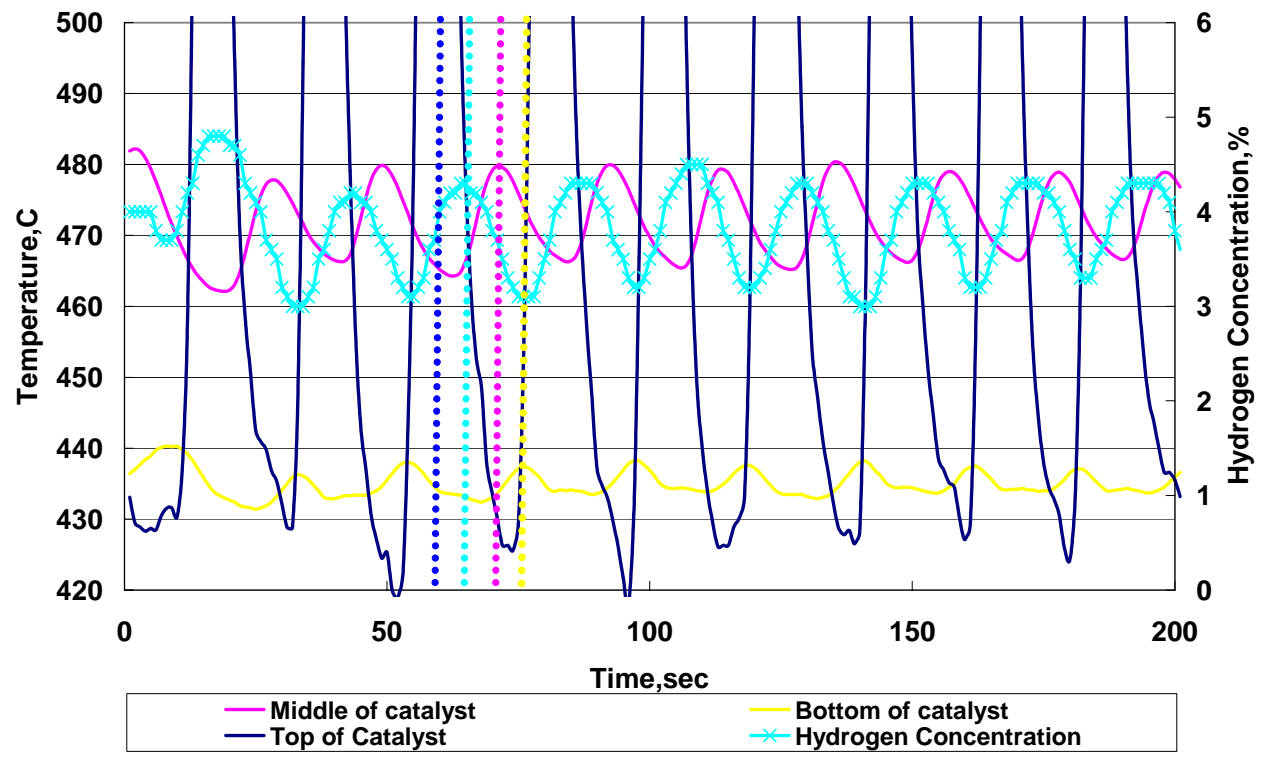

Figure 46: Hydrogen Concentration Change with temperature fluctuation

Furthermore, massive heat was consumed for steam reforming reaction. The average temperature difference between the middle of catalyst and top of catalyst is around $200 \mathrm{C}^{\circ}$. 
With this unstable temperature fluctuation, catalyst degradation tests for autothermal reformer have been performed at $0.21 \mathrm{O}_{2} / \mathrm{C}$ and $1.5 \mathrm{~S} / \mathrm{C}$ ratios.

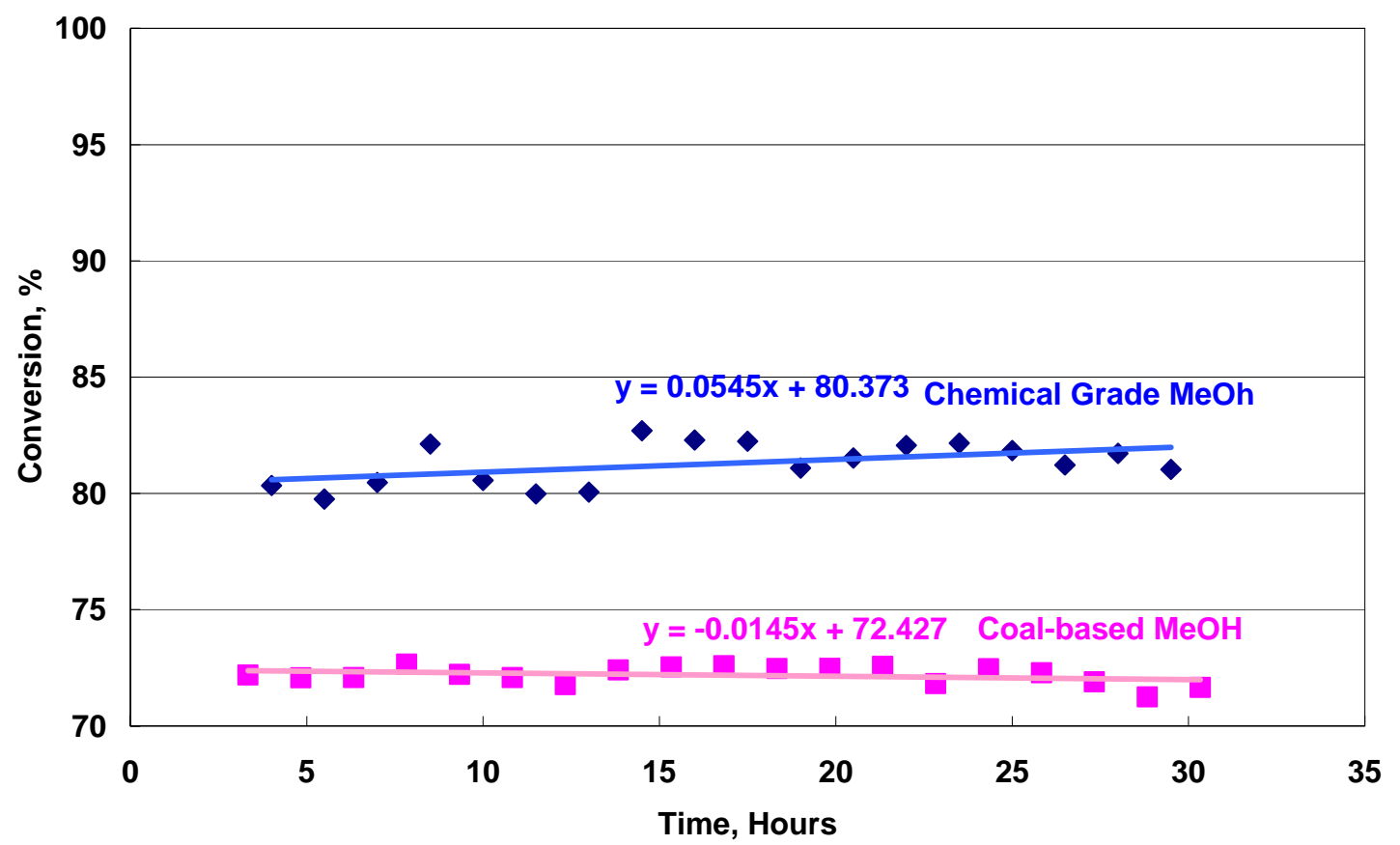

Figure 47 : Autothermal reformer degradation test for both methanol fuels

The conversion starts at different points as shown in Figure 47. This conversion difference between coal-based and chemical grade methanol might come from the difference in the reduction of the catalyst. The conversion of chemical grade methanol did not change for 30 hours. However, the conversion of coal-derived methanol was slightly decreased. To verify the autothermal reformer degradation test, a $2^{\text {nd }}$ round of autothermal degradation tests for both methanol fuels has been planned.

\section{Autothermal Reformation With Bluff Bodies}

Chemical grade methanol at a steam to carbon ratio $(\mathrm{S} / \mathrm{C})$ of 1.5:1 was used as the fuel and tested at different oxygen to carbon ratio to examine corresponding fuel conversion. . The GHSV range was 21083 to $21570\left[^{-1}\right]$ for the reactor condition of $250 \mathrm{C}$ and $0.1 \mathrm{MPa}$. The liquid flow rate was set at $9.95 \mathrm{ml} / \mathrm{min}(\mathrm{H} 2 \mathrm{O}: 4.0 \mathrm{ml} / \mathrm{min}$ and $\mathrm{MeOH}: 5.95 \mathrm{ml} / \mathrm{min}$ ). Water and methanol were separately vaporized before entering to the super heater. The catalyst was taken from a catalytic converter intended for use on automobiles and termed as low-grade, or urban catalyst. Two experiment runs were carried out including the first run without bluff body packages and a second run with bluff body packages. Due to a limited quantity of autothermal catalyst, these two experimental runs used a physically identical catalyst without replacing it. The first run (using new catalyst) was set without bluff body packages and the second run (using used catalyst) was set with bluff body packages. Therefore, catalyst degradation needs to take the 
previously used catalyst factor into account for the conversion difference analysis. The fuel conversion as function of $\mathrm{O} 2 / \mathrm{C}$ ratio is shown in Figure 48.

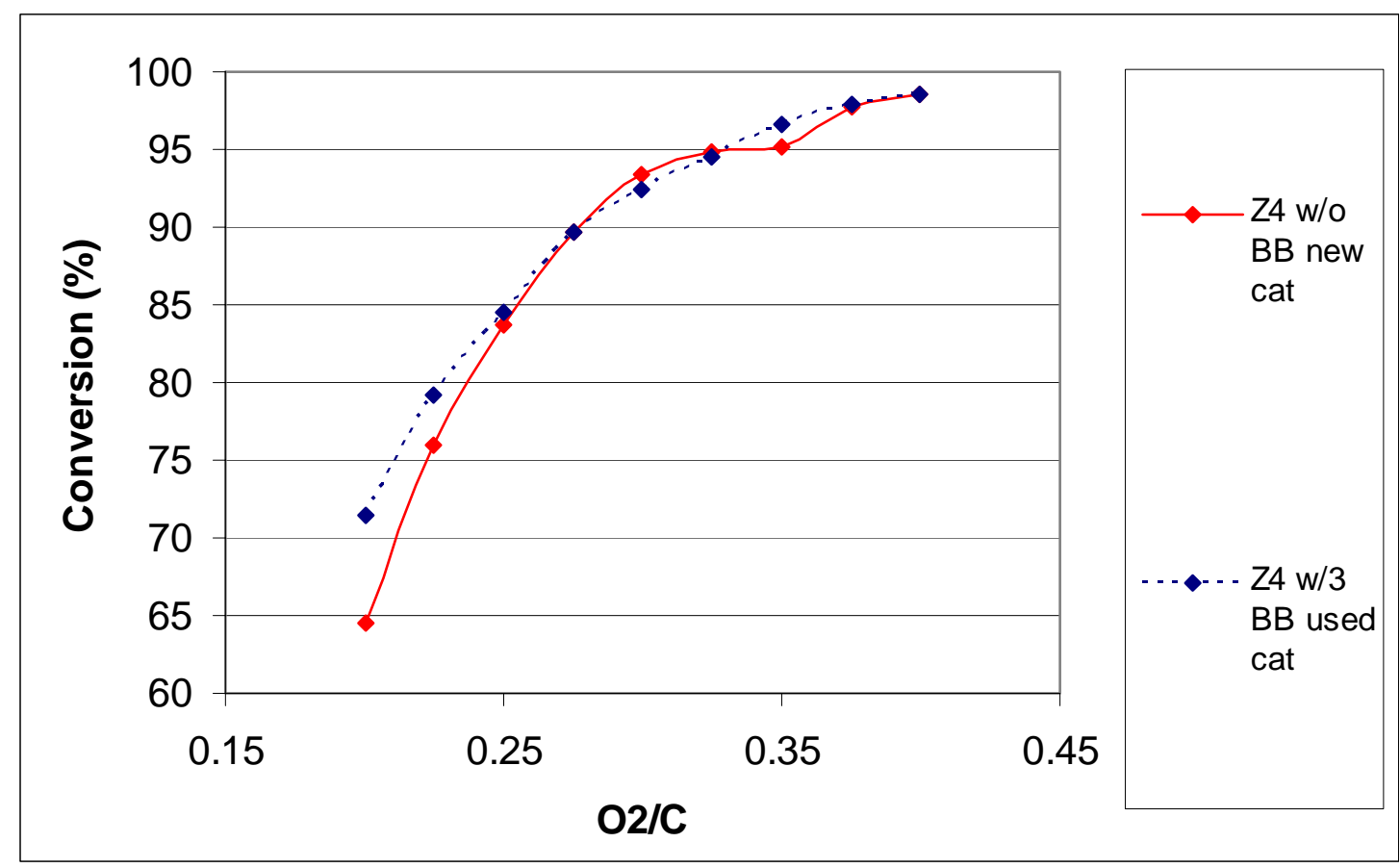

Figure 48: Fuel conversion as function of $\mathrm{O} 2 / \mathrm{C}$ for runs with and without bluff body

Figure 48 shows that when running at low $\mathrm{O} 2 / \mathrm{C}$ ratio (less than 0.25 ), the experiment run with bluff body packages (orange) presented a better fuel conversion than empty space (blue). However, when increasing the $\mathrm{O} 2 / \mathrm{C}$ ratio the fuel conversion is the same between these two runs. This is because at low $\mathrm{O} 2 / \mathrm{C}$ ratio, the mixing process can limit fuel conversion under a low oxygen environment. When increasing the $\mathrm{O} 2 / \mathrm{C}$ ratio, increased oxygen flow into the chamber compensates the poor mixing issue at low $\mathrm{O} 2 / \mathrm{C}$. Therefore the conversion difference between reformation with and without bluff body packages is small. It is necessary to note that catalyst degradation does affect the small difference in fuel conversion. The temperature profiles along the axial direction, between low (Figure 49) and high (Figure 50) O2/C ratios, show the mixing issue present in partial oxidation temperatures. Axial position 3 represents the temperature right above the monolith catalyst and position 4 is located right below the catalyst bed. While at low oxygen to carbon ratio $(\mathrm{O} 2 / \mathrm{C}=0.2)$, not enough oxygen is available for mixing (without bluff body) forming a fuel rich state resulting in a lower oxidation temperature. After introducing bluff body packages, the temperatures after position 3 were largely increased. At high oxygen to carbon ratio $(\mathrm{O} 2 / \mathrm{C}=0.4)$, the temperature increase between with and without bluff body experiment runs is not so obvious. 


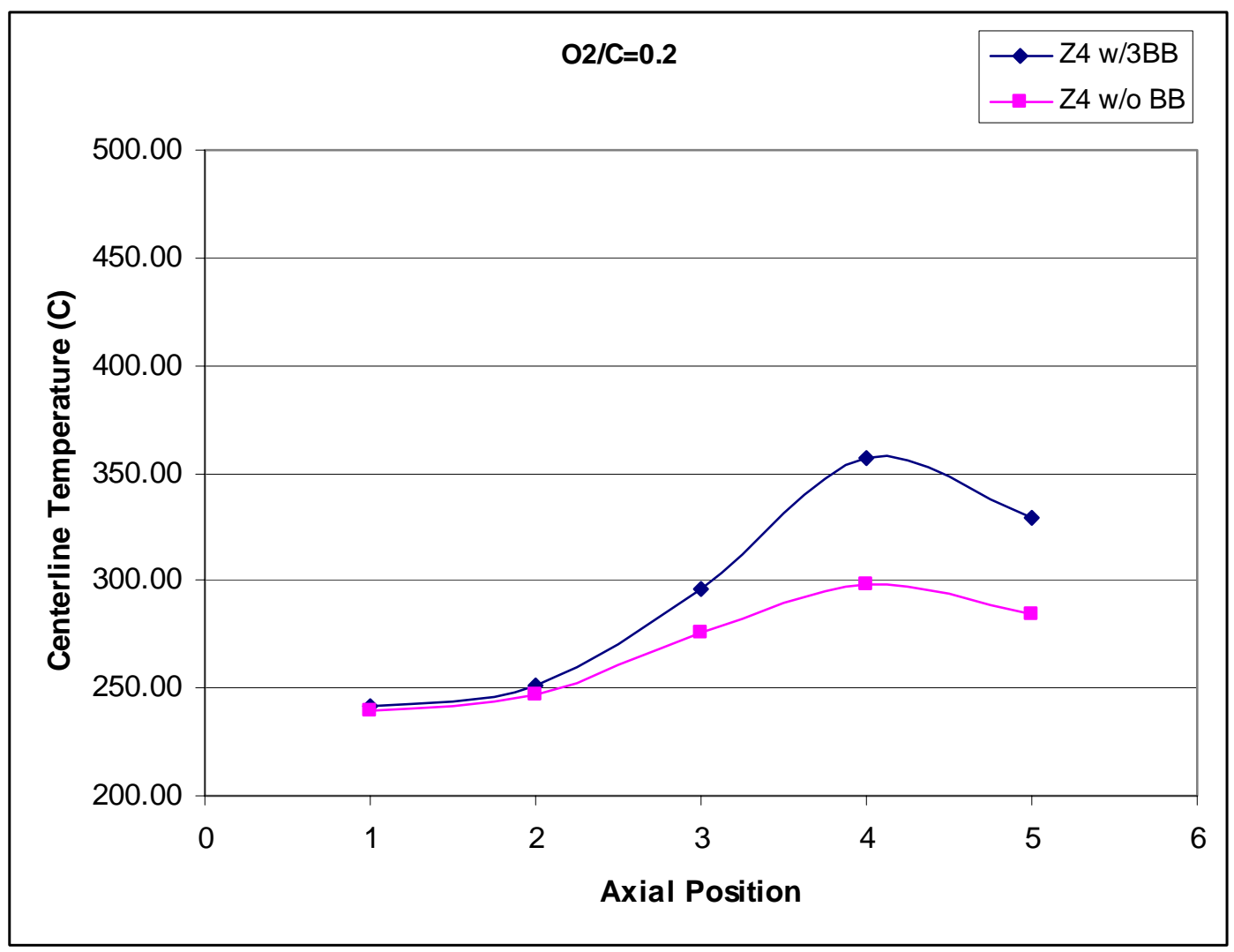

Figure 49: Temperature profile at low $\mathrm{O} 2 / \mathrm{C}$ ratio

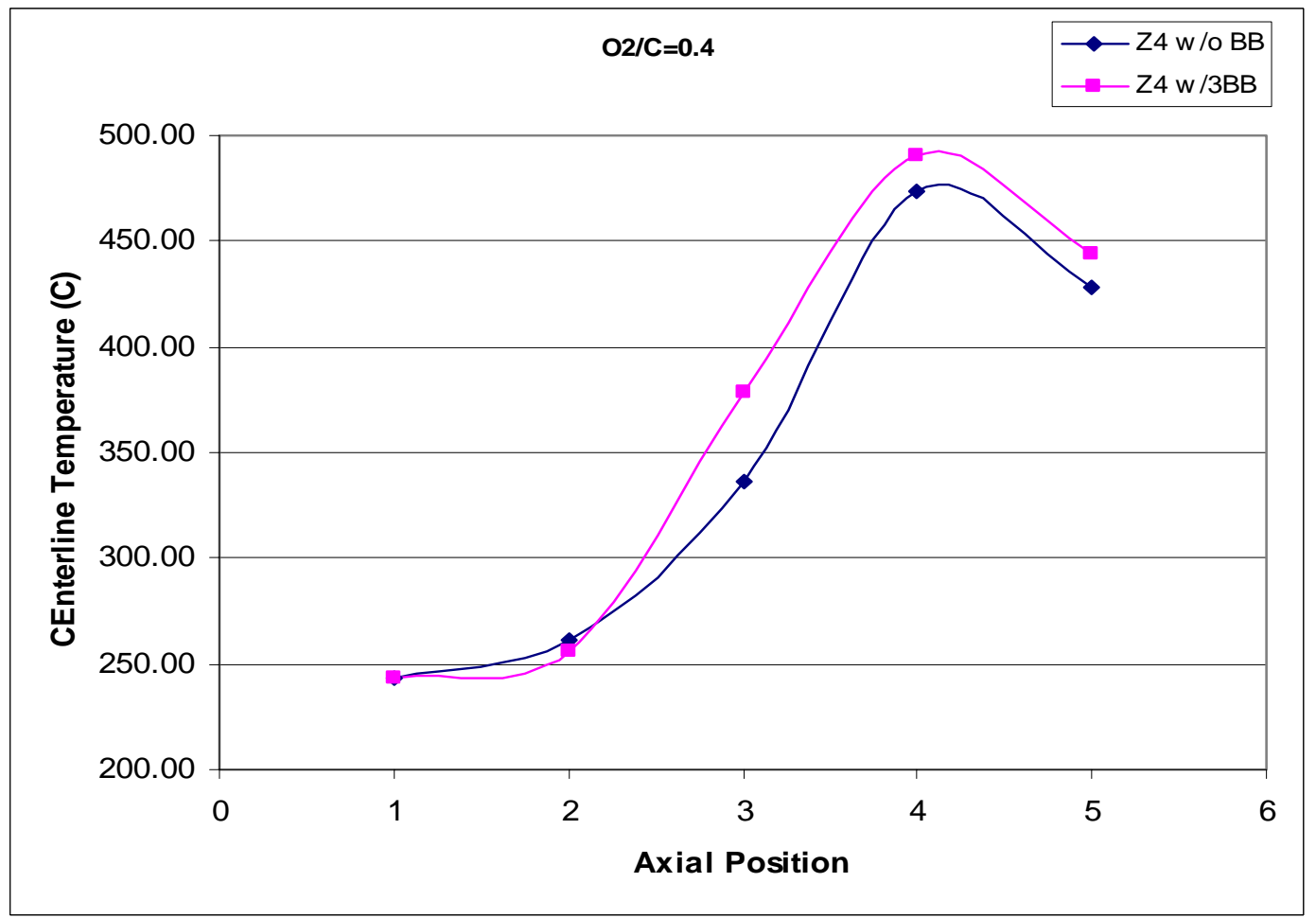

Figure 50: Temperature profile at high $\mathrm{O} 2 / \mathrm{C}$ ratio 


\section{CONCLUSION}

From the conversion data it does not appear that the addition of acoustics had a significant effect on the transient response of steam reformation. However, the information presented in this report shows that the improvement in heat transfer is evident and that a restriction by the control program was the limiting factor restricting the amount of heat supplied to the reformer. The coalderived methanol had a similar transient response to that of the chemical grade methanol, and the overall conversion of both fuels was increased by the addition of the acoustics as expected.

Data investigating the role of temperature in catalyst deactivation has been collected. There is a narrow temperature band where catalyst deactivation is slowest. Below the optimal temperature range, deactivation occurs due to fouling caused by accumulation of carbon compounds on the catalyst surface. Above the optimal temperature range, deactivation is much greater due to rapid sintering. Surface analysis will be needed to precisely determine the processes causing the deactivation. This reinforces the idea that minimizing temperature gradients within the reactor can be as important to the steam reformation process as fuel purity, if not more so. This year reactor geometry was investigated as a possible means to improve heat transfer. From the analysis, the addition of an internal cartridge heater improved methanol conversion and decreased catalyst degradation. When LHSV-M increased, the cold region along the centerline due to the condensation of bulk gas increased in length. Additionally, the cold region can be formed from the endothermic methanol reaction. However, condensate formation due to heat transfer limitations had a much greater effect than the endothermic chemical reaction on the cold region formation. Further research will be continued on reactor geometry, heat transfer and how catalyst degradation can be reduced.

Further analysis of catalyst degradation with bluff bodies was completed. The data showed degradation rate of Reactor B loaded with eight bluff body packages was 6.6 times larger than the degradation rate of Reactor $\mathrm{C}$ with chemical grade methanol. The degradation rate of Reactor B (8C) using coal-derived methanol was 1.2 times greater than Reactor B (8C) using chemical grade methanol. Again the reactor geometry was demonstrated to outweigh the fuel option effects on catalyst degradation. In contrast, the fuel option had a larger effect on the degradation rate (1.22 times lager) of Reactor B (8C) than that of bluff bodies (1.002 times larger) on Reactor B. The bluff bodies are able to increase the conversion rate of methanol and at the same time have limited affect on catalyst degradation rate. The use of bluff bodies in a reactor could compensate for the noted decrease in methanol convergence of coal-based methanol compared to chemical grade methanol. Research will continue to further investigate the relationship between degradation and bluff bodies.

An optimization study of bluff body design for steam reformation has begun. A smaller inner diameter ring guides the hotter bulk stream back to the narrower vent at centerline. A smaller I.D. ring and larger disk also drive the stream passing path length, effectively increasing the catalyst reaction region. The results in Figure 30 show that a $99 \%$ fuel conversion rate can be maintained when fuel flow rate is increased from 1.0 to 2.0 LHSV-M. This value represented a significant increase in hydrogen yield (hydrogen generating capacity) comparing to the run without bluff body packages. An observed 67\% increase over the original run (BB5) by simply changing the diameters of the rings and disks. On the contrary, BB1 with a larger I.D. ring and 
smaller disk noted decreased performance in fuel conversion than BB5. This effect occurred because the disturbance in flow path was less, therefore mixing and heat transfer was decreased. To understand which component of bluff body set (disk or ring) plays the main mechanism in bluff body enhancement, experiments will test using only disks and/or only rings inside the catalyst bed to analyze respective performance.

Since steam reformation of methanol is endothermic by nature, heat transfer enhancement becomes vital to overcome the large temperature gradients found in the reactor. Previous research has proven that reactor geometry has a greater affect on fuel conversion than fuel type. The results of Reactor A and C (internal cartridge heater) with crushed catalyst, shown in Figure 32, show improvement in reactor heat transfer through geometry. The use of bluff body packages to be used as passive flow mixing significantly improves fuel reformation, while a half turn twirl device has a minimal effect at the given flow rates.

Autothermal reforming of coal-derived methanol has taken place with a low grade catalyst. Initial findings show that reactor performance was similar to fuel cell grade methanol. Analysis of the results is continuing and further tests will be made with a specialty catalyst.

The current autothermal degradation tests show no degradation after 30 hours for both fuels, as shown in Figure 47. The chemical grade methanol has a greater fuel conversion rate than coalderived methanol. Several factors could have caused the decrease in fuel conversion. One factor is the high temperature oscillations experienced during the autothermal reformation. For the initial tests, autothermal reformation shows promise for extended use. The results are also beneficial for those looking to use coal-derived methanol for fuel cell applications, because no noticeable degradation occurred for the coal-derived methanol.

Initial testing of autothermal reformation using bluff bodies resulted in minimal increases in fuel conversion, as shown in Figures 59 and 50. This is because at low $\mathrm{O} 2 / \mathrm{C}$ ratio, the mixing process can limit fuel conversion under a low oxygen environment. When increasing the $\mathrm{O} 2 / \mathrm{C}$ ratio, increased oxygen flow into the chamber compensates the poor mixing issue at low $\mathrm{O} 2 / \mathrm{C}$. Therefore the conversion difference between reformation with and without bluff body packages is small. While at low oxygen to carbon ratio $(\mathrm{O} 2 / \mathrm{C}=0.2)$, not enough oxygen is available for mixing (without bluff body) forming a fuel rich state resulting in a lower oxidation temperature. After introducing bluff body packages, the temperatures after position 3 were largely increased. At high oxygen to carbon ratio $(\mathrm{O} 2 / \mathrm{C}=0.4)$, the temperature increase between with and without bluff body experiment runs is not so obvious.

During the last year, researchers at the Hydrogen Production and Utilization Lab have attended two conferences to present research done under the DOE grant. Chang-hsien Liao presented "Heat transfer enhancement of steam-reformation by passive flow disturbance inside the catalyst bed", at the 2005 ASME Summer Heat Transfer Conference located in San Francisco, California. In addition, Hyung Chul Yoon presented "Hydrogen from Coal-Derived Methanol: Experimental Results" at the 3rd International Energy Conversion Engineering Conference located in San Francisco, California. 
The following publications have been produced from the research completed during the second year of research under the DOE grant:

Chang-hsien Liao and Paul A. Erickson, "Heat transfer enhancement of steam-reformation by passive flow disturbance inside the catalyst bed" ASME Technical Paper \#HT 2005-72043, 2005 ASME Summer Heat Transfer Conference, San Francisco, California, pp. 1-7.

Erickson P. A., (2005) "Statistical Validation and an Empirical Model of Hydrogen Production Enhancement found by Utilizing a Controlled Acoustic Field in the Steam-Reforming Process" International Journal Of Hydrogen Energy, Accepted April 2005, GI-195 in Press

Erickson, Paul A., David D. Davieau, Robert J. Kamisky and Zachary Zoller (2005), "Space Velocity as an Insufficient Parameter in the Steam-Reforming Process," International Journal of Power and Energy Systems, Accepted Feb 2005 In Press.

Hyung Chul Yoon and Paul A. Erickson, "Hydrogen from Coal-Derived Methanol: Experimental Results", AIAA Technical Paper \#: AIAA 2005-5567, 3rd International Energy Conversion Engineering Conference, San Francisco, California, pp.1-11. 


\section{Appendix:}

\section{Autothermal Reactor Completion}

The autothermal reformation infrastructure addition to the facilities at the Hydrogen Production and Utilization Lab was completed at the end of the fifth quarter. The current setup allows two different reactors to be connected to the infrastructure, but only one to operate at a given time. Figure 51 shows total infrastructure setup, while Figure 52 shows the autothermal reformation side of the infrastructure.

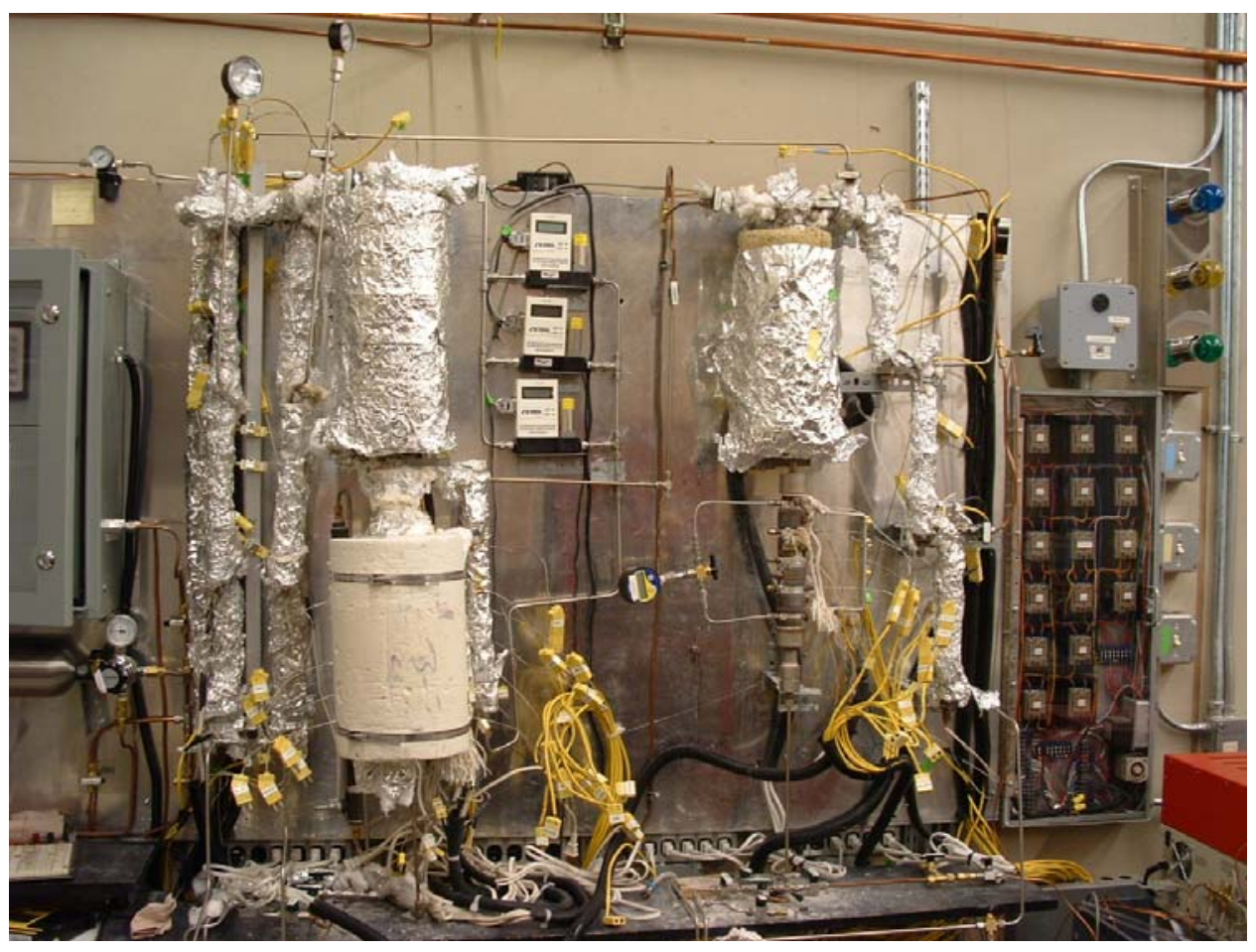

Figure 51: Complete infrastructure of the lab 


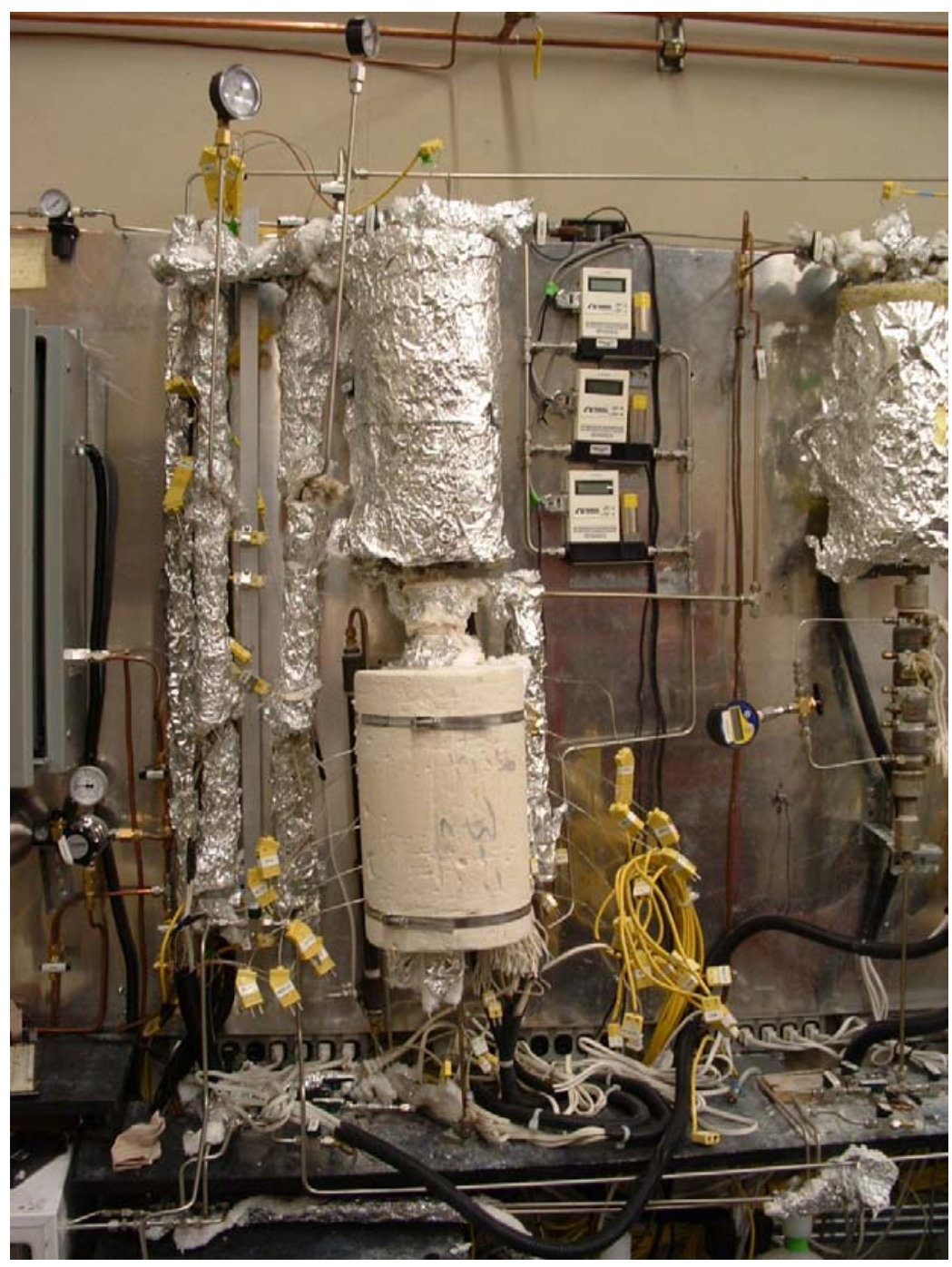

Figure 52: Autothermal reformation infrastructure 


\section{REFERENCES}

[1] Beerman, M.J., Evaluation Of The Use Of Acoustic Waves For Improving The Transient Response Of Steam Reformers, masters thesis, University of California, Davis, CA, 2005

[2] Chang-hsien Liao and Paul A. Erickson, "Heat transfer enhancement of steam-reformation by passive flow disturbance inside the catalyst bed" ASME Technical Paper \#HT 2005-72043, 2005 ASME Summer Heat Transfer Conference, San Francisco, California, pp. 1-7.

[3] Erickson, P.A., Enhancing the Steam-Reforming Process with Acoustics: An Investigation for Fuel Cell Vehicle Applications, doctoral dissertation, University of Florida, Gainesville, FL, 2002

[4] Davieau, D.D., An Analysis of Space Velocity and Aspect Ratio Parameters in SteamReforming Hydrogen Production Reactors, masters thesis, University of California, Davis, CA, 2004

[5] Dorr, J.L., Methanol Autothermal Reformation: Oxygen-to-Carbon Ratio and Reaction Progression, masters thesis, University of California, Davis, CA, 2004

[6] Dorr, J.L., and Erickson, P.A., Preliminary Modeling and Design of an Autothermal Reformer, 2004 International Mechanical Engineering Congress and Exposition, Anaheim, CA, November 2004, IMECE2004-5989

[7] Hyung Chul Yoon and Paul A. Erickson, "Hydrogen from Coal-Derived Methanol: Experimental Results", AIAA Technical Paper \#: AIAA 2005-5567, 3rd International Energy Conversion Engineering Conference, San Francisco, California, pp.1-11. 